\title{
THE MEASURED ENERGY IMPACT OF AIR LEAKAGE ON FRAME WALL SYSTEMS
}

Final Report

DE92 017374

U.S. DOE Grant \#DE-FG01-89-CE21038

June, 1991

David E. Claridge, Ph.D., P.E.

Principal Investigator

Souvik Bhattacharyya

Research Assistant

\section{DISCLAIMER}

This report was prepared as an account of work sponsored by an agency of the United States Governinent Neither the United States Government nor any agency thereof, nor any of their Governinent. Neither the United States Government nor any agency ther legal liability or responsi. bility for the accuracy, completeness, or usefulness of any information, apparatus, product, of process disclosed, or represents that its use would not infringe privately owned rights. Reference herein to any specific commercial product, process, or service by trade narne, trademark manufacturer, or otherwise does not necessarily constitute or imply its endorsement, recom. mendation, or favoring by the United States Government or any agency thereof. The views and opinions of authors expressed herein do not necessarily state or reflect those of the United States Government or any agency thereof. 


\section{Foreword}

This report presents the work performed under U.S. DOE Grant \#DE-FG01-89CE21038. A portion of the support for this work was provided by a grant from the Texas A\&M Center for Energy and Mineral Resources and the Texas Higher Education Coordinating Board. This report was initially presented as the Ph.D. thesis of Souvik Bhattacharyya. 


\author{
ABSTRACT \\ The Measured Energy Impact of Air Leakage \\ on Frame Wall Systems. (May 1991) \\ Souvik Bhattacharyya, B.M.E., Jadavpur University; \\ M.S., University of Cincinnati \\ Chair of Advisory Committee: Dr. David E. Claridge
}

Infiltration is customarily assumed to increase the heating and cooling load of a building by an amount equal to the mass flow rate of the infiltration times the enthalpy difference between the inside and outside air - with the latent portion of the enthalpy difference sometimes neglected. An experimental and analytical investigation has been conducted on the actual energy impact of air leakage on frame wall systems. Calorimetric measurements conducted on a small test cell and on a well characterized stud-cavity wall specimen with measured amounts of air leakage introduced under a variety of controlled conditions and configurations show convincingly that infiltration can lead to a much smaller change in the energy load than is customarily calculated. The data also suggest that the phenomenon occurs in full-sized houses as well.

Infiltration Heat Exchange Effectiveness (IHEE), $\epsilon_{1}$ is introduced as a measure of the effectiveness of a building in 'recovering' heat otherwise los? (or gained) because of infiltration. Measurements show that $\epsilon$ increases as:

a) flow rate decreases;

b) flow path length increases;

c) hole/crack size decreases.

$\epsilon$ also generally increases as the pressurization exponent, $n$, increases; so fan 
pressurization results may be useful in predicting c for bulldings. An analytical model based on fundamental heat and mass transter principles has toen do. veloped and all the prodieted values of $\epsilon$ as a function of alr flow rates and effective path length for the different slud-cavity wall specimen test configurations were remarkably consistent with the exporimental results.

Slgnificant experimental results include:

a) Evalues as Algh as 0.9 and as low of 0.05 for the test cell conflgurations tosted indicate an energy impact of the air loakage low as $10 \%$ of oustomary values:

b) e values in the $0.18-0.7$ ranoe in the stud-cavity (vs. theorotical maximum of 0.5); and

c) E values of 0.16 to 0.34 for wit exidng the stud-eavity slrectly aoross from the entry. 


\section{TABLE OF CONTENTS}

CHAPTER

Page

1

INTRODUCTION .................... 1

11

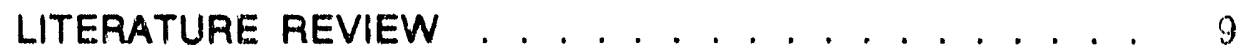

DYNAMIC INSULATION ............... 9

ENERGY CONSUMPTION

DUE TO INFILTRATION . . . . . . . . . . . . 14

III EXPERIMENTAL FACILITY ............ 24

INFILTRATION TEST CELL $\ldots \ldots \ldots \ldots$

CALIBRATED HOT BOX . . . . . . . . . . 27

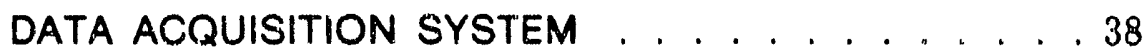

IV THEORETICAL MODEL DEVELOPMENT $\ldots \ldots \ldots . \ldots 42$

THEORETICAL BACKGROUND ......... 42

APPLICATIONS . . . . . . . . . . . . . 48

MODEL DEVELOPMENT . . . . . . . . . . . . 50

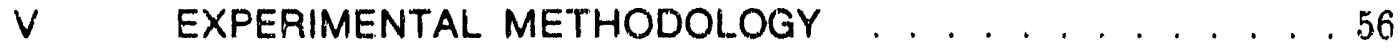

EXPERIMENTAL PROCEDURE

FOR THE TEST CELL . . . . . . . . . . 56

EXPERIMENTAL PROCEDURE

FOR THE STUD-CAVITY . . . . . . . . . . . . . 59 
TABLE OF CONTENTS (Continued)

CHAPTER

Page

VI

RESULTS: TEST CELL . . . . . . . . . . . . . . 64

INFILTRATION HEAT

EXCHANGE EFFECTIVENESS . . . . . . . . . . 65

EFFECT OF INFILTRATION

PATH ON IHEE . . . . . . . . . . . . . . . . . . . 81

HOLE-SIZE EXPERIMENT

ON TEST CELL . . . . . . . . . . . . . . . . . . . 88

VII RESULTS: STUD-CAVITY WALL SECTION . . . . . . 97

TEMPERATURE DISTRIBUTION

INSIDE THE STUD-CAVITY . . . . . . . . . . . 105

COMPARISON OF EXPERIMENTAL

RESULTS WITH MODEL . . . . . . . . . . 115

VIII CONCLUSIONS AND RECOMMENDATIONS . . . . 126

CONCLUSIONS . . . . . . . . . . . . . 126

BENEFITS . . . . . . . . . . . . . . . . . . . . . . . 129

RECOMMENDATIONS . . . . . . . . . . . . . 129

REFERENCES . . . . . . . . . . . . . . 131

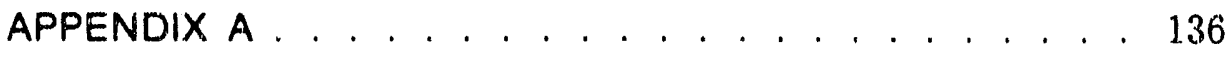

APPENDIX B . . . . . . . . . . . . . . . 139

APPENDIX C . . . . . . . . . . . . . . 156

VITA ....................... 164 


\section{LIST OF TABLES}

Table

Page

1. Description of Data Acquisition Sensor Channels . . . . . . 40

2. Pressurization Test Results

(Air Entry Through Hole P) . . . . . . . . . . . . . . . . 65

3. Linearized Dependence of $\epsilon$ on $a$

for Different Flow Configurations . . . . . . . . . . . . . . 67 


\section{LIST OF FIGURES}

Figure

Page

1. Typical Wind Pressure Profile on a Building . . . . . . . . . . 4

2. Different Types of Dynamic Insulation . . . . . . . . . . . . . . 12

3. A Hypothetical Example to Demonstrate IHEE (Classical Loss) . . . . . . . . . . . . . . . . . . . . 18

4. Infiltration Example with Modified Calculation Procedure . . . . 19

5. Test Cell Schematic Showing Thermocouple Locations . . . . . . 26

6. Test Cell Set-up Showing Different Hole Openings . . . . . . . . 28

7. Schematic of the Stud-Cavity Wall Section . . . . . . . . . . . 30

8. Layout of the Thermiocouples Inside the Stud-Cavity Wall Section . . . . . . . . . . . . . . . . . . . 31

9. Sectional Plan View of the Calibrated Hot Box . . . . . . . . . . 33

10. Sectional Elevation of the Calibrated Hot Box . . . . . . . . . . 34

11. Radiant Cooling Panel Schernatic . . . . . . . . . . . . . . 36

12. Schematic Line Diagram of the Chilled Water System . . . . . . 39

13. Heat and Mass Transfer Across a Wall . . . . . . . . . . . . . 44

14. Schematic of a House with Diffuse Infiltration . . . . . . . . . . 47

15. Wall Section Model with Intrusive Air Flow . . . . . . . . . . . . 51

16. Various Test Configurations for the Stud-Cavity . . . . . . . . . 63

17. IHEE vs. a for Diffuse (B4) Inlet and Diffuse (A) Outlet . . . . . 68

18. IHEE vs. a for Diffuse (BO) Inlet and No Outlet . . . . . . . . . 69

19. IHEE vs. $a$ for Diffuse (B1) Inlet and No Outlet . . . . . . . . . 70

20. IHEE vs. a for Diffuse (B2) Inlet and No Outlet . . . . . . . . . 71

21. IHEE vs. a for Diffuse (B3) Inlet and No Outlet . . . . . . . . . 72

22. IHEE vs. $a$ for Diffuse (B4) Inlet and No Outlet . . . . . . . . . 73

23. IHEE vs. $a$ for Diffuse (B4) Inlet and Concentrated (E) Outlet . . . . . . . . . . . . . . . . . .74 


\section{LIST OF FIGURES (Continued)}

Figure

Page

24. IHEE vs. $a$ for Diffuse (B4) Inlet and Mixed (E \& A) Outlet . . . . . . . . . . . . . . . . . . .75

25. IHEE vs. a fir Concentrated (P) Inlet and No Outlet . . . . . . . 76

26. IHEE vs. $a$ for Concentrated (P) Inlet and Diffuse (A \& B4) Outlet . . . . . . . . . . . . . . . . . .77

27. IHEE vs. $a$ for Concentrated (P) Inlet and Concentrated (E) Outlet . . . . . . . . . . . . . . . . . 78

28. IHEE vs. a for Concentrated $(P)$ Inlet and Mixed (A, B4 \& E) Outlet . . . . . . . . . . . . . . . . . 79

29. IHEE vs. $n$ at Small Flow Rate for Diffuse Inlet . . . . . . . . . 82

30. IHEE vs. $n$ at Small Flow Rate for Concentrated Inlet . . . . . . 83

31. IHEE vs. $n$ at Moderate Flow Rate for Diffuse Inlet . . . . . . . 84

32. IHEE vs. $n$ at Moderate Flow Rate for Concentrated Inlet . . . . 85

33. $m$ vs. $n$ for Diffuse Inlet . . . . . . . . . . . . . . . . . . . . 86

34. $m$ vs. $n$ for Concentrated Inlet . . . . . . . . . . . . . . . . . 87

35. IHEE vs. Leakage Path Length for Diffuse Configuration . . . . . 89

36. IHEE vs. a for $11 / 64$ inch Diffuse Inlet and Diffuse Outlet . . . . 91

37. IHEE vs. $a$ for $1 / 4$ inch Diffuse Inlet and Diffuse Outlet . . . . . 92

38. IHEE vs. a for $3 / 8$ inch Diffuse Inlet and Diffuse Outlet . . . . . 93

39. IHEE vs. $a$ for $1 / 2$ inch Diffuse Inlet and Diffuse Outlet . . . . . 94

40. IHEE vs. Inlet Size for Diffuse Air Entry . . . . . . . . . . . . . 95

41. Measured IHEE Values for Inlet at 1 and Outlet at 2 . . . . . . ?

42. Measured IHEE Values for Inlet at 1 and Outlet at 3 . . . . 100

43. Measured IHEE Values for Inlet at 1 and Outlet at 4 . . . . . 101

44. Measured IHEE Values for Inlet at 1 and Outlet at 2, 3 and 4 . . . . . . . . . . . . . . . 103

45. Measured IHEE Values for Inlet at 1 and Outlet at 5 . . . . . 104 


\section{LIST OF FIGURES (Continued)}

$\begin{array}{ll}\text { Figure Page } & \text { Page }\end{array}$

46. Uncertainty Bars for Measured IHEE Values . . . . . . . . . . 106

47. Temperature Difference Plot for

Configuration A at 11 SLPM . . . . . . . . . . . . . . . 109

48. Temperature Difference Plot for

Configuration A at 13 SLPM . . . . . . . . . . . . . . . . . 110

49. Temperature Difference Plot for

Configuration B at 12 SLPM . . . . . . . . . . . . . . . . . 111

50. Temperature Difference Plot for

Configuration B at 14 SLPM . . . . . . . . . . . . . . . . 112

51. Temperature Difference Plot for

Configuration $C$ at 11 SLPM . . . . . . . . . . . . . 113

52. Temperature Difference Plot for

Configuration C at 13 SLPM . . . . . . . . . . . . . . . 114

53. Temperature Divierence Plot for

Configuration D at 15 SLPM . . . . . . . . . . . . . . . . . 118

54. Temperature Difference Plot for

Configuration D at 17.5 SLPM . . . . . . . . . . . . . . . 117

55. Temperature Difference Plot for Configuration E at 10.5 SLPM . . . . . . . . . . . . . . . . 118

56. Temperature Difference Plot for

Configuration E at 13 SLPM . . . . . . . . . . . . . . . . . 119

57. IHEE for Configuration A: Comparison Between

Model and Experiment . . . . . . . . . . . . . . . . . . . . 121

58. IHEE for Configuration B: Comparison Between Model and Experiment . . . . . . . . . . . . . . . . . . . . 122

59. IHEE for Configuration C: Comparison Between

Model and Experiment. . . . . . . . . . . . . . . . 123

50. IHEE for Configuration D: Comparison Between Model and Experiment . . . . . . . . . . . . . . . . . . . . 124

61. IHEE for Configuration E: Comparison Between Model and Experiment. . . . . . . . . . . . . . . . 125 


\section{NOMENCLATURE}

a non-dimensional flow parameter

$A$ surface area, $f t^{2}$

d wall thickness, $f t$

$C_{p}$ specific heat, Btu/lb-F

$H$ wall specimen height, $f t$

$k \quad$ pressurization test flow constant

$L$ path length, $f t$

$\dot{m}$ mass flow rate, $l b / h r-f t^{2}$

$n$ pressurization test flow exponent

$\mathrm{Nu}$ Nusselt number

$p$ pressure difference, $P a$

$\Delta p$ pressure difference, $P a$

$Q \quad$ power consumption, Btu/hr

$q$ volume flow rate, $f t^{3} / s$

$S$ surface area, $f t^{2}$

$T$ temperature, $F$

$\Delta T$ temperature difference, $F$

$U$ thermal transmittance, $B t u / h r-f t^{2}-F$

$X$ diffuse fraction of infiltration

$\epsilon \quad$ infiltration heat exchange effectiveness

$\lambda$ thermal conductivity, $B t u / h r-f t-F$

$\rho \quad$ air density, $l b / f t^{3}$ 
SUBSCRIPTS

0 zero infiltration rate

a ambient or room

c cold space

$f \quad$ fluid

h hot space

$i \quad$ indoor

inf infiltration

o outdoor

$t \quad$ total

$w \quad$ wall 


\section{CHAPTER I}

\section{INTRODUCTION}

The rate of air infitration into buildings affects both energy consumption and indoor air quality. When space conditioning is necessary, the energy required to maintain comfortable conditiors increases with the rate of air infiltration. Infiltration is one of the major contributors to heating and cooling costs of buildings - especially houses. Therefore the relattonship between energy use and air infiltration is of considerable concern in energy consenvation.

Infiltration air flows are caused by pressure differences across o'zenings in the building envelope. These driving pressures are caused by the wind, thermal buoyancy (stack effect) from temperature differences between indoor and outdoor air, and the operation of appliances such as combustion devices and mechanical ventilation systems. The pressure difference at any given locatior depends on the magnitudis of these driving mechanisms in addition to the sharacteristics of the openings (cracks) in the building envelope. l.e., their locations and the relationship between pressure difference and aiffow for each opening. Pressure difference $(\Delta p)$ across the building envelope is based on the mass conservation principle, lie. the mass flow of air into the building equals the mass flow out. The wind striking a building causes a distribution of static pressures $\left(p_{w}\right)$ on the building's exterior envelope which depends on the wind direction and the location on the building exterior. This pressure distribution is independent of the pressure inside the bullding $\left(p_{i, r}\right)$. The indoor-outdoor temperature difference also imposes a gradient in the pressure difference. This pressure difference $\Delta p$.

Journal model is ASME Jourmal of Heat Transfer. 
is a function of height and temperature difference. The total pressure difference, $\Delta p$ is expressed as:

$$
\Delta p=p_{0}+p_{w}-p_{i, r}+\Delta p_{0}
$$

$$
\begin{aligned}
& \text { where } \\
& p_{i, r}=\text { interior static pressure at some reference height } \\
& p_{0}=\text { static pressure at the reference height in the disturbed flow } \\
& p_{w}=\text { wind pressure at the location } \\
& \Delta p_{d}=\text { pressure difference due to stack effect }
\end{aligned}
$$

The relationship between the airflow through an opening in the building envelope and the pressure difference across it is called the leakage function of the opening. The form of the leakage function depends on the geometry of the opening. The fundamental equation for the aiffow rate through an opening is :

$$
q=C_{D} A{\frac{(2 \Delta p)^{1 / 2}}{\rho}}^{1 / 2}
$$

where

$$
\begin{aligned}
q & =\text { airflow rate } \\
C_{D} & =\text { discharge coefficient for the opening } \\
A & =\text { cross-sectional area of the opening } \\
\rho & =\text { air density }
\end{aligned}
$$

The discharge coefficient $C_{D}$ is a dimensionless number and depends on the 
opening geometry and the Reynolds number of the flow.

The openings in a building envelope are not uniform in geometry. They usually have many bends and varying cross-sectional area; the flow never becomes fully developed, thereby preventing the applicability of the simple relations between $Q$ and $\Delta p$. The following expression is often used in such situations to describe the aggregate leakage characteristics of a building:

$$
q=C(\Delta p)^{n}
$$

where

$$
\begin{aligned}
& C=\text { flow coefficient } \\
& n=\text { flow exponent }
\end{aligned}
$$

Equation (1.3) only approximates the relationship between $q$ and $\Delta p$. In fact, the values of $C$ and $n$ depend on the range of $\Delta p$ over which equation (1.3) is applied. The cracks with larger flow resistance, i.e., greater depths or narrower widths, tend to have an exponent $n$ closer to 1 than that for gaps with less resistance. For openings in the shell of a building, the value of $n$ depends on the opening geometry, as well as on the entrance and exit effects.

Figure 1 shows a typical wind pressure profile on a building. The positive pressure side will experience infiltration whereas exfiltration will occur on the leeward side or the negative pressure side.

Knowledge of infiltration and models for predicting the amount of infiltration were very limited until the late 1970s. Earlier air leakage models used what 


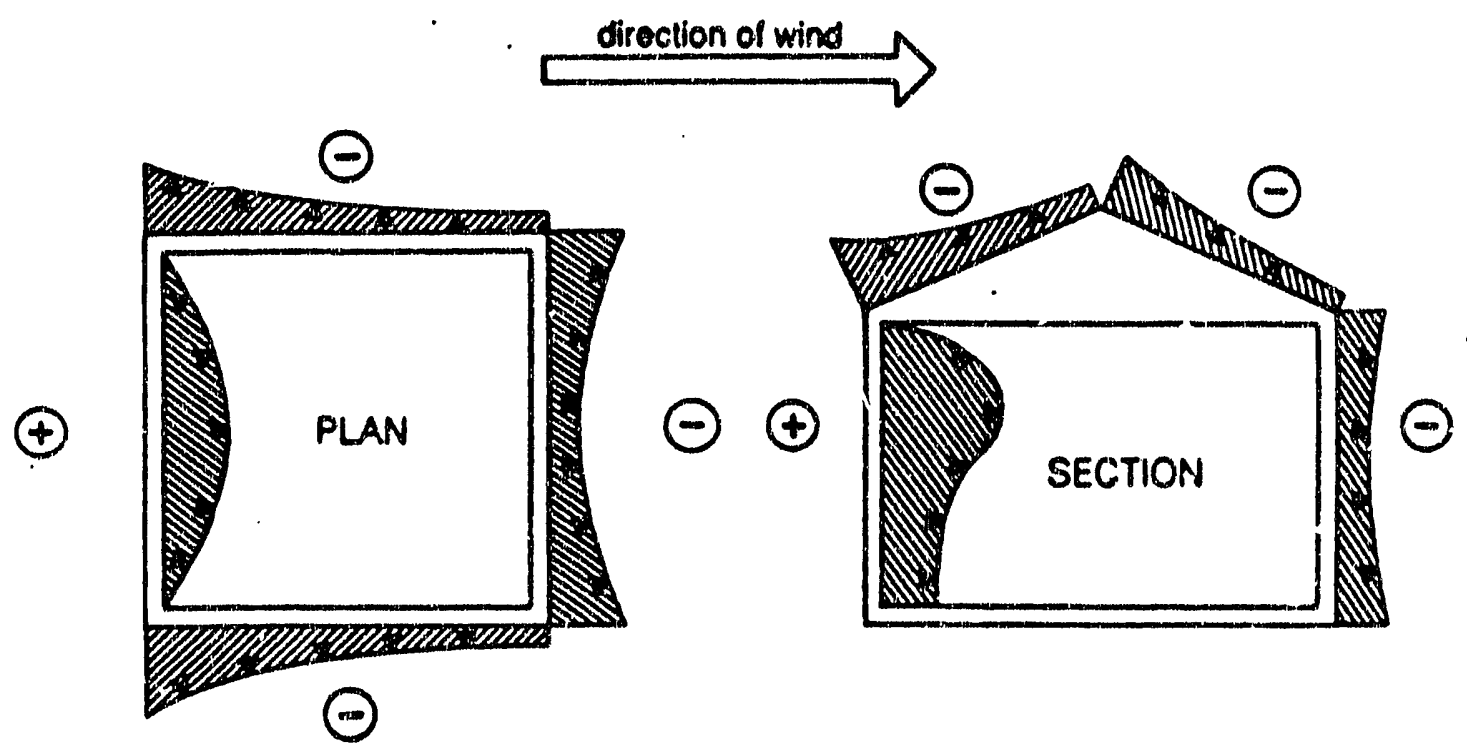

Fig. 1. Typical Wind Pressure Profile on a Building 
is conventionally known as the crack method. The air leakage temperature depends on the following parameters: temperature of the incoming air, flow rate, heat transfer in the crack, and crack form. The crack form primarily depends on the type of building component and workmanship. Crack deformation depends on the change of temperature, moisture content, and time. The crack air flow is mostly a mixed flow regime consisting of laminar, turbulent and transition flows. The proportion of each regime depends on the physical form of the crack and the pressure difference. The power law form (equation 1.3) is widely used for its simplicity. However, as Etheridge [1] points out, equations of this type lack generality because they are not dimensionally homogeneous, that is they do not obey Reynolds law of similitude. It is suggested that instuad of equation 1.3 , the following equation might be used:

$$
\Delta p=A q+B q^{2}
$$

From the appearance, it seems this equation represents both turbulent and laminar flow. The coefficients remain independent of the rate of flow.

Ore of the earliest studies which quantified air leakage in a large number of houses was the work of Caffey [2]. Based on the measurements on 50 houses in the Dallas area, he concluded that up to $40 \%$ of the heating and cooling cost was due to air infiltration. The contribution of infiltration to heating and cooling requirements varies from house-to-house, but in one comprehensive study of infiltration, Persily [3] ascribed an average of one-third of these requiremenis to infiltration. Thus, infiltration constitutes a significant part of the total space conditioning load.

Extensive work has been done on the prediction and measurement of infil- 
tration for building systems and comprehensive reviews of various methods and models are available [4-6]. But a very scant amount of research has been devoted to the actual energy consumption due to air infiltration. Recently a twelve. month workshop titled 'COMIS' (Conjunction of Multizone Infiltration Specialists) was concluded at the Lawrence Berkeley Laboratory, where a multi-national team of infiltration experts developed a reliable, versatile multizone infiltration model on a modular base. An extensive list of areas were identified for further investigation, but unfortunately the energy consumption aspect of air infiltration was again ignored. Moreover, the understanding of processes, factors and relationships have been largely qualitative. An improved quantitative understanding will enable the utilities, the consumer and the agencies to make sound decisions that are attractive from both an indoor air quality and an energy consumption point of view. Substantially more precise information than is now available is needed to characterize the physical processes involved. With this background, an experimental and analytical investigation was initiated to develop an understending of the relationship between energy consumption and air leakage in frame walls.

It has been universally assumed that the amount of energy required to heat (or cool) infiltrating air is the same as that required to heat (or cool) outdoor air to the indoor conditions; this is the product of specific enthalpy difference between outdoor and indoor conditions and the mass flow rate of the infiltrating air. Measurements conducted for this dissertation [7] have convincingly shown that intiltration can lead to a much smaller change in the energy load on a test cell than is customarily calculated. The data obtained also suggest that the phenomenon occurs in full-sized houses and that infiltration in a typical house contributes 28 to $79 \%$ as much as is now calculated. 
This investigation was initiated to gain a better understanding of the heat exchange which occurs in building components when coupled heal and mass transfer is present, as is the case when air leaks through the stud-cavity in a building wall structure. Design models for building heat transfer calculations universally assume no interaction between this heat and mass transfer. Failure to account for this interaction results in over-estimation of heat transfer by significant fractions of the heat loss or gain normally attributed to infiltration in houses. The objective of this investigation is to determine the actual energy transfer occurring while air infiltrates/exfiltrates through porous insulation in wall structures. A procedure is hypothesized which would use data from a normal pressurization test to estimate the actual energy impact due to infiltration in houses. A simple theoretical model is also developed to predict the actual energy impact of air infiltration.

This dissertation includes a review of the available and relevant literature, design and description of the experimental facility, an analysis of the theory behind this work and also the development of an analytical model, discussion of the experimental results and the concluding remarks. Chapter II summarizes the literature reviewed for this study. The review was undertaken to ascertain the current state of knowledge in the area of infiltration and energy consumption and to justify the need for additional research. Chapter lli provides the design and construction details of the experimental test facility - the infiltration test ceil and the calibrated environmental chamber; these were built exclusively for this investigation and the construction of the apparatus including the elaborate in. strumentation is considered to be a part of this dissertation. The theoretical background and analytical modeling of the phenomenon and the prediction procedure of the Infiltration Heat Exchange Effectiveness is carried out in Chapter IV. 
The experimental methodology developed for measuring the energy consumption due to air infiltration in the test cell as well as in the calibrated environmental chamber is discussed in Chapter V. Chapter VI reviews the experimental results for the test cell and Chapter VII describes the test results for the calibrated hot box. Conclusions and recommendations for future researion are presented in Chapter VIII. 


\section{CHAPTER \|}

\section{LITERATURE REVIEW}

The International Energy Agency (IEA) Executive Committee for building and community systems in the late 1970 s highlighted areas in building science where the level of knowledge was unsatisfactory and there was unanimous agreement that infiltration was the area about which least was known. Historically, with that perspective, the Air Infiltration Group was formed and consequently the Air Infiltration and Ventilation Center, England was started with participation by thirteen countries from Europe and North America. Many studies and investigations of air infiltration have been carried out during the last decade and presently there is a large volume of information available on the general subject of air infiltration. Most of this information is related to the measurement techniques and mathematical models for prediction of infiltration. The available literature on the energy impact of infiltration is quite limited and has been focused on two major areas:

(i) dynamic insulation and (ii) energy consumption due to infiltration.

\section{DYNAMIC INSULATION}

Before any studies were carried out on the actual energy impact of infiltration, dynamic insulation systems were in existence. This type of system is referred to as dynamic as compared to siatic, corresponding to a classic configuration with no air flow. Since the same thermal phenomenon is involved in both cases, a review of the available information on dynamic insulation is 
useful. Research on dynamic insulation goes back to 1978, when the first prototype experimental building [8] was completed in France. This was followed by a second prototype - with improved design and more extensive instrumentation - built in 1981 and commissioned late in 1982. Several definitions of dynamic insulation can be found in the literature; simply stated, it is a means of reducing building heat loss significantly without the use of massive thermal insulation. It is achieved by recyc.ing the heat conducted through the fabric or reducing the temperature gradient across the wall section by means of a suitable heat transport fluid - usually air. Most of the structures that have been built and tested are in Sweden, France, Finland and Canada, and significant improvements over classic insulation methods have been reported. The physical phenomenon which occurs wher an aiflow circulates in the wall of a building can be described as heat exchange which takes place between the material of the wall and the air. The conductive flow through the wall is modified, and the airflow leaves the wall at a generally higher temperature (in a winter configuration when it is cold outside and warm inside).

A formal classification of generic dynamic insulation system has been reported in the literature [9] and the three types which can be associated with building applications are enumerated below.

\section{Parietodynamic insulation}

In this case, ventilation air needed for the building circulates along the wall; this air can be either fresh or used air. In the first case, fresh air from the outside is preheated before it enters inside (Figure 2a). In the second case, used air warms up the wall, and consequently, conduction heat losses are 
decreased (Figure 2b). This circulation requires the creation of one or two air gaps (Figure 2c). It is applicable to double or triple glazed windows [10].

\section{Permeodynamic Insulation}

Ventilation air needed for the building circulates through the walls; more precisely the air flows through a permeable porous medium, generally mineral fiber (Figures $2 d$ and 2e), which acts as a heat exchanger. As in parietodynamic, the circulation air can be either used or fresh air; the last case (Figure 2d), where air flows in a direction opposite to the conduction heat flow, is sometimes referred to as counterflow or contraflux insulation.

In both cases, the air flow changes the local temperature within the porous medium. In counterflow, temperature will decrease compared to a situation with no air flow. The slope of the temperature profile at the cold side is lower and consequently heat losses are reduced. Similarly, the slope at the hot side is higher but a certain amount of prewarmed air is brought inside.

\section{Thermodynamic Insulation}

Parietodynamic and permeodynamic systems are involved only if ventilation air is needed. This is generally the situation, and in addition the ventilation requirements correspond to an air velocity compatible with good working conditions of the system.

However the present trend to reduce the ventilation flow rates has led to a third kind of dynamic insulation, named thermodynamic. It is in principle similar 


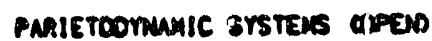

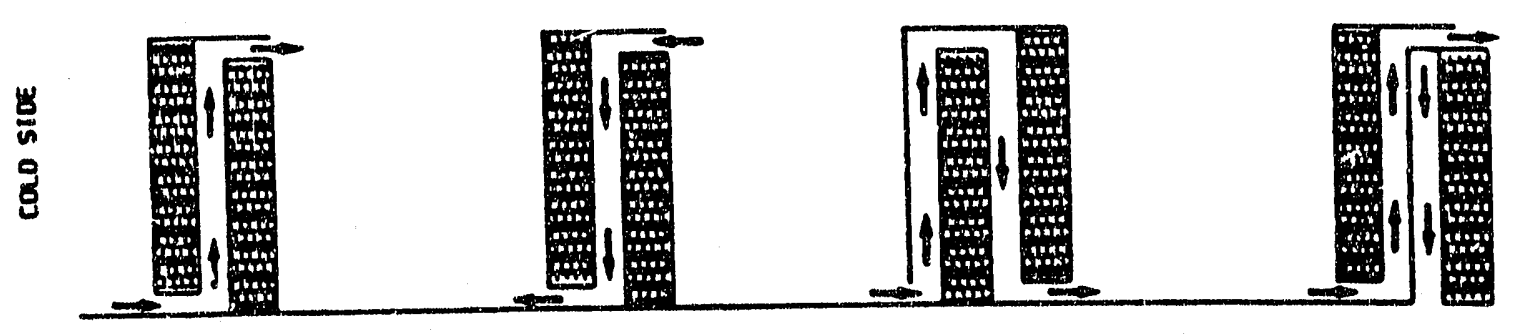

(a)

(b)

(c)

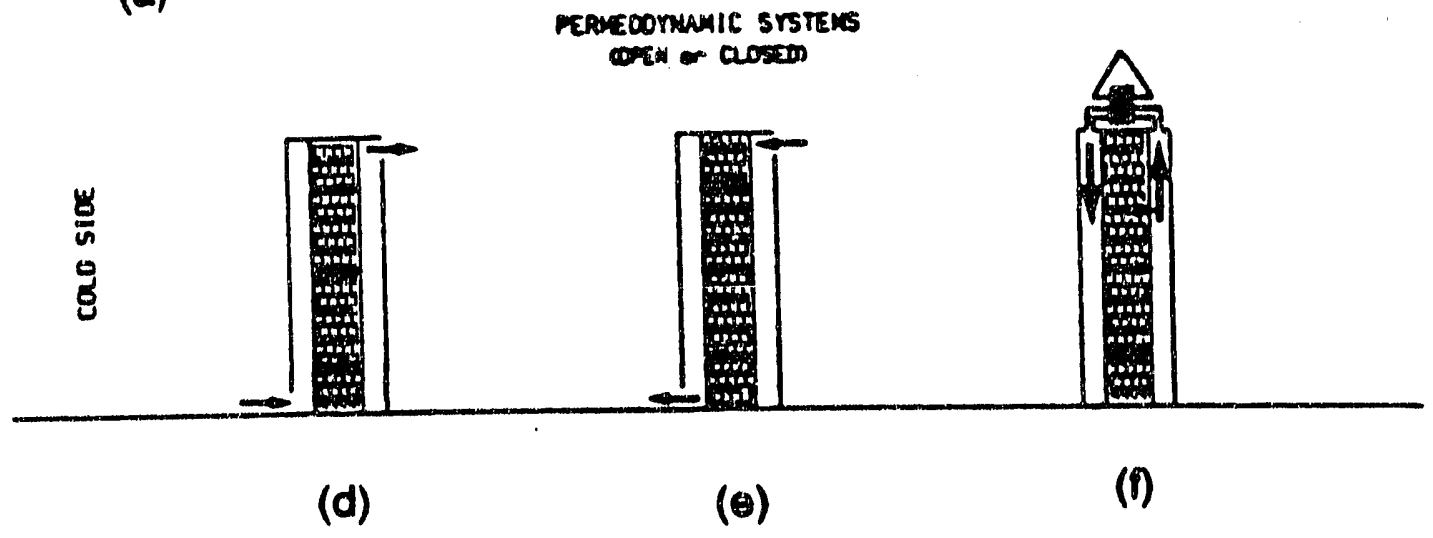

Fig. 2. Different Types of Dynamic Insulation 
to permeodynamic (counterflow configuration) but the air circulates in a closed circuit independent of the ventilation system. A heat exchanger is required to recover what is gained by the air as it flows through the porous medium. In practice, for appreciable gains, this heat exchanger is the evaporator of a heat pump (Figure 2f).

Arquis and Langlais [9] reported a theoretical model and an efficiency parameter for evaluation of dynamic insulation systems as compared to "conventional' insulation. Limitations of such systems, where ventilation air circulated through a permeable porous medium which acts as a heat exchanger, and their most feasible applications were also discussed. It was concluded that the conventional insulation techniques were still competitive for houses, but dynamic insulation systems offered greater possibilities for industrial buildings.

In a study to demonstrate the concept and operation of a building ventilated by dynamic insulation in cold weather and strong winds, Timusk [11] reported that there would be energy savings for such an operation. Discussions were presented on related problems, e.g., the effect of dynamic insulation on indoor air quality, whether the slow infiltration of air into the building increases the moisture levels in walls.

Bailly [12] presented a comprehensive and informative review of dynamic insulation in general, where such systems were compared to the operation of an air-to-air heat exchanger. Transient models and experiments were used to evaluate the performance of dynamic insulation systems during the heating season and energy savings of the order of 7 to $14 \%$ were reported.

Dubois [13] reported sorne data on energy efficient building walls which 
incorporated dynamic insulation. This formed part of a retrofitting project which produced significant energy savings. The beneficial effect of dynamic insulation increased with increase in specific airflow rate and a nominal 10\% reduction in energy use was achieved when fresh air flowed through the wall and into the apartment.

None of the authors made an attempt either to derive a general expression to calculate the actual amount of heat transferred by the fluid flowing through the porous insulation or to investigate the heat transfer experimentally.

\section{ENERGY CONSUMPTION DUE TO INFILTRATION}

All computer models used for calculating energy consumption of buildings assume that infiltration increases the heating/cooling load on a building by an amount equal to the mass flow rate of the infiltration times the enthalpy difference between the inside and outside air - with the latent portion of the enthalpy difference sometimes neglected. The energy consumption due to infiltration is usually calculated using the simplified equation:

$$
Q_{\text {inf }}=\dot{m} C_{p}\left(T_{i}-T_{o}\right)
$$

where:

$$
\begin{aligned}
& Q_{\text {inf }}=\text { energy consumption due to infiltration }(B t u / h r) \\
& \dot{m}=\text { infiltration rate }(\mathrm{lbm} / \mathrm{hr}) \\
& C_{p}=\text { specific heat of air }(B t u / l b m-F) \\
& T_{i}=\text { indoor temperature }(F)
\end{aligned}
$$




$$
T_{\mathrm{o}} \quad=\text { outdoor temperature }(F)
$$

This practice is followed in simple models such as the Modified Degree-Day Method and the Variable-Base Degree-Day Method [14] as well as the most com. plex hourly simulation programs used for research and difficult design problems, including DOE-2.1 [15] and SERI-RES [16].

Observations have shown that attic temperatures are often higher than pre. dicted by resistive models of attic insulation. This was first reported by Beyea ot al. [17] followed by Harrje et al. [18], who conducted careful experiments on a group of townhouses in Twin Rivers. New Jersey. Claridge et al. [19] found that attic temperatures in nine of a group of 25 houses examined in the Denver area had less than half the temperature drop expected across attic insulation. These higher attic temperatures are due to air flow into the attic which bypasses the insulation. The overall loss coefficient calculated for 20 of these houses was 27 to 54 percent higher than values regressed from gas consumption data [20].

Consideration of the combined problem of conduction through insulation and air flow into the attic shows that total heat loss through an attic under these conditions is less than the conductive loss plus the normal extiltration loss. The attic serves as a heat exchanger and the extiltrating air reduces the "conductive" loss by increasing the attic temperature. Anderlind $[21,22]$ has shown that this phenomenon is more general and that energy loss due to inflitration can have a maximum value given by the inside/outside enthalpy difference for the infiltrating/exfitrating air. He suggests the use of a multiplier 
$R(0 \leq R \leq 1)$ in combination with the coefficient, $(U A)_{\text {inf, }}$ customarily used. The energy lost by infiltration is then given by:

$$
Q_{\text {inf }}=R \dot{m} C_{p}\left(T_{i}-T_{o}\right)
$$

When air leakage enters a wall at one point and travels several feet through the wall before entering the house, it is termed "diffuse" leakage; that which directly enters the building such as through cracks around a door is termed "concentrated". Air infittrating into a building affects the temperature distribution inside the walls of the building, especially when the air leakage is diffuse.

A new non-dimensional factor Infiltration heat Exchange Effectiveness, IHEE. $(\epsilon)$ is introduced here. IHEE is the degree of effectiveness of the heat exchange process occurring while the infiltrating/exfiltrating air diffuses through the wall systern. IHEE is directly related to the reduction factor, as defined by Anderlind [21], and is given by:

$$
\epsilon=(1-R)
$$

The total heat lost through the walls due to transmission is reduced by diffuse air leakage. This reduction is properly described if the air leakage heat losses are multiplied by a factor, $(1-\epsilon)(0 \leq \epsilon \leq 1)$ and the transmission losses are calculated in a normal way (i.e. assuming a linear temperature distribution across the walls). Accordingly, the energy lost by intiltration is given by:

$$
Q_{\text {inf }}=(1-\epsilon) \dot{m} C_{p}\left(T_{i}-T_{o}\right)
$$


The value of the factor $\epsilon$ depends primarily on the relative amounts of diffuse and concentrated air leakage which enter and leave the building envelope.

To explain the concept of the IHEE, a simplified and hypothetical example of a two-dimensional house with specified insulation values is illustrated hele (Figure 3). The building has an infiltration rate of $55.6 \mathrm{cfm}$ and the ambient temperature is $40 \mathrm{~F}$ whereas the indoor temperature is maintained at $70 \mathrm{~F}$. In the conventional estimates using a simple resistive model, the attic and crawl space will be at $46 \mathrm{~F}$ and $55 \mathrm{~F}$ respectively. The energy loss due to infiltration is $1800 \mathrm{Btu} / \mathrm{hr}$ and the total energy loss due to conduction and infiltration is 4500 Btu/hr, using customary calculation procedures. But if it is assumed that the cold air first enters the crawl space which acts as a heat exchanger and subsequently performing energy balances (Figure 4), the crawl space temperature decreases to $51.5 \mathrm{~F}$; similarly, the modified attic temperature is $50.7 \mathrm{~F}$. With these modified temperatures, the total energy loss for the house is now reduced to $3922 \mathrm{Btu} / \mathrm{hr}$. Hence the effective infiltration loss is:

$$
Q_{\text {inf }}{ }^{\prime}=[1800-(4500-3922)]=1222 \mathrm{Btu} / \mathrm{hr}
$$

where $Q_{\text {inf }}{ }^{\prime}=(1-\epsilon) \dot{m} C_{p} \Delta T$. Thus in the current example $\epsilon$ has a value of 0.32 .

In design heating load calculations, the infiltrating air is assumed to enter the room at the outside temperature. Kohonen [23-26] has reported that the infiltrating air warms up clue to the heat transfer between infiltrating air and the wall structure along the air leakage path. Defining a Nusselt Number $(N u)$ as the ratio of the heat transfer on the control surface (a wall section) with and without 


\section{CLASSICAL IRIRAT LOSS}

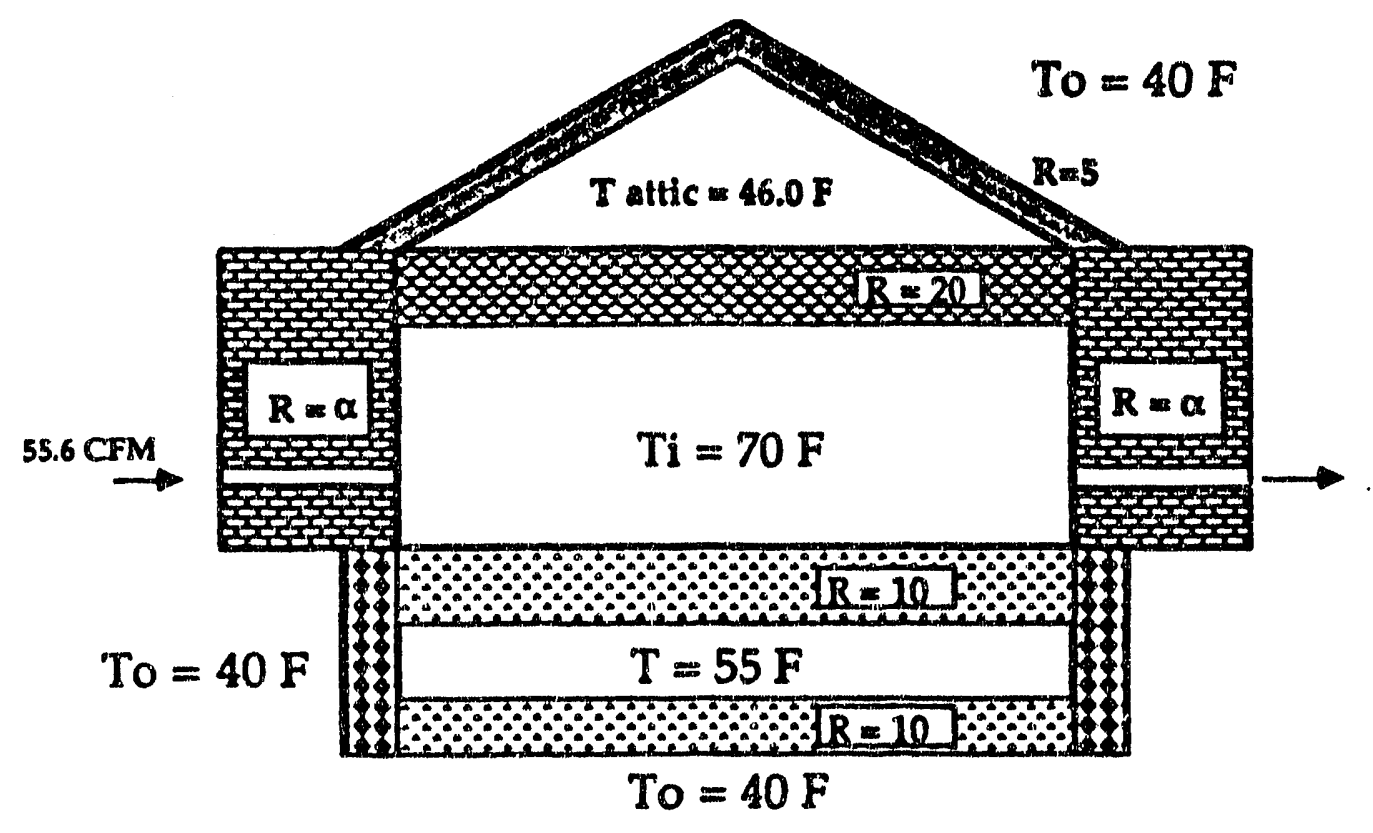

Fig. 3. A Hypothetical Example to Demonstrate IHEE (Classical Loss) 


\section{INEIRTHATLON BXAMELE}

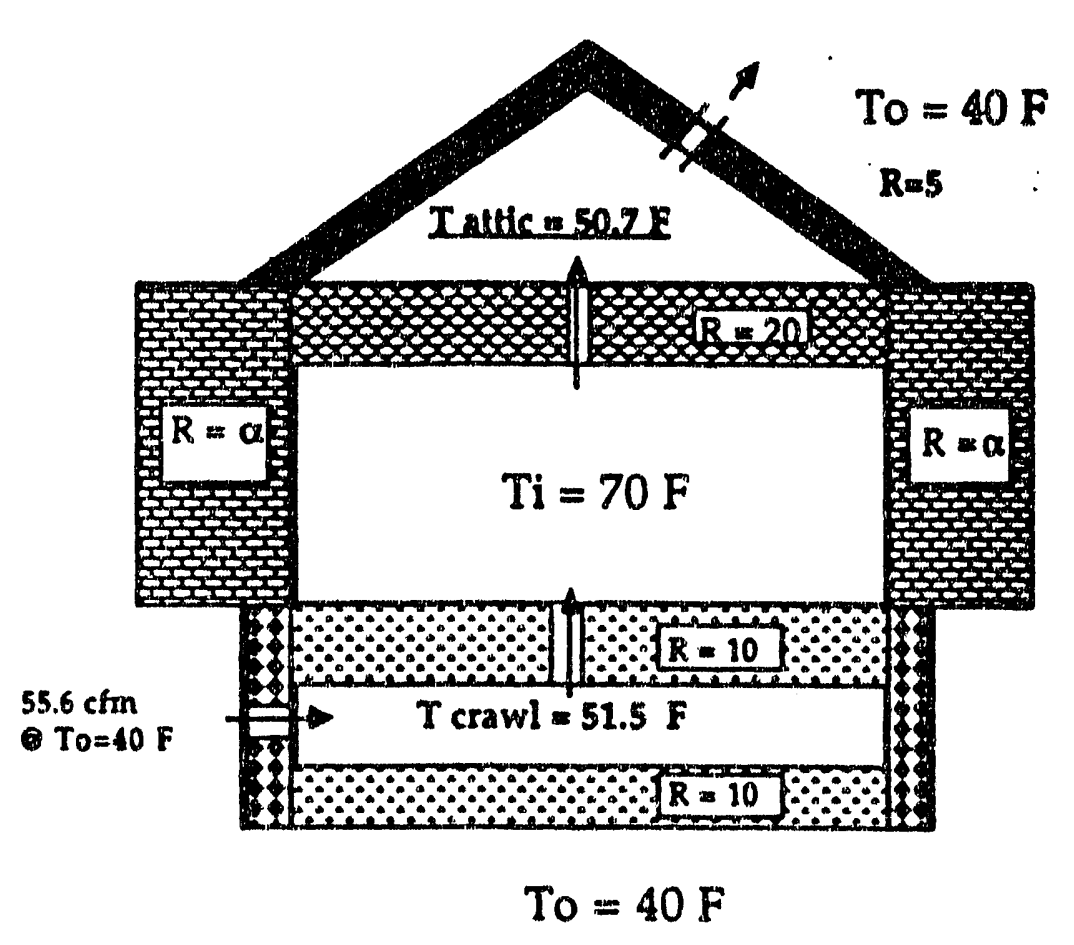

Fig. 4. Infiltration Example with Modified Calculation Procedure 
convection or leakage flows, it was shown that for typical leakage routes, $N u$ is about $0.6-0.8$; which means that the combined heating load of infiltration air and transmission is commonly overestimated in the design heat loss calculations. Both simulation and experiments were carried out to investigate the thermal effects of air flow on the thermal performance of wall structures. An equation to take into account the interaction of air flows and sonductive heat transfer in structures was suggested (assuming the exterior envelope of the building as the control surface boundary), and is given below in a schematic form :

$$
\dot{Q}=\left(-\sum_{i} \dot{m}_{i} T_{o}+\sum_{e} \dot{m}_{e} T_{e}+\left(\sum_{i} \dot{m}_{i}-\sum_{e} \dot{m}_{e}\right) T_{r}\right) C_{p}+\sum_{k} N u_{k} \bar{K}_{k} A_{k}\left(T_{r}-T_{o}\right)
$$

where:

$$
\begin{aligned}
N u_{k}= & \text { Nusselt number which takes into account the thermal effect of } \\
& \text { leakage flows as well as internal convection flows of structures } \\
\dot{Q}= & \text { heat transfer rate across the building envelope } \\
T= & \text { temperature } \\
\bar{K}_{k}= & \text { overall average thermal transmittance of the structure } \\
\dot{m}= & \text { air flow rate }
\end{aligned}
$$

and subscripts :

$$
\begin{aligned}
& i=\text { infiltration } \\
& e=\text { exfiltration } \\
& o=\text { outdoor } \\
& r=\text { indoor } \\
& k=\text { conduction }
\end{aligned}
$$


It can be observed that several factors present in equation (2.5) are hard to determine, and accordingly, the heating load estimation becomes a complicated and empirical procedure. But if it is possible to predict the Nusselt number for a particular structure, the value of the transmission heat flow without infiltration should be multiplied by $\mathrm{Nu}$ in order to have the correct (valid with infiltration) transmission heat flow, i.e., in order not to overestimate the heat load of transmission and infiltration.

Theoretical and experimental analyses of heat transfer rates for permeable insulation systems which sustain infiltrative-exfiltrative air intrusion effects have been reported by Berlad et al. $[27,28,29]$ who made an attempt to estimate the effective ' $R$ ' (thermal resistance) value for such systems. It was concluded that the intrusive airflow can serve to degrade the insulating value of various permeable insulator sj'stems; but here the analyses included part of the convective heat transfer in the conductive fraction and thus failed to note that the combined loss due to convection and conduction is less than the customarily calculated value.

De Gids [30] studied the effects of building tightness, wind velocity, temperature, wind direction, surroundings and degree of exposure on infiltration loss and concluded that the relationship between airtightness and the heat loss due to infiltration was not linear. Investigations of the energy consumption due to infiltration have been reported $[31,32,33]$, but they fail to bring out information as to how the actual energy consumption can be estimated or why the current estimates are not accurate for certain configurations. Michell et al. [31] conducted studies on houses in Melbourne, Australia (single story timber framed houses with an external wall of single brick, tiled roof and lined internally with 
plasterboard) and quantified savings that occurred when the buildings were tightened to specified conditions. Heidt et al. [32] in a similar study conducted in the Federal Republic of Germany estimated energy-saving potential of houses through air-tightening and pre-heating of ventilation air applying waste-heat recovery. Nantka [33] carried out investigations on energy consumption in the Polish building sector. The work, carried out from 1980 to 1985 , aimed at developing methods for measuring air flows and their influence on heat consumption in typical Polish dwellings. The basic criteria for the correct design of dwellings were formulated and ventilation heat loss reduction was estimated to be as high as $45 \%$ to $70 \%$. Generally these studies, indicate that about one-third of the total energy consumption is due to air infiltration.

Persily [34] tested a residential air-to-air heat exchanger for effectiveness of heat recovery. Some of the data obtained during experiments to account for the heat loss due to air infiltration indicated that the actual infiltrative loss was less than that estimated by the conventional procedure of using the enthalpy difference between the indoor and outdoor air.

To demonstrate retrofit effects and to develop mathematical models of the physical processes, Nagda et al. [35] carried out a highly controlled experimental and analytical investigation on the relationship among air exchange, energy consumption and key indoor pollutants in residential buildings. Reduction in air infiltration rate and energy use in the retrofitted buildings was quantified; put no effort was devoted to the investigation of the energy impact of infiltration, and their energy modeling employed the customary procedure (equation 2.1).

Although a number of researchers have recognized the importance of air infiltration and its energy impact in building systems, mostly general discussions 
and theoretical modeling of the heat transfer phenomenon in porous vertical cavities exist in the available literature [36-40]; a practical application oriented modeling approach for the energy consumption due to air infiltration in buildings has not been reported. Since accurate measurements of the actual energy impact of air leakage has not been undertaken, this study was initiated as an attempt to fill in that void from the experimental point of view. But this dissertation still does not offer a complete modeling work for this phenomenon. Furthermore, this work embodies measurements taken for building components under laboratory conditions only; outdoor test house data and real building data will not be reported here. 


\section{CHAPTER III}

\section{EXPERIMENTAL FACILITY}

A series of experiments were devised to characterize the dependence of Infiltration Heat Exchange Effectiveness on the four key parameters: 1) leakage type; 2) flow rate; 3) leakage path length; and 4) pressurization exponent. The experimental investigations were carried out in two phases. Initially a small test cell was designed, built and used for preliminary testing and confirmation of the hypothesis. Then a more sophisticated apparatus was used for testing a single. stud-cavity. A modified calibrated hot-box with the associated instrumentation was designed and constructed for the stud-cavity tests. Both test facillties were assembled and operated in room 405 (T) of the Engineering Physics Building. The design and construction details of each facility are described below:

\section{INFILTRATION TEST CELL}

A set of experiments was designed to measure the energy impact of controlled amounts of infiltration air in a small test cell. The test cell was constructed using standard frame construction for the six wall, ceiling and floor surfaces. This construction was:

- $3 / 8$ inch plywood sheathing

- $2 \times 4$ (1.5 in $\times 3.5$ in) studs

- R-11 fiberglass batt insulation between the studs

- $3 / 8$ inch plywood sheathing

The external measurements of the test cell are 56.5 inches wide by 48 inches high by 96 inches long. Each surface was constructed separately, and then, all 
six surfaces were bolted together and caulked; this form of assembly permits replacement or rebuilding of individual surfaces as needed. One of the 56.5 inch by 48 inch end-walls contained a removable 24 inch square window glazed with $3 / 8$ inch plexiglass. This aperture also served as the door to the test cell between experiments. All joints between the walls and all visible cracks in the wood were tightly caulked to minimize uncontrolled air leakage. The test cell was supported by six large casters to provide portability.

Type T (copper-constantan) thermocouples were used to measure the test cell temperature (including the air inlet and exit temperatures) at nine points as shown in Figure 5. The interior locations were located close to the center point of each wall surface. Another sensor was used to measure the temperature outside the test cell. All temperatures were recorded by a programmable datalogger (Omega OM205).

The pressure difference between the interior and exterior of the test cell was measured using a pressure gage (Retrotec RDF-700 blower door instrumentation). A regulated DC power supply (Adtech Power, Brute III; 5-50 V and 2-25 A, 1200 Watts) and wire-wound resistors (six resistors of 5 Ohms each, equivalent resistance 3.33 Ohms) were used for heating the test cell; an AC fan was employed to reduce temperature stratification. The power input for the heater and the fan was determined by measuring the voltage, current and power factor using an $A C / D C$ multimeter. A pressurization test was performed whenever the test cell had been opened to ensure that cell tightness was maintained.

The various holes provided in the test cell for air inlet and outlet are illustrated in Figure 6. Air was introduced through a $1 / 2$ inch hole (hole P) for all the pressurization tests. This hole and a diffuse hole (hole $\mathrm{B}$ on the exterior) 
Thermocouples

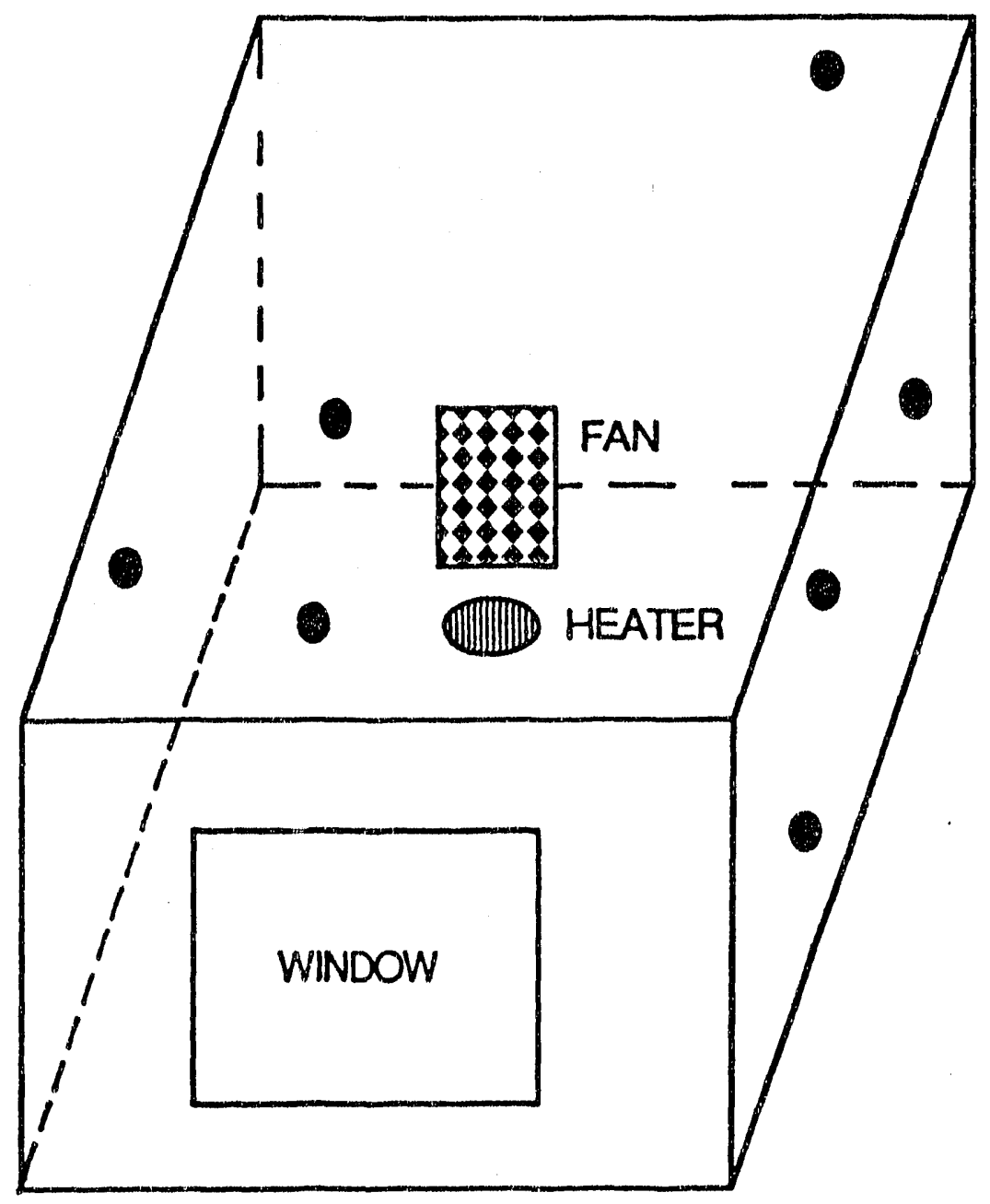

Fig. 5. Test Cell Schematic Showing Thermocouple Locations 
were used as the air inlets in the heating tests to calculate $\epsilon$. The 1.5 inch hole ' $E$ ' and another diffuse hole (hole A) were used as air outlets. The vertical position of holes BO and B1 were 26 and 16 inches respectively from the floor of the cell; holes B2, B3 and B4 were close to the floor. The horizontal position of hole BO was close to the back wall and holes B1, B2, B3 and B4 were 3 , 14, 46 and 74 inches respectively from the back wall. The air flow rate was measured by a rotameter (Dwyer RMC series) before it entered the test cell.

\section{CALIBRATED HOT BOX}

The calibrated hot box method provides for the laboratory measurement of heat transfer through a specimen under controlled temperatures established in a metering chamber on one side and in a climatic chamber on the other side. It is primarily intended for measurements under steady-state conditions and at temperatures typical of normal building applications. The apparatus is generally operated in a conditioned laboratory space free from localized hot and cold sources; thus, in principle, the laboratory space acts as a guard. Accuracy of this procedure is obtained through careful analysis of the metering chamber wall heat transfer mechanism. This is achieved through the use of a calibration standard section, having known thermal characteristics; hence the name calibrated hot box. The apparatus usually consists of two large, fivesided, boxes with highly insulated sides plus an equally well-insulated frame which supports a test wall clamped between the open sides of the two boxes. One of the boxes is equipped with conditioning and control equipment suitable for maintaining a range of indoor temperature conditions and the other box is provided with similar equipment suitable for maintaining a range of outdoor 

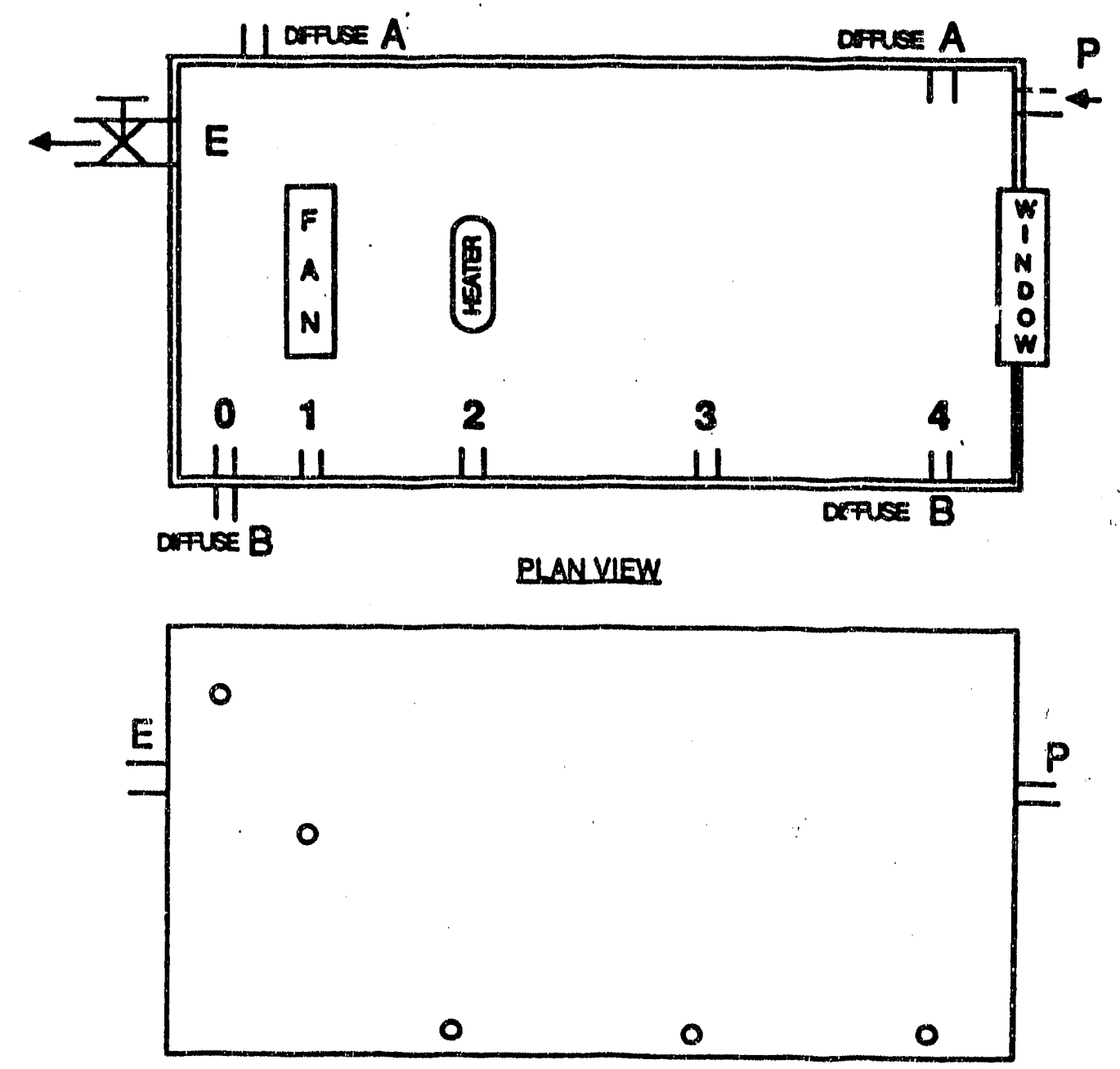

PROELLEVIEN

Fig. 6. Test Cell Set-up Showing Different Hole Openings 
conditions. Instrumentation is provided to measure the heat input on the indoor side.

The standard calibrated hot box test [41] does not provide for mass transfer of air through the specimen during measurements of heat iransfer. The present work modified the standard method to include air flow through the specimen. The design of such an apparatus requires that the range of test conditions be compatible with those naturally occurring.

Test Specimen

A single stud-cavity wall section (Figure 7) of external dimension 17.625 inches by 4.5 inches by 8 feet was constructed to serve as the test specimen. The stud-cavity was made up of $1 / 2$ inch plywood facing and $2 \times 4$ studs. The 3.5 inch thick cavity was filled with four pieces of lightweight blanket type insulation (Microlite Insulation, Manville, I lom/ct density) made of fine flame attenuated glass fibers bonded with a thermosetting resin. The thermal resistance $(R)$ of the insulation arrangement was $15.385 \mathrm{hr} f t^{2} \mathrm{~F} / \mathrm{Btu}$ according to the manufacturer's specifications. Five layers of thermocouples were mounted between the insulation blankets with each layer consisting of a grid of fifteen thermocouples. The layout of these 75 thermocouples is illustrated in Figure 8. The plywood and the studs were coated with polyurethane clear paint to seal of the pores and thereby minimize undesirable airlow through the test specimen. Highly dried furniture grade siluds and cabinet grade plywood were used to build the standard stud-cavity.

All thermocouples were constructed using arc welded wire and small bead a.ameters. Finished thermocouples were spot checked with a precision $\mathrm{Hg}$ 


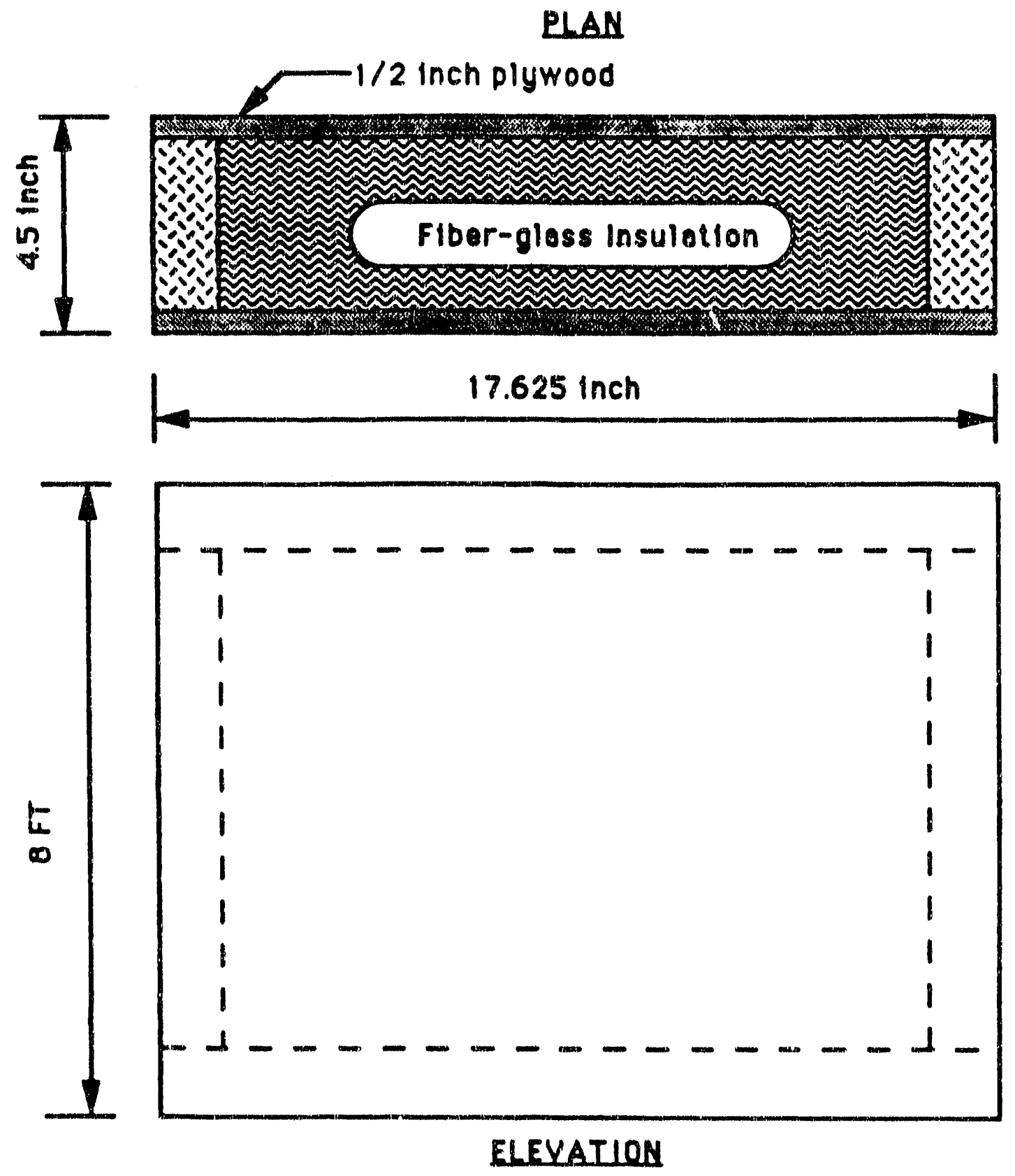

Fig. 7. Schematic of the Stud-Cavity Wall Section 


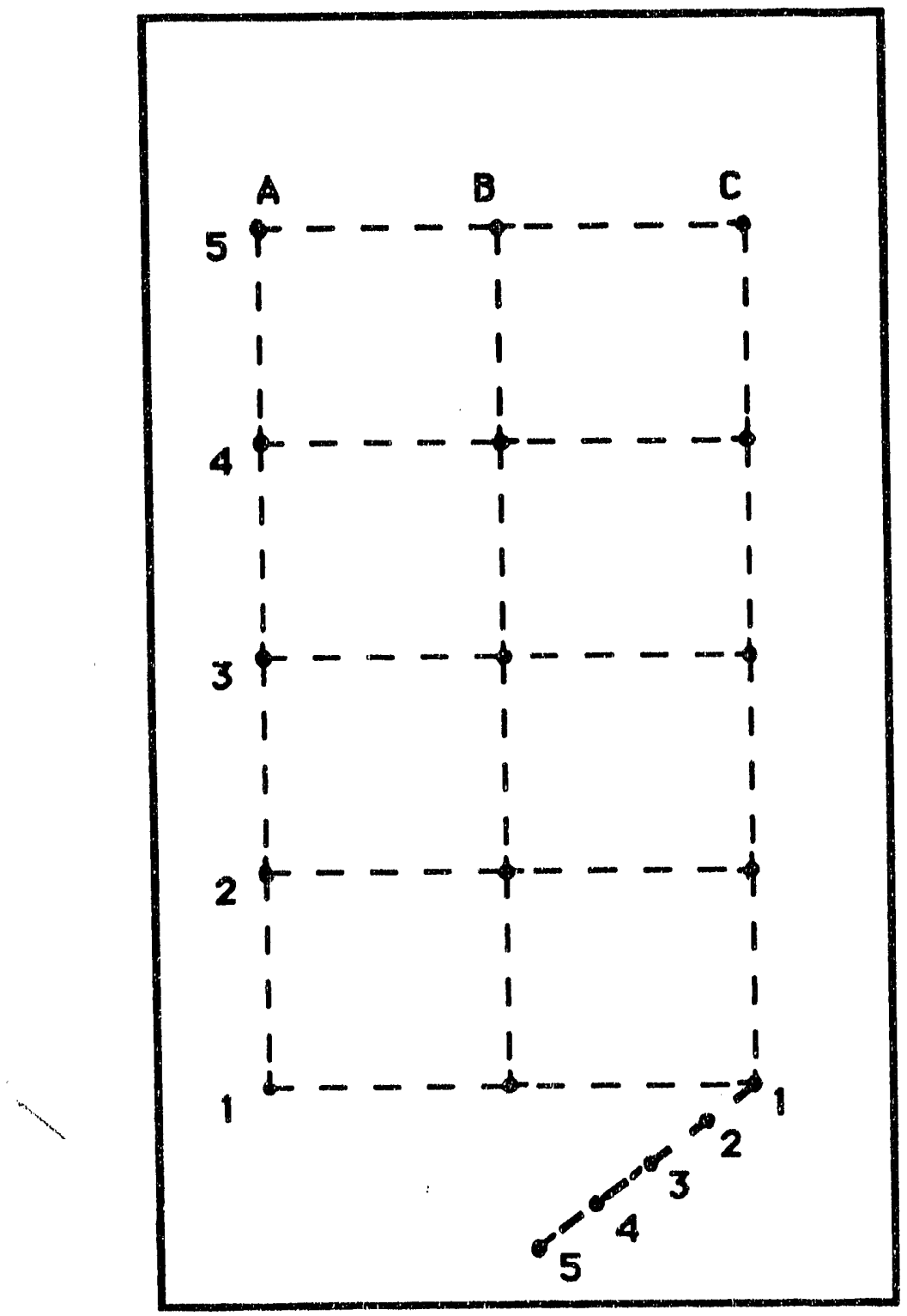

Fig. 8. Layout of the Thermocouples Inside the Stud-Cavity Wall Section 
thermometer to see that they were all within the standard error limits of $\pm 0.75^{\circ}$ $F$. Type $T$ thermocouples made of 30 gage wire (Omega) were used, the smaller wire size offering greater accuracy and compactness. Thus the exit hole from the stud-cavity and the hot box for the thermocouple bunch was kept to a minimum thereby maintaining the stringent tightness criterion needed for the experiment. The pressure difference between the wall specimen and ambient was monitored by a differential pressure transducer (Setra Systems, 239 series, -0.5 inch $W C$ to +0.5 inch $W C$ ) connected to the datalogging system.

The design of the enclosure (Figure 9) around the stud-cavity incorporated 20 inch thick extruded polystyrene foam insulation, (Therma Foam, R-76) for the vertical surfaces and in order to restrict the overall height of the structure, 7 inch thick poly-isocyanate board insulation (Thermacore, R-50) was used for the horizontal surfaces. All insulation was covered internally with $1 / 2$ inch thick plywood and enclosed externally in a $3 / 4$ inch plywood casing. The external size of the box was 69.5 by 60.5 by 112.5 inches. Customarily, the hot box, the cold box and the specimen are all built and supported separately on casters and the three pieces are brought together during tests. This design philosophy presented a problem for the current set-up. Since this was an infiltration test facility, stringent airtightness requirements were adopted; hence a composite design with swing-out door, for access to the stud-cavity and the hot and cold space on either side of it, was incorporated. This kept the air leakage rate to a minimum. The elevation of the calibrated hot box is illustrated in Figure 10. Better quality lumber was used to reduce deformation, warpage etc. Metal reinforcements were avoided to reduce heat transmission. The entire enclosure along with the door was mounted on metal casters (with provision for level adjustment) for maneuverability. 
styrofoom insulation stud-covity woll plywood sheothing
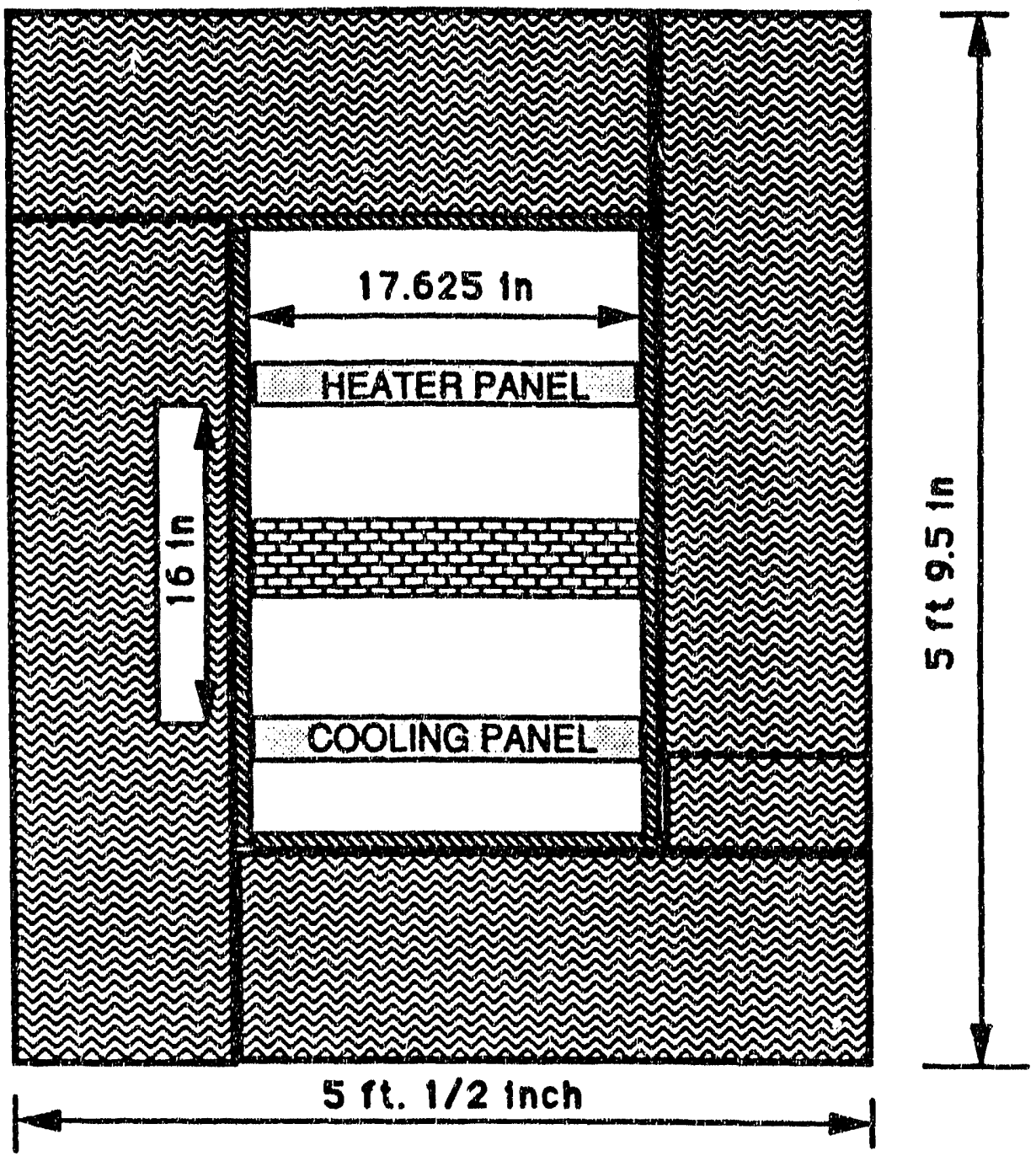

Fig. 9. Sectional Plan View of the Calibrated Hot Box 


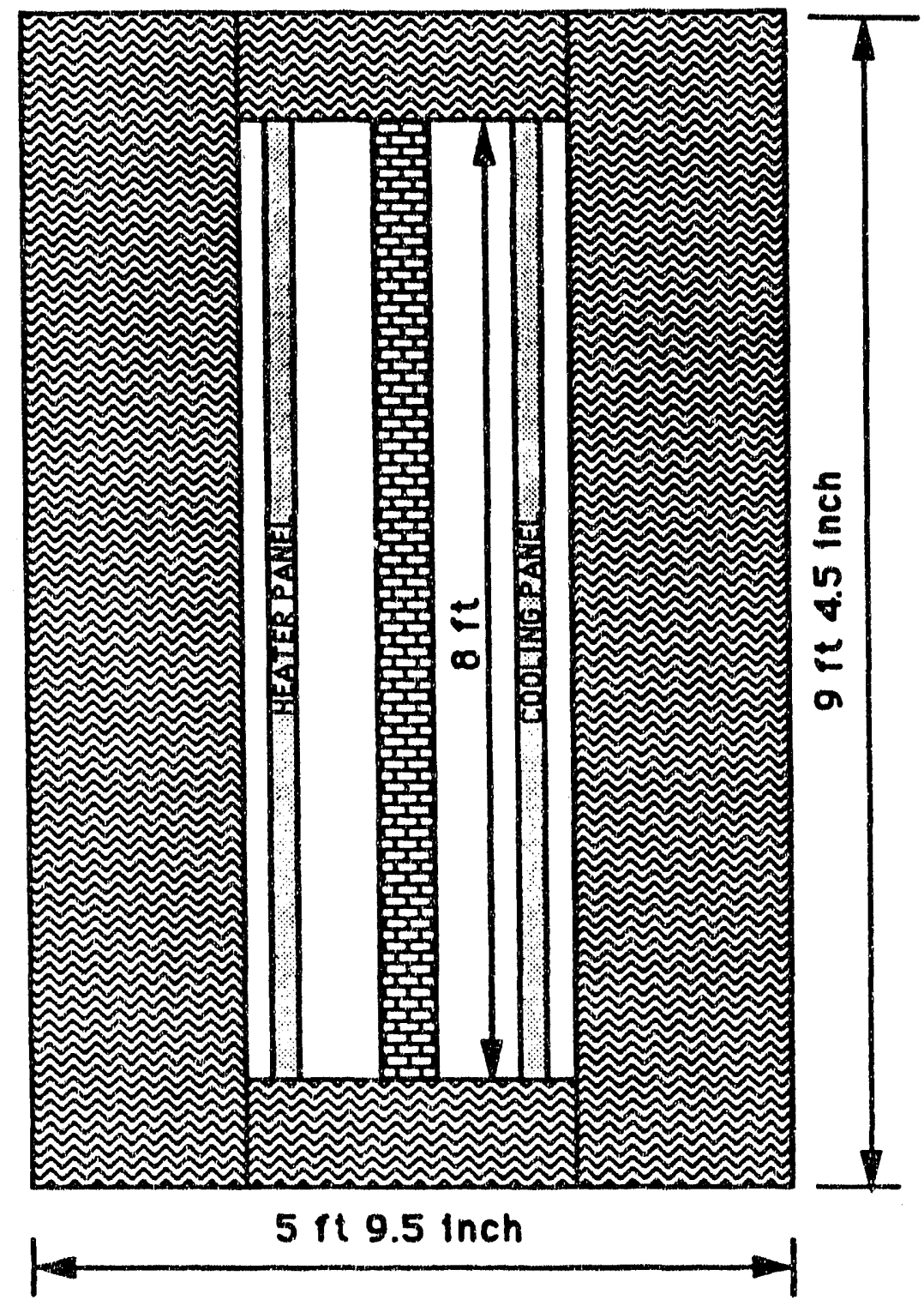

Fig. 10. Sectional Elevation of the Calibrated Hot Box 


\section{Heating System}

A flexible rollout resistance heating element (Aztec Flexel, 84 Ohms and 175 Watts), 16 inches wide by 8 feet long, was affixed to a 1/8 inch thick aluminum plate to serve as the radiant heating panel. The heating element consists of fiberglass cloth impregnated with a conducting carbon graphite dispersion. Copper buss bars were stitched along each edge and a plastic film was laminated to each face. This assembly was backed by styrofoam insulation. A microprocessor controlled precision DC power supply (Lambda model LLS6120, $0.120 \mathrm{~V}$ and $0-1.4 \mathrm{~A}$ ) provided constant power to the heating panel assembly. This power supply was capable of operating as a constant current or constant voliage power source with front panel display of the voltage and current supplied.

\section{Cooling System}

The radiant cooling panel (Airtex Corporation) (Figure 11) was made of extruded aluminum; 5 -inch wide individual extrusions were cut to 8 feet in length, painted white and assembled to span the width of the stud-cavity. One-half inch diameter copper tubing was then pressed into the oval saddle of the extrusions. This mechanical process conforms the copper tubing (carrying the chilled water) to the configuration of the saddle, maximizing the contact area and securing the tube so that separation from the panel cannot occur during normal operation.

An elaborately designed chilled water system with a sophisticated proportional control loop was used for the radiant cooling panel. A 55 gallon container stored a $50 \%$ glycol solution which in furn was cooled by a cooling unit through 


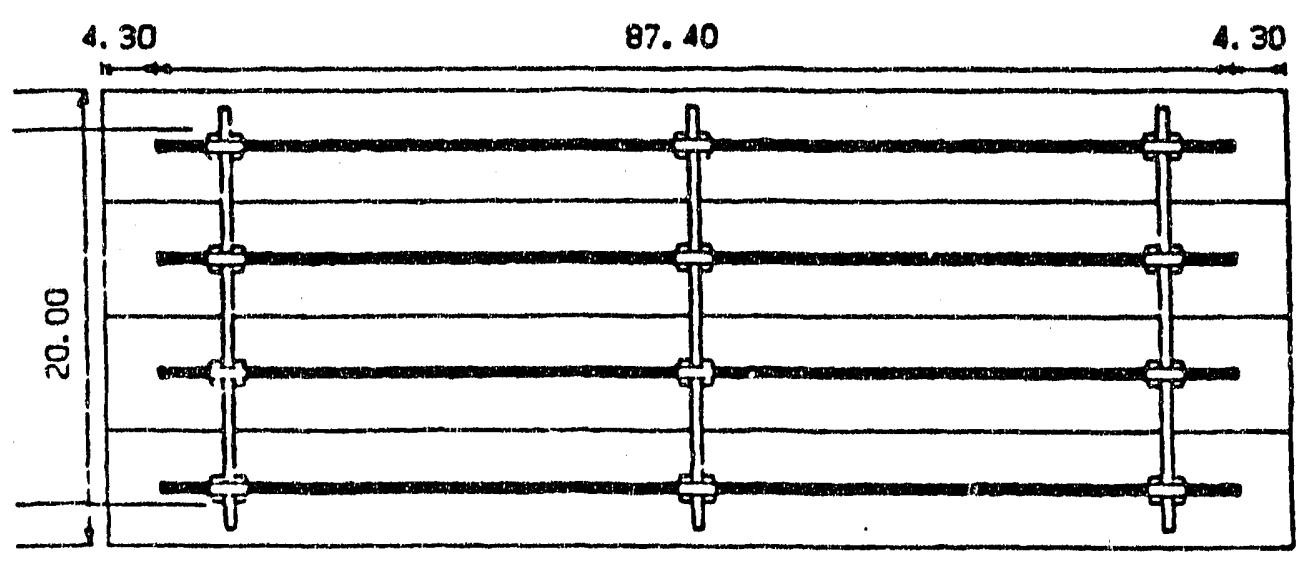

Fig. 11. Radiant Cooling Panel Schemalic 
a heat exchanger; the cooling unit was built from components for this system only. A three way mixing valve-motor assembly in conjunction with a very accurate temperature controller formed the control loop for the cooling panel. The mixing valve assembly was formec 'rom four components:

1. Double inlet and single outlet 3-way mixing valve (Honeywell V5013);

2. Modulating spring-return motor for controlling the valve (Honeywell M945D);

3. Valve linkage (Honeywell Q618A) used to connect the modutrol motor to the 3-way valve assembly;

4. Transformer for the motor.

This assembly provides a proportional control system for the chilled water supply to the radiant cooling panel. An RTD measured the temperature in the cold space and formed the control input to a microprocessor based temperature controller (Omega $\mathrm{CN} \mathrm{6071A)} \mathrm{which} \mathrm{in} \mathrm{turn} \mathrm{sent} \mathrm{an} \mathrm{output} \mathrm{signal} \mathrm{to} \mathrm{the} \mathrm{mod-}$ utrol motor for the necessary proportional opening/closing of the bypass line of the 3-way valve. This output signal $(4-20 \mathrm{~mA})$ is a function of the temperature difference between the set point for the space being controlled and the space temperature being measured by the RTD. The temperature controller was programmed from the front panel and displayed the process temperature being controlled. A magnetic drive centrifugal pump circulated the chilled water from the reservoir to the cooling panel. The 55 gallon glycol solution container was surrounded by a cold air-space and then finally enclosed by a two-inch thick poly-isocyanate board envelope. The air space was kept to a temperature very close to that of the chilled water by an auxiliary cooling unit and hence the 
heat gain by the chilled water from the surroundings was kept to a minimum. A schematic line diagram of this system is depicted in Figure 12.

\section{Air Flow Control System}

The air supply to the sfud-cavity wall specimen was metered and controlled by a mass flow controller (Sierra Instruments Series 840 Side-Trak) which employed a large diameter thermal mass flow sensor and a proportional control valve. Enthalpy transfer across the thermal sensor was the control parameter which attenuates the mass fiow of the fluid flowing through the controller. A built-in electromagnetic servo-control valve modulates the flow, set previously by the user, within $\pm 1 \%$ accuracy. The air coming in to the stud-cavity was brought close to the temperature of the cold space temperature by allowing sufficient (about 20 feet) flow length in the space inside the calibrated hot box $(\mathrm{CHB})$. Temperatures of the air at the inlet and exit to the wall specimen were also measured.

\section{DATA ACQUISITION SYSTEM}

Sensor signals from the points listed in Table 1 were collected and converted to engineering units by an Acurex (model Netpac) distributed data acquisition and control system, which conditioned milli--volt, volt and milli-amp signals generated at various process locations. During each scan of the data, information collected and processed by the datalogger was transferred to an IBM/AT compatible personal computer where it was programmed to be stored on a hard disk on the proper directory and in a pre-configured file. The scanning rate was adjustable and user-specified and could be varied from as small as 


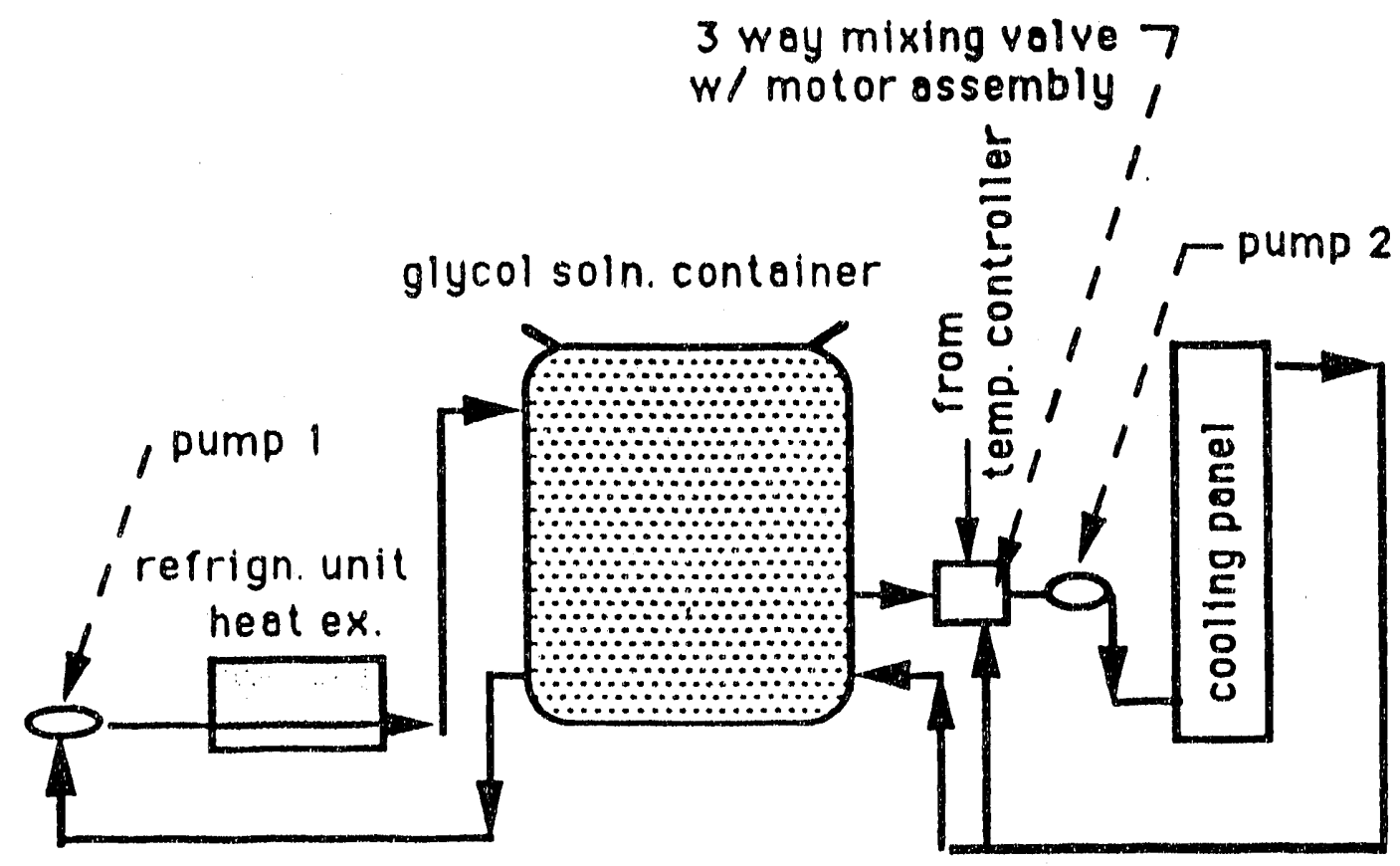

Fig. 12. Schematic Line Diagram of the Chilled Water System 
TABLE 1. Description of Data Acquisition Sensor Channels

\begin{tabular}{|c|c|c|}
\hline Channel & Sensor Type & Location \\
\hline $01-15$ & Thermocouple & Stud-cavity Series 1 \\
\hline $16-30$ & Thermocouple & Stud-cavity Series 2 \\
\hline $31-45$ & Thermocouple & Stud-cavity Series 3 \\
\hline $46-60$ & Thermocouple & Stud-cavity Series 4 \\
\hline $61-75$ & Thermocouple & Stud-cavity Series 5 \\
\hline $76-83$ & Thermocouple Grid & Cold-space Temperature \\
\hline $84-91$ & Thermocouple Grid & Hot-space Temperature \\
\hline 92 & Pressure Transducer & Probe in HotCold Space \\
\hline 93 & Thermocouple & Air Exit from CHB \\
\hline 94 & Thermocouple & Air Inlet to CHB \\
\hline 95 & Thermocouple & Glycol Solution in Drum \\
\hline 96 & Thermocouple & Ambient Temperature \\
\hline 97 & DC Volts & Hot Side Fan Power \\
\hline 98 & DC Amps & Hot Side Fan Power \\
\hline 99 & DC-Watts & Hot Side Fan Power \\
\hline
\end{tabular}


a continuous scan (each scan spanning 7.5 seconds) to several hours between scans. For this study and for all the steady-state experiments the scanning period for the 100 channel datalogger was 30 minutes. A data acquisition program (Netcom) was employed to acquire and store the data and also to form the interface between the datalogger and the computer. Real time on-screen display with tabular and graphical trends of selected variables facilitated better control and visual monitoring of the process during tests. After the completion of a test (normal duration of about 12-20 hours) all the data stored in the hard disk were analyzed and reduced; subsequent graphical and statistical analyses were carried out as described in Chapter VII. 


\section{CHAPTER IV}

\section{THEORETICAL MODEL DEVELOPMENT}

Existing literature, as reported in Chapter II, shows that only a few researchers have modeled the actual energy consumption due to air infiltration. One of them, Kohonen [26], adopted a modeling appruach which focused on the modification of the conductive heat transfer term and hence is quite different from the approach used in this dissertation. Anderlind [21] used a modeling scheme which modifies the infiltration loss term and attempted to correct for the problem. But the model uses parameters which are hard, if not impossible, to measure in practical situations. Thus a simplified model which helps predict the energy impact of air infiltration using measurable parameters would provide a useful extension to the previous work.

This Chapter briefly provides a theoretical background of the phenomenon where a generalization of the existing theory is presented; details of the analytical modeling and the prediction procedure of the Infiltration Heat Exchange Effectiveness is also reported here.

\section{THEORETICAL BACKGROUND}

To generalize Anderlind's [21] approach, a permeable insulating material section (Figure 13) is considered having a cold boundary temperature $T_{1}$ at $x=0$ and a hot boundary temperature $T_{2}$ at $x=d$. This permeable slab or wall sustains a steady infiltrative (cold) flow from the cold boundary to the hot boundary at a mass flow rate of $\dot{m}$ per unit surface area. The conductive part 
of the energy flow is:

$$
Q_{h}=-\lambda \frac{d T}{d x}
$$

The energy flow due to mass transport (air flow) is:

$$
Q_{c}=\dot{m} C_{p}\left(T-T_{r}\right)
$$

where:

$$
\begin{aligned}
& C_{p}=\text { specific heat of air } \\
& \lambda=\text { thermal conductivity of the insulation material } \\
& T=\text { temperature of the wall section at } x \\
& T_{r}=\text { arbitrary reference temperature for the fluid }
\end{aligned}
$$

Performing energy balance, energy stored = convected energy + conducted energy. Hence, $Q_{t}=Q_{c}-Q_{h}$

Since $Q_{t}$ is constant as a function of $x$ and $\frac{d T_{r}}{d x}=0$, differentiating with respect to $x$ results in:

$$
\dot{m} C_{p} \frac{d T}{d x}-\lambda \frac{d^{2} T}{d x^{2}}=0
$$

or.

$$
\frac{d^{2} T}{d x^{2}}-\frac{\dot{m} C_{p}}{\lambda} \frac{d T}{d x}=0
$$

Let us define a non-dimensional parameter, $a$, which is comprised of the same variables as the Peclet Number except that the conductivity used here is 


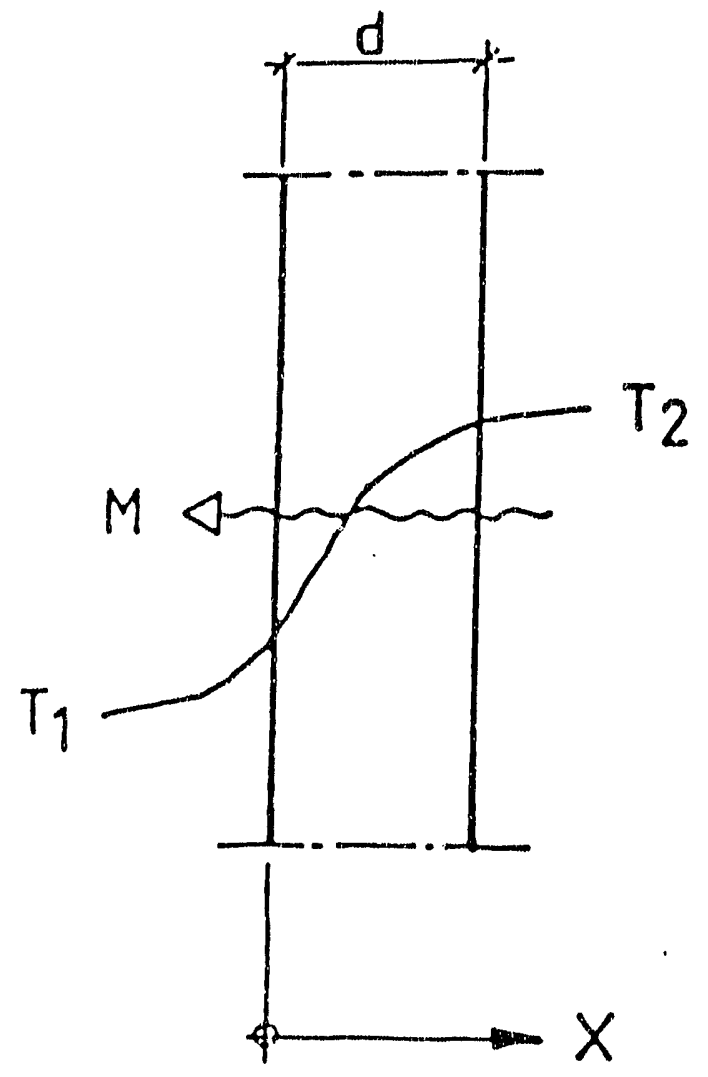

Fig. 13. Heat and Mass Transfer Across a Wall 
that of the solid which is the insulation material:

$$
a=\frac{\dot{m} C_{p}}{(\lambda / d)}
$$

Hence,

$$
\frac{d^{2} T}{d x^{2}}-\frac{a}{d} \frac{d T}{d x}=0
$$

The solution of this differential equation is given by:

$$
T=A e^{u x / d}+B
$$

Ignoring the surface thermal resistance, the simplified boundary conditions are:

$$
\begin{aligned}
& T=T_{1} \text { at } x=0 \\
& T=T_{2} \text { at } x=d
\end{aligned}
$$

This simplification overestimates the energy losses to a relatively small extent [21]. Solving for $A$ and $B$, finally the temperature at any position. $x$, is given by:

$$
T=T_{2}+\frac{T_{2}-T_{1}}{e^{a}-1}\left(e^{a x / d}-e^{a}\right)
$$

The temperature gradient is given by:

$$
\frac{d T}{d x}=\frac{T_{2}-T_{1}}{e^{a}-1}(a / d)\left(e^{a x / d}\right)
$$


or,

$$
Q_{t}=\dot{m} C_{p}\left[T_{2}+\frac{T_{2}-T_{1}}{e^{a}-1}\left(e^{a x / d}-e^{a}\right)\right]-\lambda \frac{T_{2}-T_{1}}{e^{a}-1}\left(\frac{a}{d}\right)\left(e^{a x / d}\right)
$$

hence, at $x=d$, the heat flux is given by:

$$
Q_{t}=\frac{\lambda a\left(T_{1} e^{a}-T_{2}\right)}{d\left(e^{a}-1\right)}
$$

If it is assumed that air is penetrating through a wall (A) of suriace area $(\mathrm{S} / 2)$ and is escaping through another wall (B) of the same surface area as illustrated in Figure 14. If $X_{A}$ is the diffuse fraction of the air infiltrating through wall $A$, then $\left(1-X_{A}\right)$ is the concentrated fraction flowing through. Similarly for wall $B$, it is assumed that $X_{B}$ and $\left(1-X_{B}\right)$ are the diffuse and concentrated fractions of the air exfiltrating through wall B. Let $U_{W}$ be the heat loss coefficient for each of the walls. Thus the total heat loss from the building is :

$$
Q_{t o t}=\frac{S}{2}\left(Q_{t B}-Q_{t A}\right)
$$

where

$$
\begin{aligned}
& Q_{t A}=X_{A} U_{W} a \frac{\left(T_{2}-T_{1} e^{X_{A}^{a}}\right)}{e^{X_{A}^{a}}-1}-\left(1 \div X_{A}\right) a U_{W} T_{1} \\
& Q_{t B}=X_{B} U_{W} a \frac{\left(T_{1}-T_{2} e^{X_{B}^{a}}\right)}{e^{X_{B} a}-1}-\left(1-X_{B}\right) a U_{W} T_{2}
\end{aligned}
$$

The net heat loss due to air leakage is: 


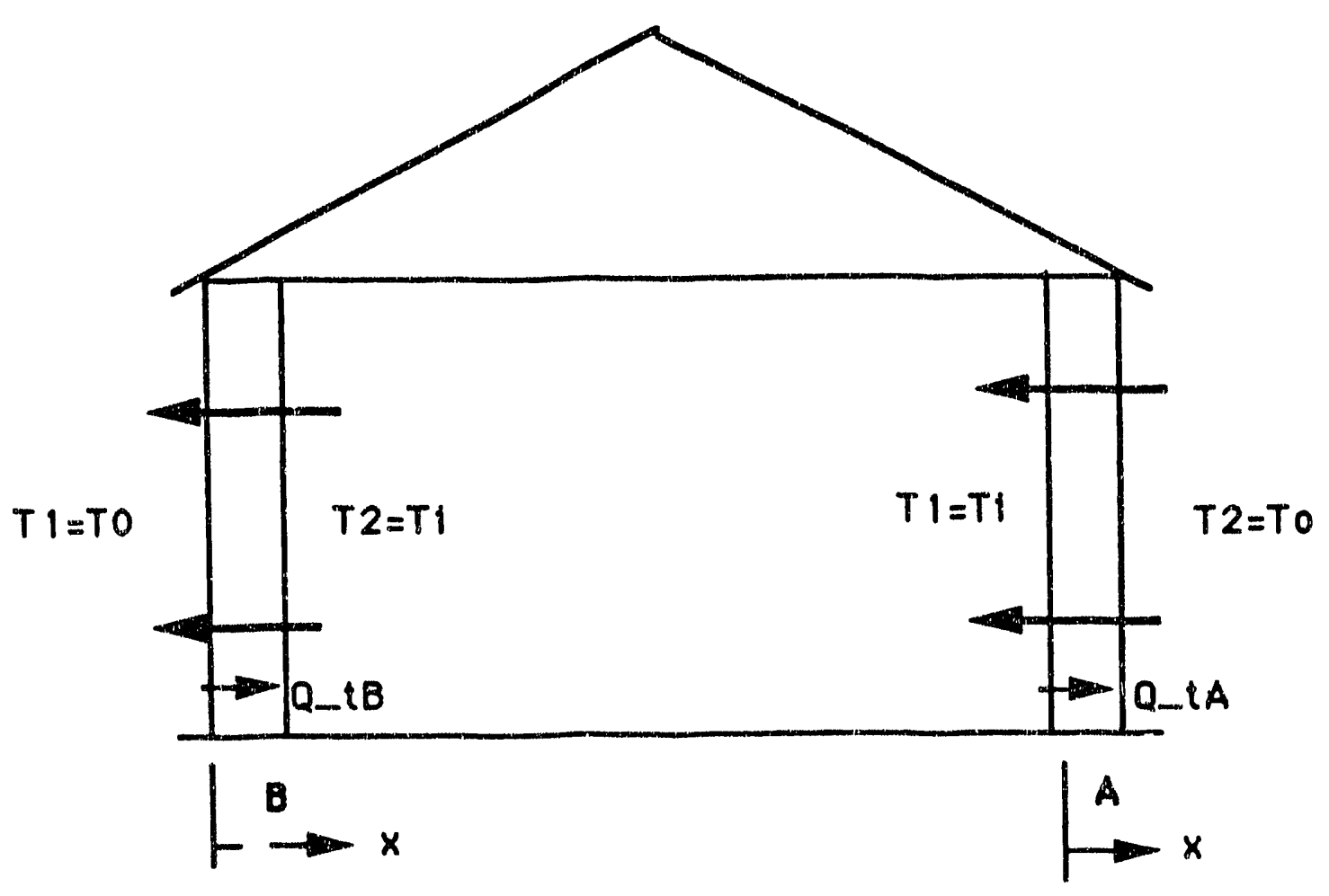

Fig. 14. Schematic of a House with Diffuse Infiltration 


$$
Q_{\text {infil }}=Q_{\text {tot }}-S U_{W}\left(T_{1}-T_{2}\right)
$$

Substituting for $Q_{t A}$ and $Q_{t B}$ and simplifying it can be shown that:

$$
Q_{\text {infil }}=(S / 2)\left(\dot{m} C_{p}\right)\left(T_{1}-T_{2}\right)\left[\frac{X_{A}}{e^{X_{A} a}-1}+\frac{X_{B}}{e^{X_{B} a}-1}+1-\frac{2}{a}\right]
$$

where $(S / 2) \dot{m}$ is the mass flow rate of air through each wall. Comparing this with the IHEE equation:

$$
Q_{\text {infil }}=(1-\epsilon) \dot{m} C_{p} \Delta T
$$

Hence IHEE can be expressed as:

$$
\epsilon=\left\lfloor\frac{2}{a}-\frac{X_{A}}{e^{X_{A}^{a}}-1}-\frac{X_{B}}{e^{X_{B^{a}}-1}}\right\rfloor
$$

\section{APPLICATIONS}

1. For equal infiltrating and exfiltrating fractions $X_{A}=X_{B}=X$ :

$$
\epsilon=\frac{2}{a}-\frac{2 X}{e^{X_{a}}-1}
$$

The limiting cases of this expression are discussed below:

1A. For totally concentrated leakage, i.e. $X=0$, expansion of the denominator of the second term of case 1 in the form of a power series can be used 
to show that $\epsilon \rightarrow 0$ when $X \rightarrow 0$.

1B. For totally diffuse leakage, i.e. $X \rightarrow 1$ :

$$
\epsilon=\left[\frac{2}{a}-\frac{2 X}{e^{X a}-1}\right\rfloor=\left(\frac{2}{a}-\frac{2}{\left(e^{a}-1\right)}\right)
$$

or,

$$
\epsilon=\frac{2\left(e^{a}-1-a\right)}{a\left(e^{a}-1\right)}
$$

which is the same as equation (15) in reference [21].

1C. For extremely small flow rates, i.e. $a \rightarrow 0$ and totally diffuse leakage, i.e. $X \rightarrow 1$ :

$$
\epsilon=\left[\frac{2}{a}-\frac{2}{e^{a}-1}\right]
$$

the ratio becomes $0 / 0$ and thus applying L.'Hospital's rule it can be shown that $\epsilon \rightarrow 1$ for $a \rightarrow 0$ and for $X \rightarrow 1$.

2. For very large flow rates, i.e. $a \rightarrow \infty$, it is obvious from equation (4.10) that $\epsilon \rightarrow 0$; from a physical perspective this is expected, since at large flow rates the heat exchange process barely takes place before the fluid leaves the insulation and it gives rise to extremely small IHEE values.

3. For fully concentrated exfiltration, i.e. in the limit as $X_{B} \rightarrow 0$ and $X_{A}=X$, it can be shown that:

$$
\epsilon=\frac{1}{a}-\frac{X}{e^{X a}-1}
$$

In a real building system, estimation of the diffuse and concentrated fractions 
of the air leakage is extremely difficult and the success of the modeling approach as described above depends primarily on those estimates. To overcome these limitations, an alternative modeling approach is adopted whereby measurable quantities are used as prediction parameters for IHEE; the model developed is described below.

\section{MODEL DEVELOPMENT}

It is assumed that a simple one-dimensional mathematical formulation can be used to simulate the flow phenomenon with measurable quantities as key model parameters. A wall section (Figure 15), simulating the single stud-cavity test specimen, is considered here; if sustains intrusive air flow, at a mass flow rate $i n$ through a crack. The air path traverses a vertical configuration through the mid-thickness of the wall specimen with end effects ignored. The air inlet side temperature is $T_{c}$ (typically the cold temperature) and the exit side temperature is $T_{h}$ (iypically the warm temperature). The width of the specimen (perpendicular to the plane of the paper) is assumed to be $w$. The heat flow by conduction is assumed to be one-dimensional, along the thickness of the specimen. $H$ is the height of the wall specimen and hence is also the maximum path length for the air flow. The air can exit the wall at any vertical height and accordingly the path length $(L)$ can vary from $x=0$ to $x=H$. The heat transfer coefficient of the insulation on either side of the air path (including the surface coefficients) is assumed to be $U$. $U_{0}$ is the conductive heat transfer coefficient (i.e. at zero air flow) of the wall specimen including surface coefficients. $T_{f}$ is the air temperature which varies along $x$.

Different configurations of the air path were tested before choosing the 


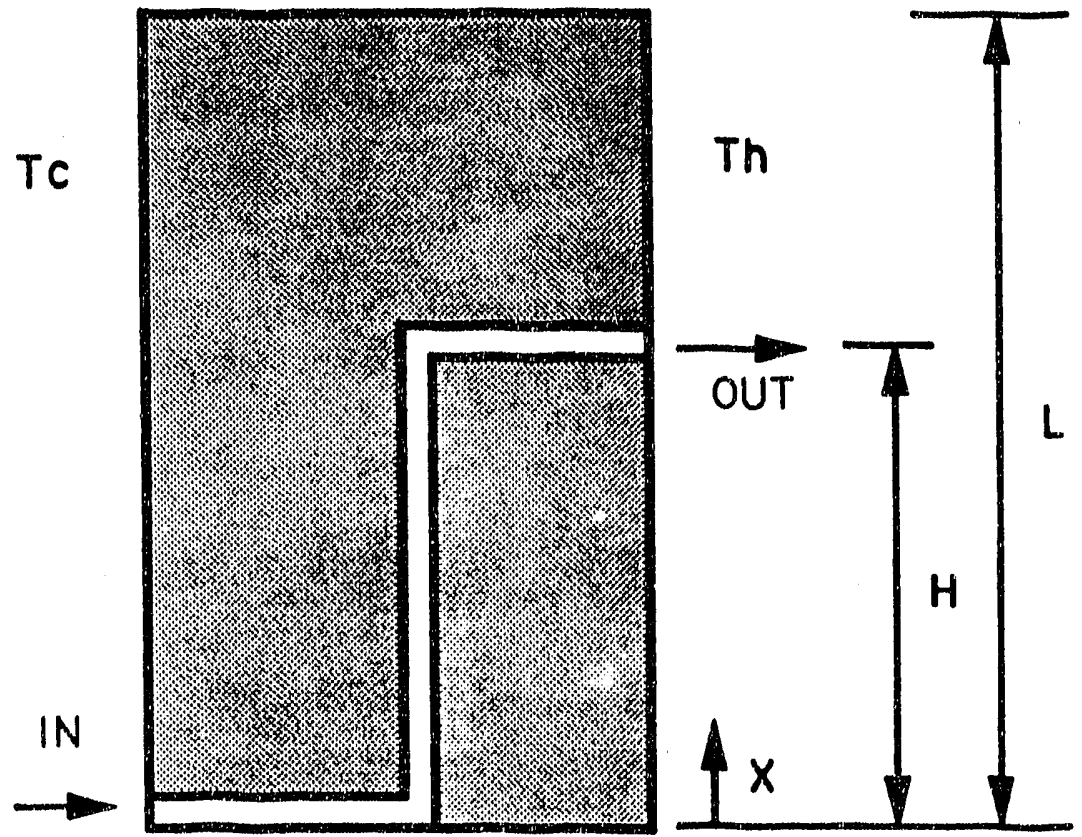

Fig. 15. Wall Section Model with Intrusive Air Flow 
configuration described above for further investigation. Performing an energy balance on a differential air element for a steady state condition:

$$
\begin{gathered}
\text { Energy Lost }=\text { Energy Gained } \\
\dot{m} C_{p} d T_{f}+(w d x) U\left(T_{f}-T_{c}\right)=(w d x) U\left(T_{h}-T_{f}\right)
\end{gathered}
$$

or.

$$
\frac{d T_{f}}{d x}=\frac{w U}{\dot{m} C_{p}}\left(T_{h}+T_{c}-2 T_{f}\right)
$$

Substituting for the constant terms, let $A=\frac{2 w U}{\dot{m} C_{p}}$ and $B=\frac{\left(T_{h}+T_{c}\right) w U}{\dot{m} C_{p}}$; hence equation (4.12) can be written as:

$$
\frac{d T_{f}}{d x}+A T_{f}=B
$$

Equation (4.13) is a non-homogeneous differential equation with constant coefficients. This equation can be solved using an integrating factor given by:

$$
e^{\left(\int A d x\right)}=e^{(A x)}
$$

Equation (4.13) when multiplied by $e^{A x}$ yields:

$$
e^{A x} \frac{d T_{f}}{d x}+e^{A x} A T_{f}=e^{A x} B
$$

or,

$$
\frac{d}{d x}\left(T_{f} e^{A x}\right)=e^{A x} B
$$


Integrating,

$$
T_{f} e^{A x}=\frac{B}{A} e^{A x}+C
$$

where $C$ is the constant of integration. Thus the air temperature is given by:

$$
T_{f}=\frac{B}{A}+C e^{-A x}
$$

Using the boundary condition, at $x=0, T_{f}=T_{c}$, thus $C=\left(T_{c}-\frac{B}{A}\right)$. Hence the solution to equation (4.13) is given by:

$$
T_{f}=\frac{B}{A}+\left(T_{c}-\frac{B}{A}\right) e^{-A x}
$$

Substituting for $A$ and $B$ the temperature of the air at any $x$ is given by:

$$
T_{f}=\frac{T_{h}+T_{c}}{2}-\frac{\left(T_{h}-T_{c}\right)}{2} e^{-(2 w U: s) /\left(m C_{p}\right)}
$$

To calculate Infiltration Heat Exchange Effectiveness, $\epsilon$, an energy balance on the whole building must be performed. Diffuse infiltration through wall $A$ and concentrated exfiltration through wall $B$ is assumed. Heat transfer in the vertical direction is neglected; i.e., no heat transfer takes place through the floor and through the ceiling. Indoor temperature is $T_{h}$ and outdoor temperature is $T_{c}$.

$$
\text { Total heat loss }=Q_{A}+Q_{B}
$$

where subscripts refer to the walls. The wall heat losses will have two components each, conductive and convective. If the actual conductive loss at wall $A$ is designated by $Q_{c, A}$, then the total heat loss $Q_{\text {loss }}$ is given by: 


$$
Q_{\text {loss }}=Q_{c, A}-\dot{m} C_{p}\left(T_{f}(L)-T_{\text {ref }}\right)+U_{0} S\left(T_{h}-T_{c}\right)+\dot{m} C_{p}\left(T_{h}-T_{\text {ref }}\right)
$$

where $S$ is the surface area of the entire wall. Also from the definition of IHEE, the total loss is given by:

$$
Q_{\text {lose }}=U_{0} S\left(T_{h}-T_{c}\right)+U_{0} S\left(T_{h}-T_{c}\right)+(1-\epsilon) \dot{m} C_{p}\left(T_{h}-T_{c}\right)
$$

where the first two terms are the customary conductive loss terms for walls $A$ and $B$, and the third term is the modified infiltration loss term. Hence, equating these two heat loss expressions:

$$
(1-\epsilon) \dot{m} C_{p}\left(T_{h}-T_{c}\right)=Q_{c, A}+\dot{m} C_{p}\left(T_{h}-T_{f}(L)\right)-U_{0} S\left(T_{h}-T_{c}\right)
$$

the IHEE is given by:

$$
\epsilon=\frac{T_{f}(L)-T_{c}}{T_{h}-T_{c}^{\prime}}-\frac{Q_{c, A}}{\dot{m} C_{p}\left(T_{h}-T_{c}\right)}-\frac{\left(U_{0} S\right)}{\left(\dot{m} C_{p}\right)}
$$

Now the actual conductive heat loss from wall $A, Q_{c, A}$ has to be found:

$$
Q_{c, A}=U_{0}(H-L) w\left(T_{h}-T_{c}\right)+\int_{0}^{L} w U\left(T_{h}-T_{f}(x) d x\right.
$$

On simplification,

$Q_{c, A}=U_{0}(H-L) w\left(T_{h}-T_{c}\right)+w U L \frac{\left(T_{h}-T_{c}\right)}{2}+\frac{\dot{m} C_{p}}{4}\left(T_{h}-T_{c}\right)\left[1-e^{-(2 w U x) /\left(\dot{m} C_{p}\right)}\right]$

Hence, from equation (4.18) and (4.20), $\epsilon$ is given by: 


$$
\epsilon=\frac{T_{f}(L)-T_{c}}{T_{h}-T_{c}}+\frac{w L}{\dot{m} C_{p}}\left(U_{0}-\frac{U}{2}\right)-\frac{1}{4}\left[1-e^{-(2 w U x) /\left(\dot{m} C_{p}\right)}\right]
$$

Thus knowing the path length of the air crack, dimensions and thermal resistance values of the wall section, the air flow rate and the temperatures, the Infiltration Heat Exchange Effectiveness, $\epsilon$, can be predicted. The air exit temperature, $T_{f}(L)$, in the above expression is given by equation (4.17). 


\section{CHAPTER V}

\section{EXPERIMENTAL METHODOLOGY}

There are a number of variables which presumably affect the infiltration heat exchange effectiveness with the most significant parameters being: (i) flow rate, (ii) crack length, (iii) crack diameter, and (iv) the pressurization exponent of the cell or specimen (which represents the crack characteristics also).

A procedure for measuring these variables along with IHEE was established to ensure the repeatability and reliability of the test data. The procedure followed for these tests and the tests performed are described below.

\section{EXPERIMENTAL PROCEDURE FOR THE TEST CELL}

The test cell was heated by a measured electrical input winich powered the heater and the fan which was used to reduce stratification in the test cell. Prior to the experiment, the cell pressurization characteristics were determined by pressurizing the unheated cell and measuring the air flow required to maintain pressure levels ranging from $10-60 \mathrm{~Pa}[42,43]$. This data was then used to determine the flow constant, $k$, and the flow exponent, $n$, of the cell according to the equation:

$$
q=k(\Delta P)^{n}
$$

where $q$ is the air flow rate in $\mathrm{m}^{3} / \mathrm{s}$ and $\Delta P$ is the pressure difference in $\mathrm{Pa}$. This equation has been shown by many investigators [44] to describe the relationship between infiltration flow, $q$, and pressure difference, $\Delta P$. On physical grounds, it is expected (and has been observed) that the flow exponent, 
$n$, should be between 0.5 (for orifice flow) and 1.0 (for fully developed, long pipe laminar flow). It has been observed [44] that some tight buildings exhibit values of $n$ closer to 1.0 than to 0.5 .

The test cell was then heated until steady state conditions were obtained for various inlet flow rates. The temperatures $T_{i}$ were values measured at different positions within the test cell as indicated in Figure 5. The temperature $T_{a}$ was the temperature measured in the room near the test cell. The average temperature, $\bar{T}_{i}$, within the test cell was taken as the average of all $T_{i}$ values. The value of the overall $U A$ for the test cell and air flow was calculated as

$$
U A=\frac{Q}{\left(\bar{T}_{i}-T_{a}\right)}
$$

where $Q$ is the heating power which is the sum of the heater input and the fan power, $U$ is the overall heat transfer coefficient of the fest cell and $A$ is the total suriace area of the test cell.

The experimental procedure has been used to test several configurations of the test cell, i.e., different sizes and positions of inlet and outlet holes. The initial experiment was the base case for which infiltration was negligible. In this configuration, the gate valve at exit $E$ was kept closed, and no air was injected into the test cell. For the tests to determine ' $\epsilon$ ', the following configurations (Figure 6) comprising different air entry and exit arrangements were used :

1. Entry : through hole 'B4', exir: through hole ' $A$ '.

2. Entry: through hole ' $\mathrm{BO}$ ', exit : none.

3. Entry: through hole 'B1', exit : none. 
4. Entry : through hole 'B2', exit : none.

5. Entry : through hole 'B3', exit : none.

6. Entry : through hole 'B4', exit : none.

7. Entry : through hole 'B4', exit: through hole 'E'.

8. Entry: through hole ' $B$ ', exit : through holes ' $E$ ' and ' $A$ '.

9. Entry: through hole ' $P$ ', exit : none.

10. Eniry: through hole ' $P$ ', exit: through holes ' $A$ ' and ' $B$ '.

11. Entry: through hole ' $P$ ', exit : through hole ' $E$ '.

12. Entry: through hole ' $P$ ', exit: through holes ' $A$ ', ' $B$ ' and ' $E$ '.

Air flow through holes ' $A$ ' or ' $B$ ' is termed diffuse, and flow through hole ' $E$ ' or ' $P$ ' is considered concentrated. When the exit listed is 'none', there will be a small amount of diffuse leakage through the walls of the test cell. This will also be present in parallel with the other openings used. The explicit diffuse leakage site (hole $A$ or $B$ ) consists of two 0.75 inch diameter holes created in the same wall; the first hole was drilled in the exterior plywood, while the second hole was drilled in the interior plywood near the opposite corner of the wall. Thus when air was forced through the exterior hole, it flows inside the wall and enters the test cell through the interior hole. Hole ' $E$ ' consists of a 2 inch length of 1.5 inch 10 tubing.

The base case UA represents the steady-state conductive heat loss co. efficient of the test cell. Using measured temperatures and heating power in 
equation (5.2), for the base case, $U A=22.44$ Btu/hr-deg $F$. This value is consistent with the calculated value $U A=20.93 \mathrm{Btu} / \mathrm{hr}$-deg F. Corner and edge effects were ignored in the calculated value. Throughout this dissertation it is assumed that in absence of any infiltration, $U A=22.44 \mathrm{Btu} / \mathrm{hr}-\mathrm{deg} \mathrm{F}$ and that $\epsilon=0$. For all other cases, the value of $\epsilon$ is calculated from the measured $U A$ value and the injected flow rate $\dot{m}$ as:

$$
\epsilon=1-\frac{U A-(U A)_{0}}{(U A)_{i n f}}
$$

The difference $\left[\left(U A-(U A)_{0}\right]\right.$ represents the measured infiltration $U A$ value, while the term $(U A)_{\text {inf }}=\left(\dot{m} C_{p}\right)$ is the infiltration loss coefficient as is usually calculated.

\section{EXPERIMENTAL. PROCEDURE FOR THE STUD-CAVITY}

The methodology for testing the single stud-cavity specimen in the modified calibrated hot box is fairly similar to the procedure described above for the test cell. The temperature difference in this case is defined by the cold and hot space temperatures on each side of the stud-cavity. The calibration of the hot box was done in a very elaborate pattern. Initially a 8-piece composite specimen was built out of $1 / 2$ inch thick polystyrene boards and this was used to investigate heat conduction by the thermocouple leads across the stud-cavity. The outcome of this test was instrumental in a major change of thermocouple layout iriside the stud-cavity. At every thickness location in the stud cavity, the thermocouples were laid along the width instead of running them parallel to the thickness. This was followed by the actual calibration procedure where a 
4 inch thick extruded polystyrene insulation of known thermal resistance (R-20) was subjected to a set of steady state tests with various temperature differences across the calibration specimen attained by modulating the power input to the heater panel. Hence, to generate a dataset, measurements were made to record the hot space temperature, the cold space temperature, the ambient temperature and the power input to the heater panel. Since the thermal resistance of the calibration specimen was known, the energy flow through the specimen could be estimated accurately; thus the rest of the energy input to the heater panel would constitute the heat loss from the hot side to the ambient and also from the hot side to the cold side through surfaces other than the specimen. Multiple linear regression conducted on this dataset generated a heat loss mudel which sufficiently describes the energy flow from the hot enclosure to the ambient and to the cold space (flanking loss). This loss quantity does not include the heat flow through the test specimen, i.e. the stud-cavity wall specimen. Additionally, the hot and the cold enclosures in the hot box were continuously monitored for air tightness by carrying out pressurization tests to estimate the infiltration loss from the hot space during these calibration tests. When the stud-cavity wall section was used for actual experiments, these energy loss quantities were used to calculate the $(U A)_{0}$ or the base $(U A)$ value of the stud-cavity with no airflow through it ( $A$ being the surface area).

The energy loss model, regressed from the calibration test data and which adequately describes the heat transfer from the hot-space to outside and to the cold space, is given by:

$$
Q_{\text {loss }}=1.0249\left(T_{h}-T_{c}\right)+2.3075\left(T_{h}-T_{a}\right)
$$


where $Q_{\text {lose }}$ is in Btu/hr and $T_{h}$ and $T_{c}$ are the hot and cold space temperatures in deg $\mathrm{C}$. The base $(U A)$ value of the stud-cavity wall specimen is then given by:

$$
(U \cdot A)_{0}=\frac{\left(Q_{\text {in }}-Q_{\text {loso }}\right)}{\left(T_{h}-T_{c}\right)}
$$

where $Q_{\text {in }}$ is the total power input, which is the sum of the heater power and the fan power. The Infiltration Heat Exchange Effectiveness is calculated as given by equation (5.3) for the test cell case. The direct-current power quantities delivered to the electrical heater and the fan were determined by computing the product of voltage and current supplied to each electrical device. The fan current was determined by measuring the voltage across a $3 \Omega \pm 1 \%$ precision shunt resistor (Dale, 3 watts, metal film resistor) and computing the current from Ohm's law. These voltages were measured by the Netpac data acquisition system.

The base case UA represents the steady-state conductive heat loss coefficient of the stud-cavity. Using measured temperatures and heating power in equation (5.5), for the base case, $(U A)_{0}=0.87 \mathrm{Btu} / \mathrm{hr}$-deg $\mathrm{F}$. Whenever the test specimen was removed or changes occurred in the experimental set-up these measurements were repeated to check for any modification in the value of $(U A)_{0}$. Only in the case of configuration 5 (described later) was a change observed and a modified $(U A)_{0}$ of $0.79 \mathrm{Btu} / \mathrm{hr}$-deg $\mathrm{F}$ was used in data analysis. The value of $\epsilon$ was calculated from the measured base case $(U A)_{0}$ value and the injected flow rate $\dot{m}$ as:

$$
\epsilon=1-\frac{Q_{\text {in }}-Q_{\text {lose }}-\left(T_{h}-T_{c}\right)(U A)_{0}}{\left(T_{h}-T_{i}\right)(U A)_{\text {inf }}}
$$


The numerator of the fraction represents the measured infiltration $U A$ value, while the term $(U A)_{\text {inf }}=\left(\dot{m} C_{p}\right)$ is the infiltration loss coefficient as usually calculated and $T_{i}$ is the air inlet temperature in deg $\mathrm{C}$.

Prior to the experiment, the test specimen pressurization characteristics were determined by pressurizing the unheated stud-cavity and measuring the air flow required to maintain pressure levels ranging from $10-60 \mathrm{~Pa}$. This data was then used to determine the flow constant, $k$, and the flow exponent, $n$, of the cell according to equation 5.1. The stud-cavity was then subjected to hot and cold temperatures on either side simultaneously until steady state conditions were obtained for various air flow rates. The experimental procedure has been used to test several configurations of the wall specimen, i.e., different positions of inlet and outlet holes. For the tests to determine ' $\epsilon$ ', the following configurations (Figure 16) with different air exit arrangements were used :
A. Entry : through hole '1', exit : through hole ' 2 '.
B. Entry : through hole ' 1 ', exit : through hole ' 3 '.
C. Entry : through hole ' 1 ', exit : through hole ' 4 '.
D. Entry : through hole ' 1 ', exit : through hole ' 2 ', ' 3 ' and ' 4 '.
E. Entry : through hole ' 1 ', exit : through hole ' 5 '.

As can be seen from the arrangements, all the inlet-exit configurations that have been used were diffuse in nature, except for configuration $E$ which exhibited a more concentrated flow regime. 

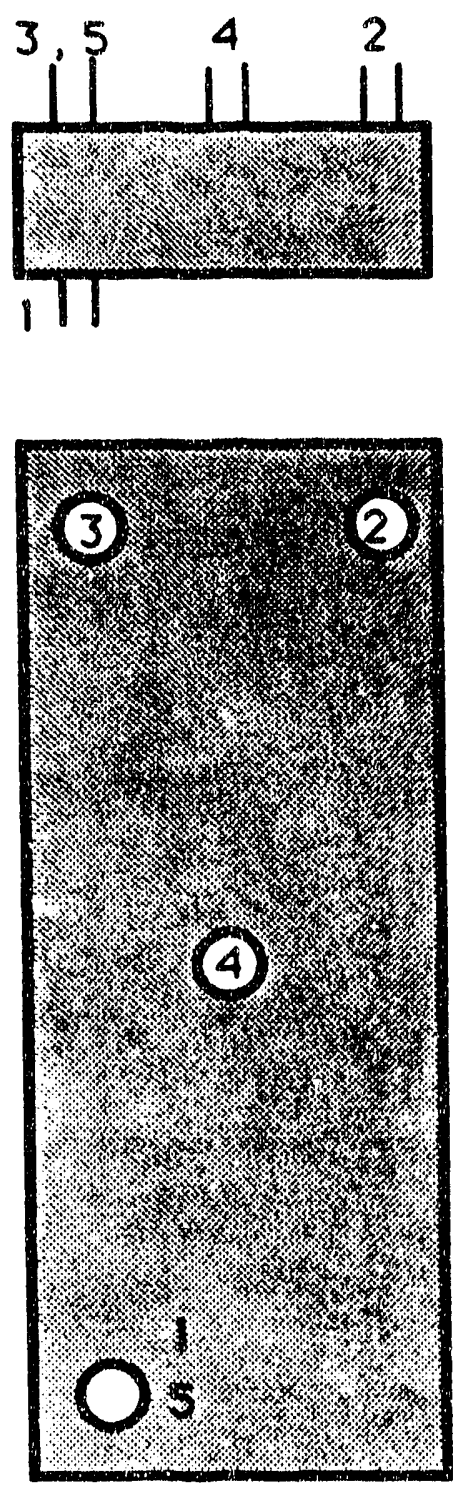

Fig. 16. Various Test Configurations for the Stud-Cavity 


\section{CHAPTER VI}

\section{RESULTS: TEST CELL}

Steady state tests were run on the test cell and the results are presented here in this chapter. Pressurization tests accompanied each experiment for every configuration to provide a quantitative measure of the degree of diffuse leakage for each configuration.

Table 2 shows the results of pressurization measurements for the test cell in various configurations ranging from extremely tight to the leakiest configuration tested. It also shows the leakage coefficient, $k$, and the air changes per hour for the cell if pressurized to $4 \mathrm{~Pa}$. The units of $k$ provide air flow in $\mathrm{m}^{3} / \mathrm{s}$ when pressure difference is measured in $\mathrm{Pa}$. Each pair of $n, k$ values corresponds to the average resulting from two to six pressurization measurements of the configuration shown. The standard deviation of $n$ is typically 0.03 while that of $k$ is 0.02 . The $4 \mathrm{~Pa}$ results shown are frequently used to approximate the rate at which natural infiltration might occur.

It can be observed that when the test cell is sealed and the only leakage occurs through naturally occurring cracks and holes (hole opening $=$ none), $n$ is large, indicating primarily diffuse leakage as expected. The air change rate at $4 \mathrm{~Pa}$ is about $0.25 \mathrm{ACH}$, indicating tight construction. Addition of the diffuse holes (hole opening $=B 0, B 1, B 2, B 3, B 4$ or $A, B$ ) increases the leakage appreciably and also lowers the flow exponent, since the flow through these holes is apparently less diffuse. Addition of the large hole ( $E$ or combinations of $E$ and $A, B$ ) increases the leakage by an order of magnitude and drops the flow exponent to $0.50-0.53$. The air change rate is somewhat larger than that of 
TABLE 2. Pressurization Test Results (Air Entry Through Hole P)

\begin{tabular}{|c|c|c|c|}
\hline $\begin{array}{l}\text { Exit Hole } \\
\text { Opening }\end{array}$ & $\begin{array}{c}n \\
\text { (average) }\end{array}$ & $\begin{array}{c}k \\
\text { (average) }\end{array}$ & $\begin{array}{l}\mathrm{ACPH} \\
\text { (4 PA) }\end{array}$ \\
\hline None & 0.7520 & $8.90 \times 10^{-5}$ & 0.250 \\
\hline BO & 0.6982 & $9.64 \times 10^{-5}$ & 0.252 \\
\hline B1 & 0.7165 & $9.52 \times 10^{-5}$ & 0.255 \\
\hline B2 & 0.7300 & $9.71 \times 10^{-5}$ & 0.265 \\
\hline B3 & 0.7400 & $9.38 \times 10^{-5}$ & 0.260 \\
\hline B4 & 0.7500 & $8.90 \times 10^{--5}$ & 0.250 \\
\hline$A$ and $B 4$ & 0.7144 & $1.23 \times 10^{-4}$ & 0.329 \\
\hline$E$ & 0.5120 & $1.31 \times 10^{-3}$ & 2.640 \\
\hline$B 4$ and $E$ & 0.5030 & $1.42 \times 10^{-3}$ & 2.830 \\
\hline$A, B 4$ and $E$ & 0.5288 & $1.34 \times 10^{-3}$ & 2.780 \\
\hline
\end{tabular}

typical houses, although it should be observed that the surface to volume ratio of the test cell is approximately three times that of a typical house, so direct comparisons can be misleading.

\section{INFILTRATION HEAT EXCHANGE EFFECTIVENESS}

The measurements show that the Infiltration Heat Exchange Effectiveness (IHEE) depends on the flow rate for any configuration. It is useful to define a normalized flow parameter

$$
a=\frac{\dot{m} C_{p}}{(U A)_{0}}
$$


where $(U A)_{0}$ is the total loss coefficient of the cell in the absence of air flow into/out of the cell. Hence $a$ is zero for no air flow and is unity when the air flow rate gives an "infiltration loss coefficient," $\dot{m} C_{p}$, as large as the "conductive" loss coefficient, $(U A)_{0}$.

$\epsilon$ is shown as a function of the normalized flow rate a for different flow configurations in Figures 17-28. For the range of flow rates examined, $\epsilon$ appears to be an essentially linear function of a within measurement error. Consequently, for purposes of this discussion, $\epsilon$ is approximated by

$$
\epsilon=\epsilon(0)+m a
$$

where $m$ is an empirical slope coefficient determiried by linear regression. The values $\epsilon(0), m$ and the range of $a$ used to determine $\epsilon(0)$ and $m$ are summarized in Table 3.

It can be observed that in all cases except one the slope $m$ is negative and $0<\epsilon(0)<1$ as expected; the measured positive slope is very small and may be due to measurement error. Examination of Figures 17-28 also shows that $0<\epsilon<1$ for all values of $a$ for which measuremen.s were conducted. This appears to be the most significant result of these measurements. The values of IHEE are greater than zero for every case measured, indicating that the standard procedure for calculating infiltration loads systematically overestimates infiltration loads. Furthermore, the measurements verify that significant Infiltration Heat Exchange Effectiveness can be measured in frame construction.

The data shown in Table 3 and Figures 17-28 can also be used to construct other hypotheses which should be investigated. These include the following:

1. For cases where the flow into or out of the test cell is highly diffuse, the 
TABLE 3. Linearized Dependence of $\epsilon$ on a for Different Flow Configurations

\begin{tabular}{|c|c|c|c|c|}
\hline Inlet & Outlet & $\epsilon(0)$ & $m$ & $\begin{array}{l}\text { Range of } \\
\text { a Measured }\end{array}$ \\
\hline B4 & $A$ & 0.87 & -1.00 & $0.05-0.25$ \\
\hline BO & None & 0.75 & -0.51 & $0.08-0.20$ \\
\hline B1 & None & 0.75 & -0.59 & $0.08-0.18$ \\
\hline B2 & None & 0.81 & -0.58 & $0.05-0.18$ \\
\hline B3 & None & 0.76 & -0.66 & $0.06-0.20$ \\
\hline B4 & None & 0.82 & -1.54 & $0.05-0.16$ \\
\hline 84 & $E$ & 0.76 & -1.61 & $0.08-0.25$ \\
\hline B4 & $E \& A$ & 0.60 & .0 .56 & $0.06-0.25$ \\
\hline$P$ & None & 0.63 & -2.53 & $0.04-0.17$ \\
\hline$P$ & $A \& B 4$ & 0.59 & -1.10 & $0.05-0.26$ \\
\hline$P$ & $E$ & 0.08 & 0.111 & $0.07-0.28$ \\
\hline$P$ & $A, B 4 \& E$ & 0.21 & -0.09 & $0.05-0.28$ \\
\hline
\end{tabular}




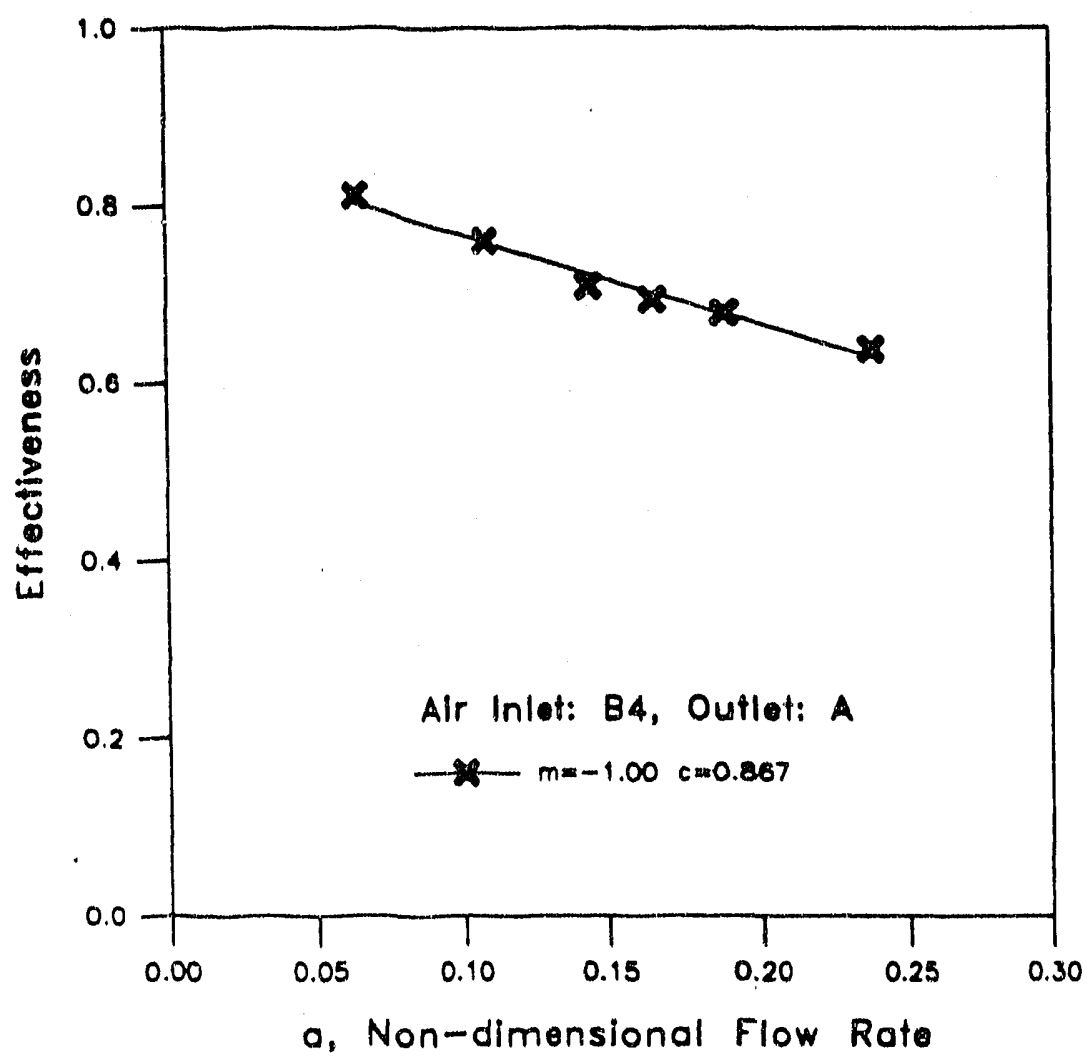

Fig. 17. IHEE vs. a for Diffuse (B4) Inlet and Diffuse (A) Outlet 


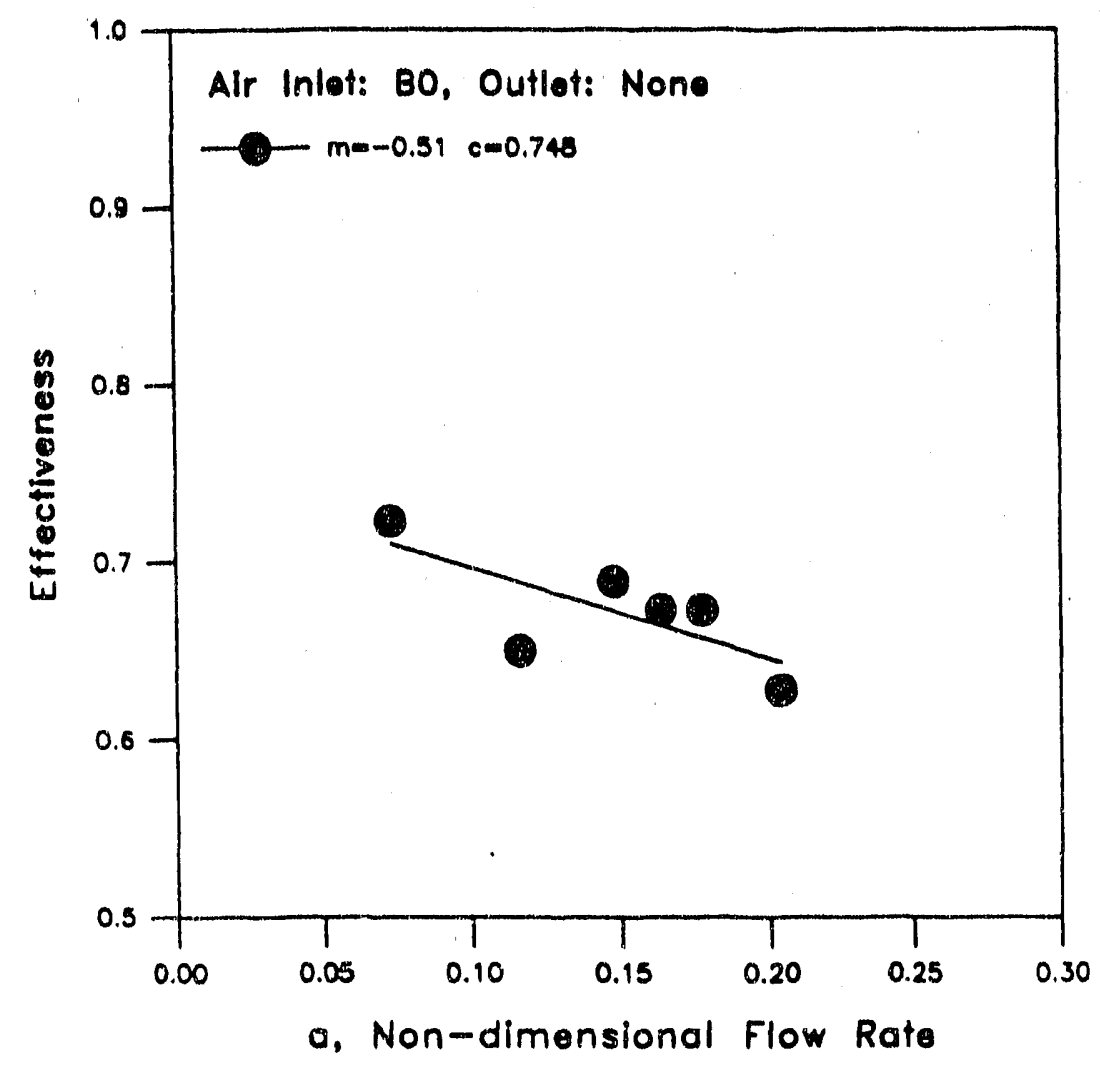

Fig. 18. IHEE vs. a for Diffuse (BO) Inlet and No Outlet 


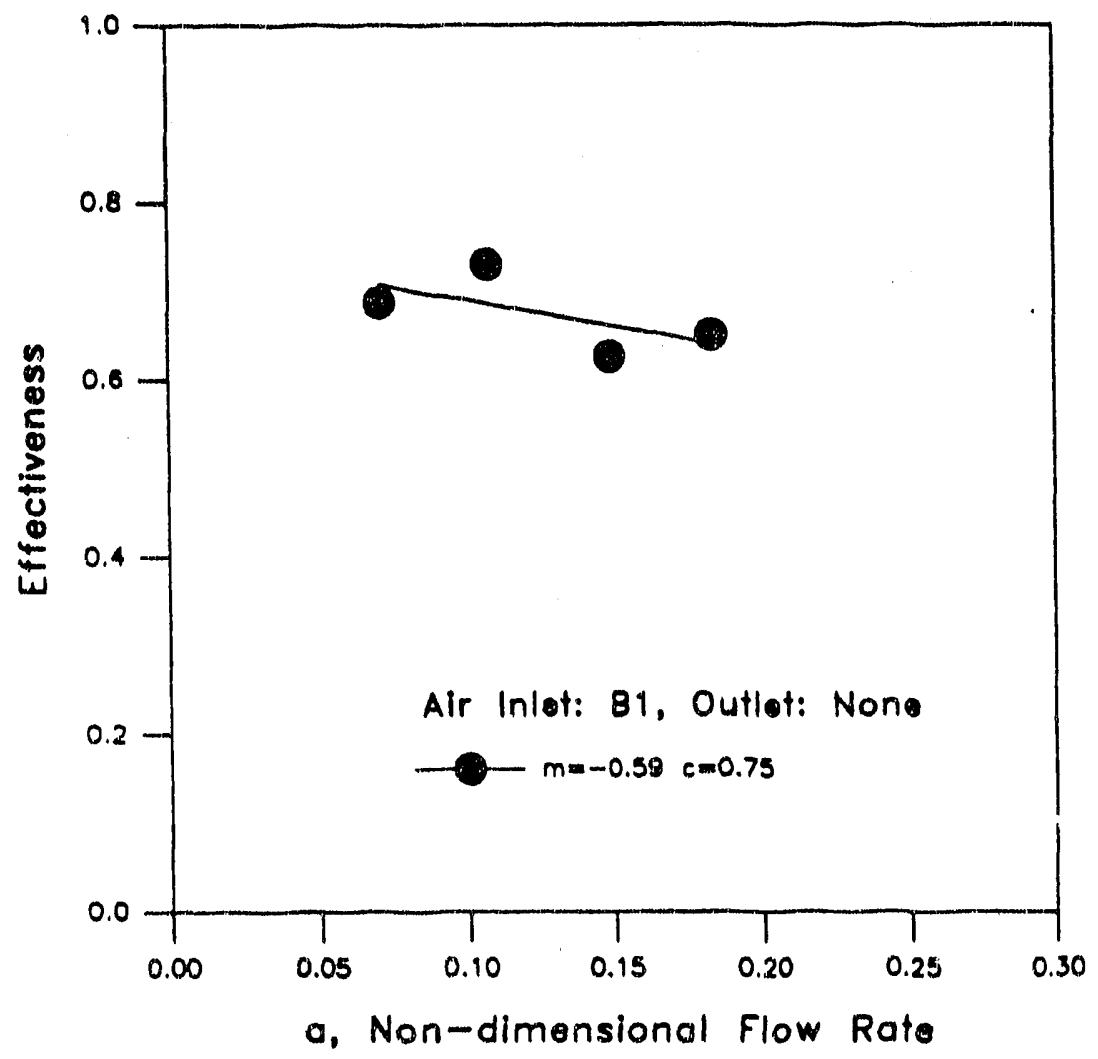

Fig. 19. IHEE vs. a for Diffuse (B1) Inlet and No Outlet 


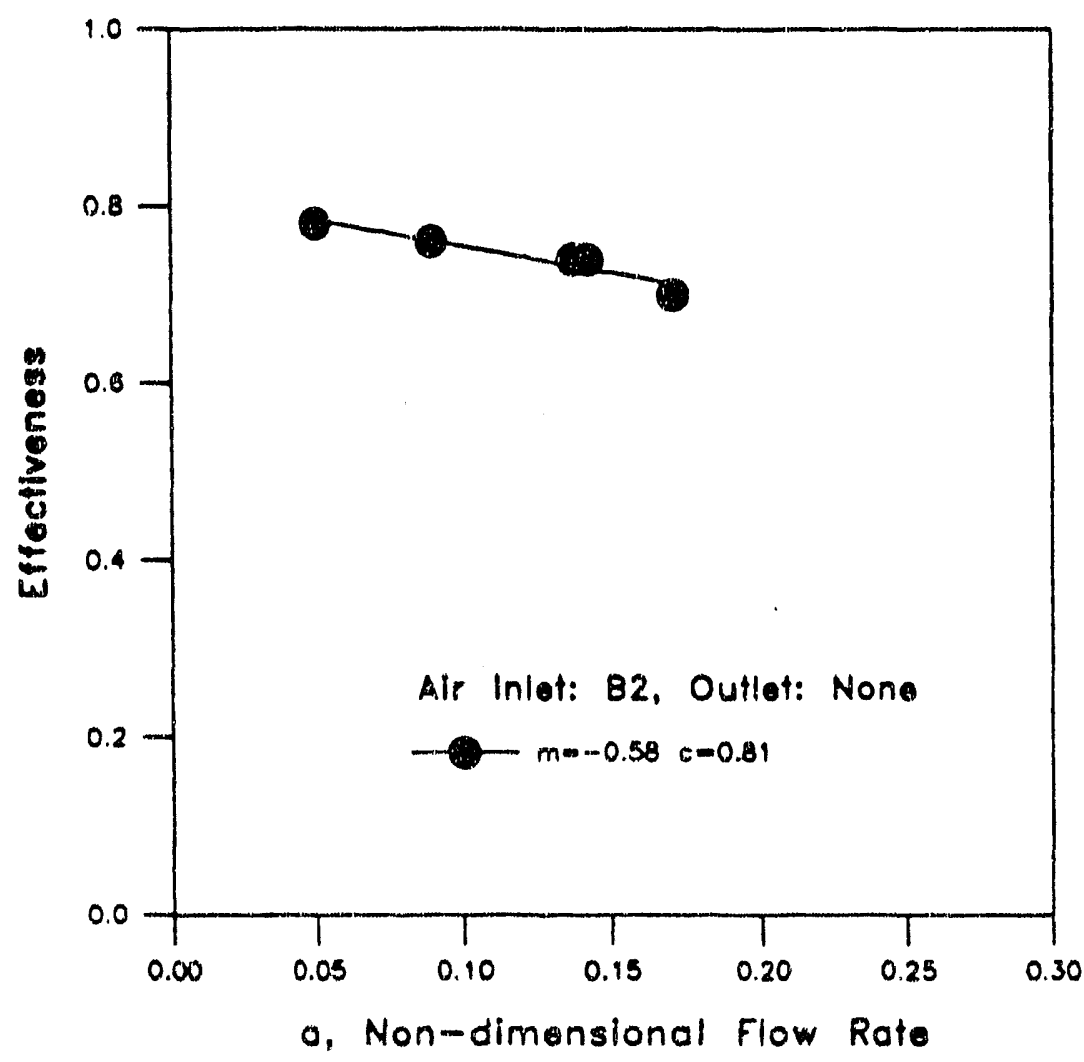

Fig. 20. IHEE vs. a for Diffuse (B2) Inlet and No Outlet 


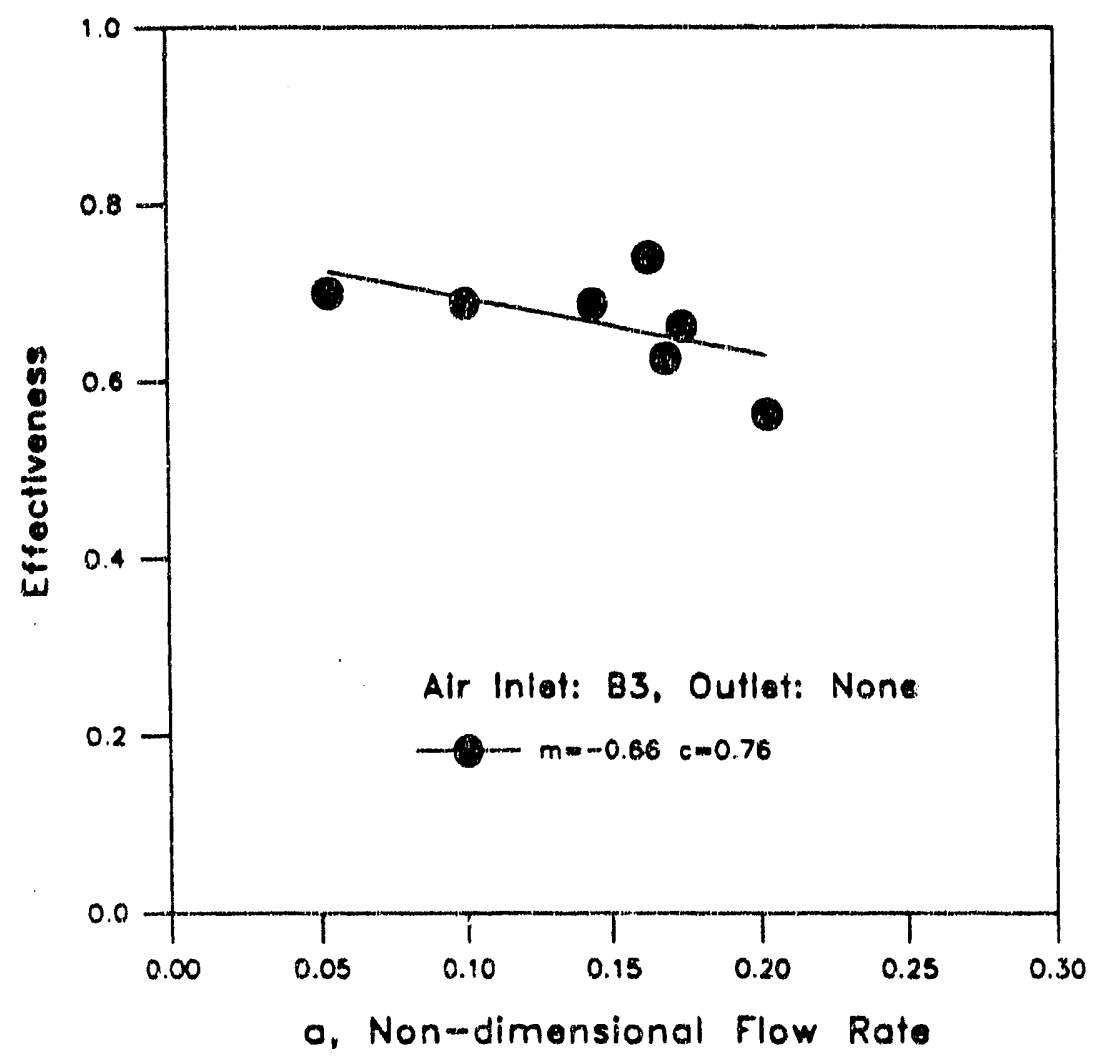

Fig. 21. IHEE vs. a for Diffuse (B3) Inlet and No Outlet 


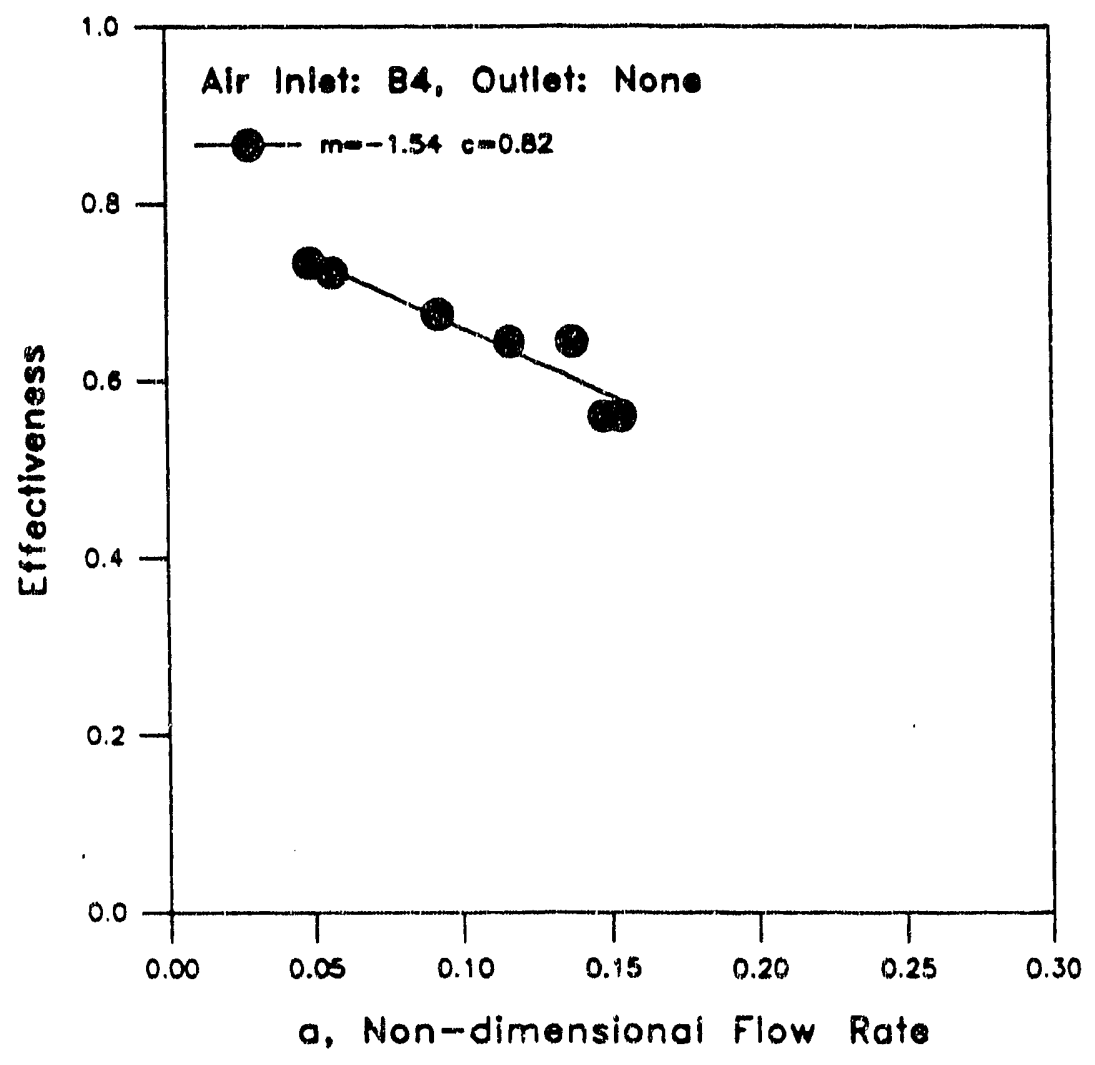

Fig. 22. IHEE vs. a for Diffuse (B4) Inlet and No Outlet 


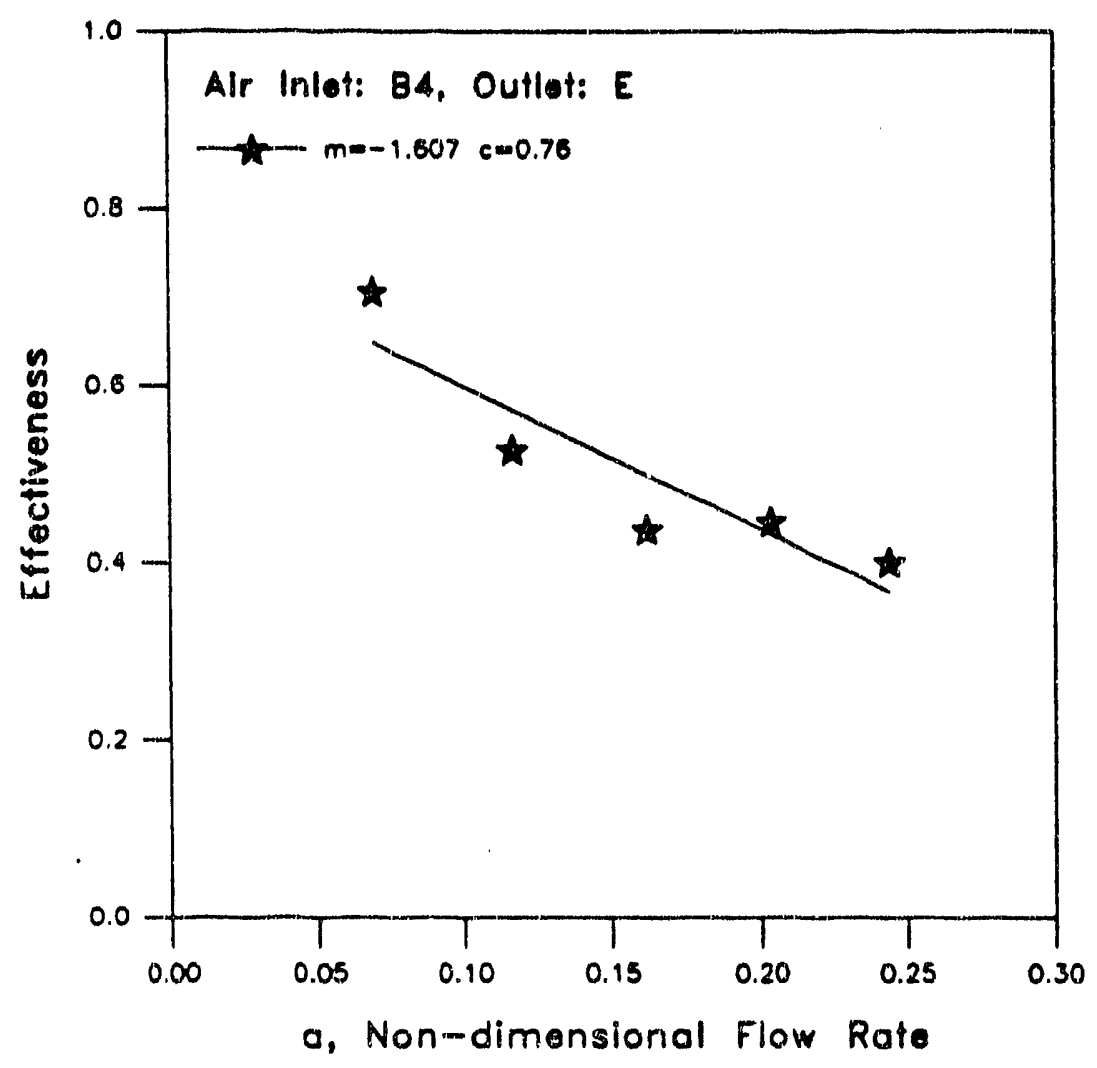

Fig. 23. IHEE vs. a for Diffuse (B4) Inlet and Concentrated (E) Outlet 


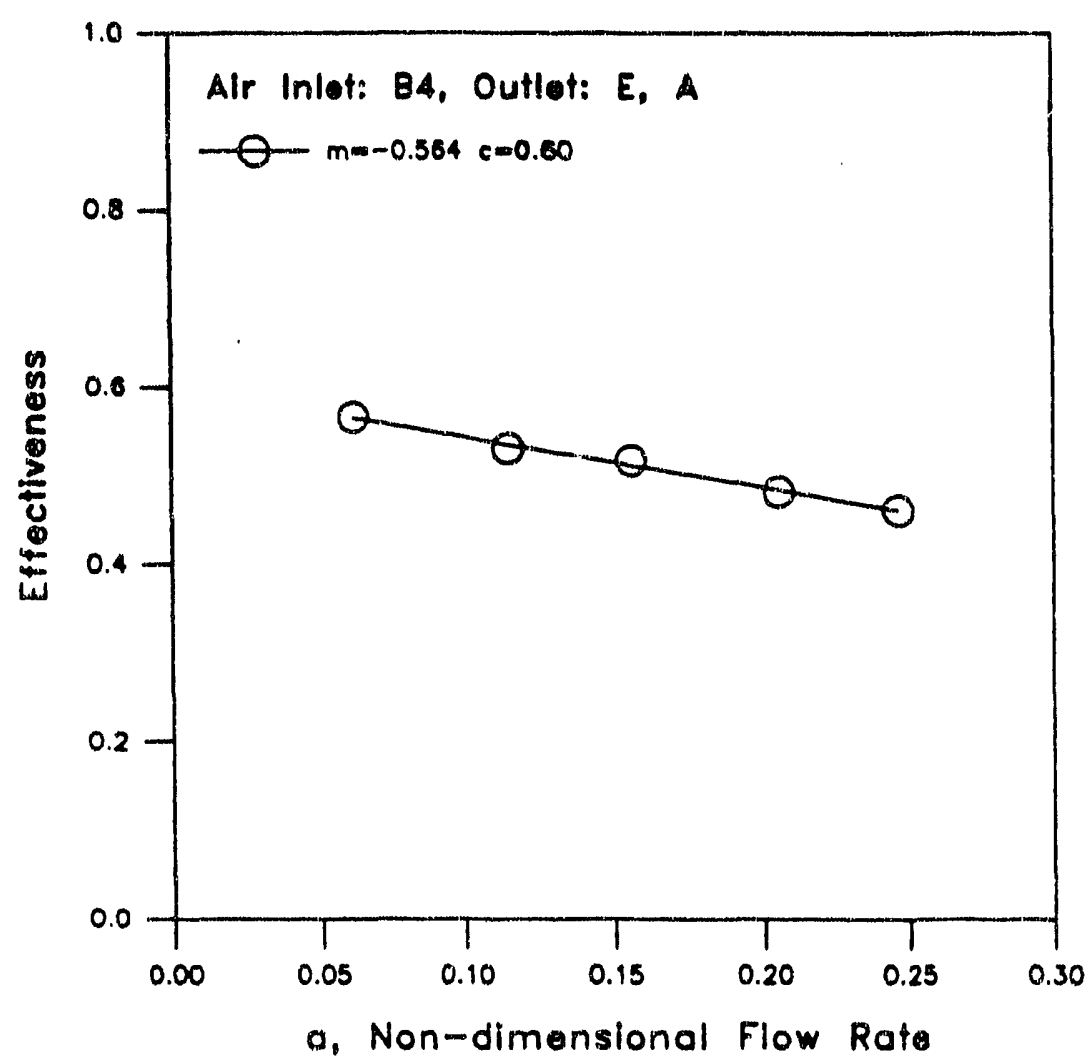

Fig. 24. IHEE vs. a for Diffuse (B4) Inlet and Mixed (E \& A) Outlet 


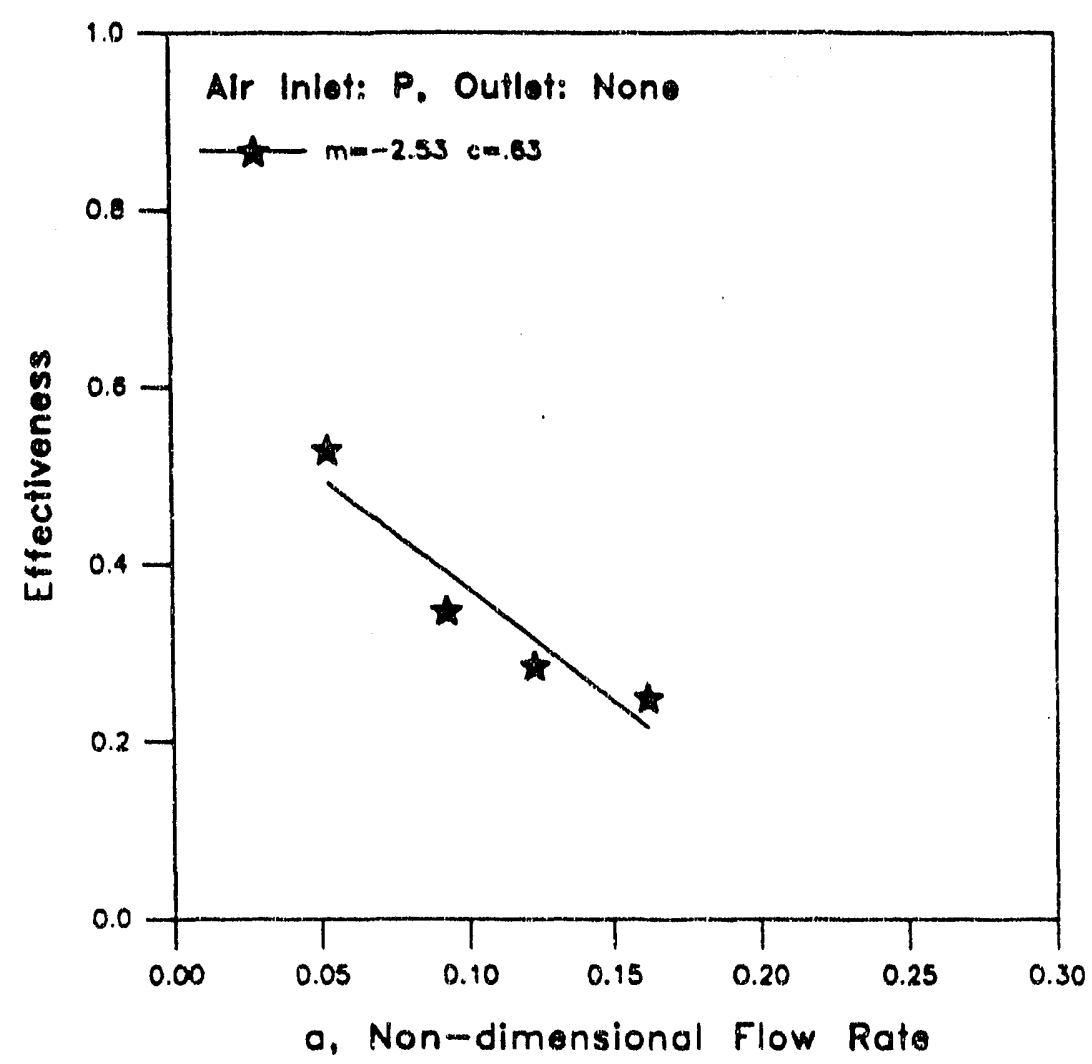

Fig. 25. IHEE vs. $a$ for Concentrated (P) Inlet and No Outlet 


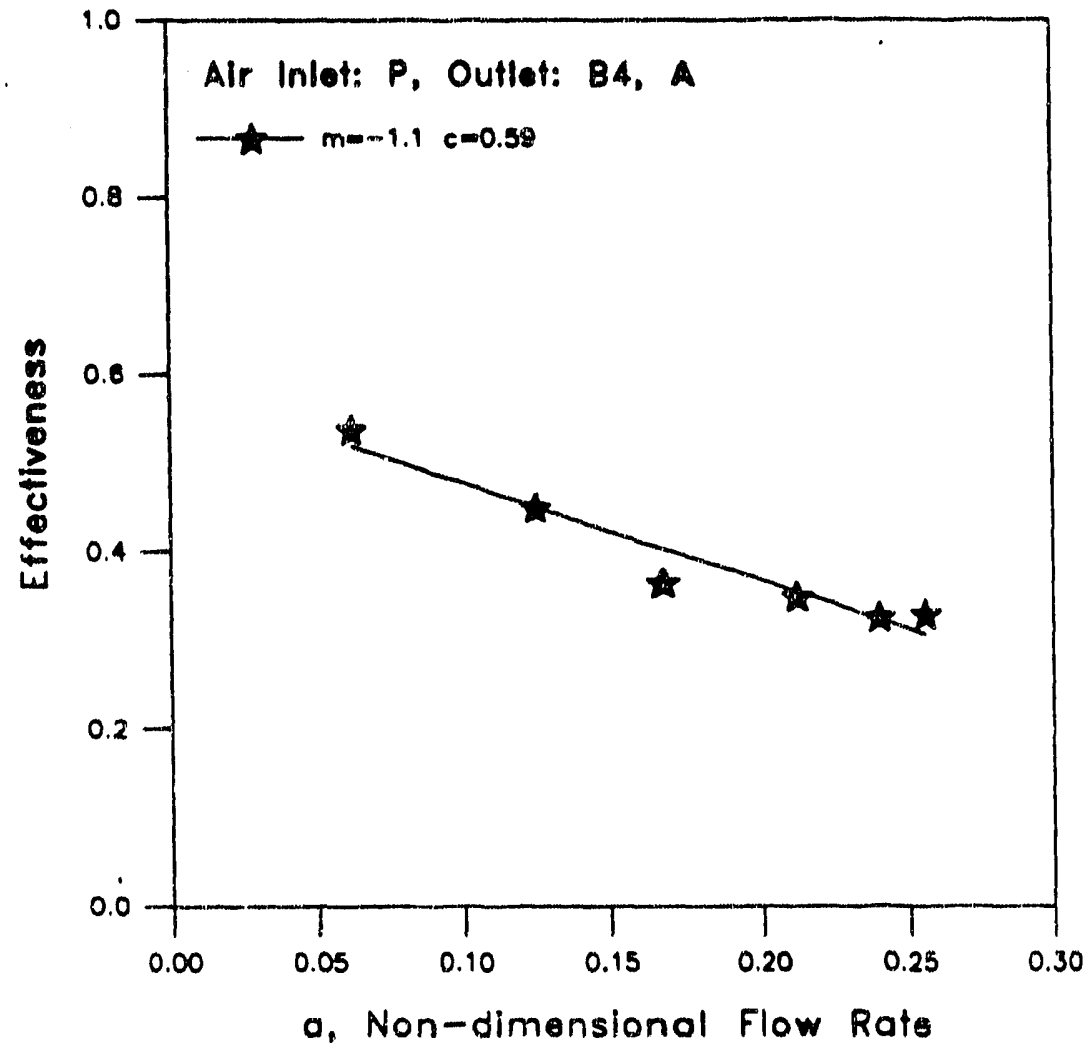

Fig. 26. IHEE vs. a for Concentrated (P) Inlet and Diffuse (A \& B4) Outlet 


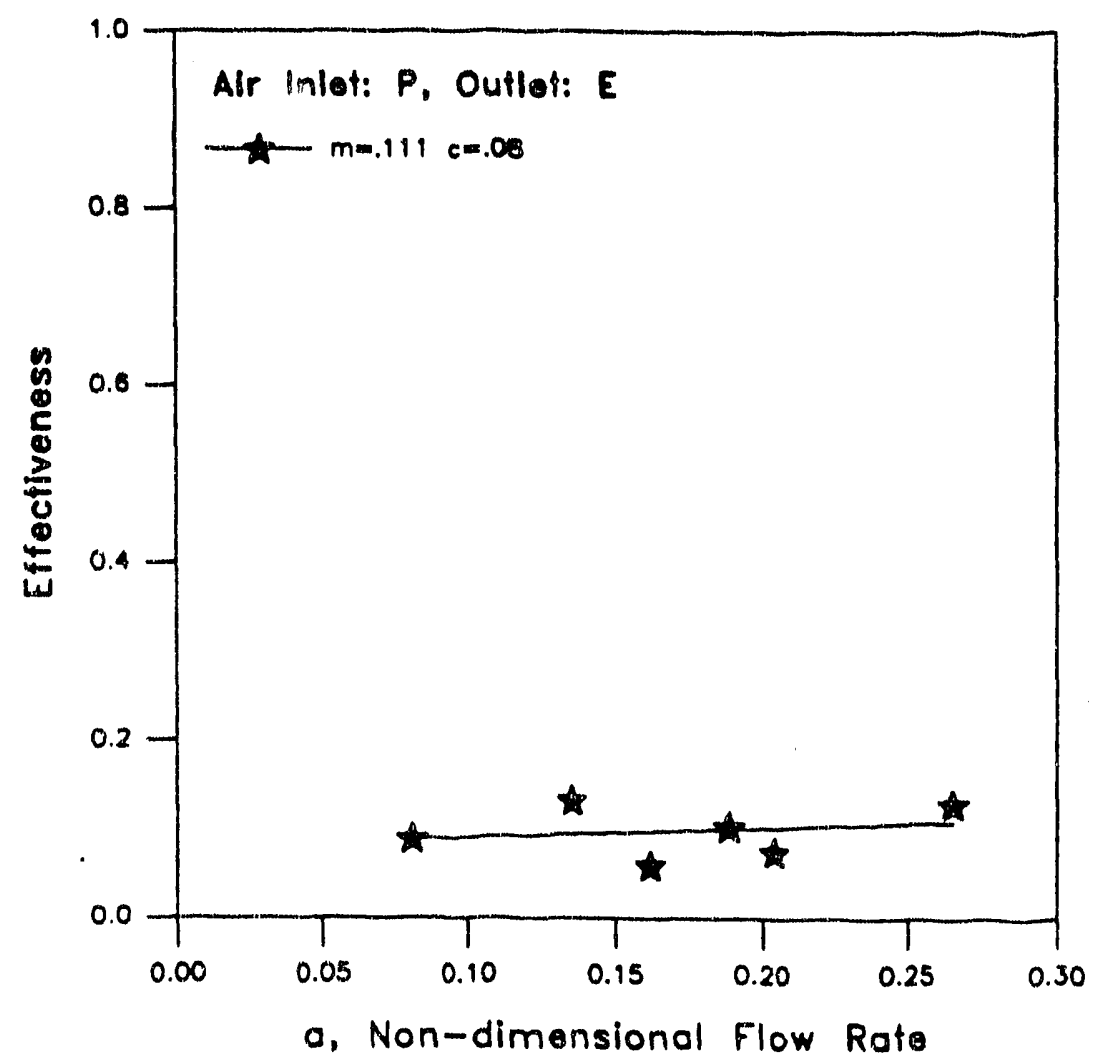

Fig. 27. IHEE vs. a for Concentrated (P) Inlet and Concentrated (E) Outlet 


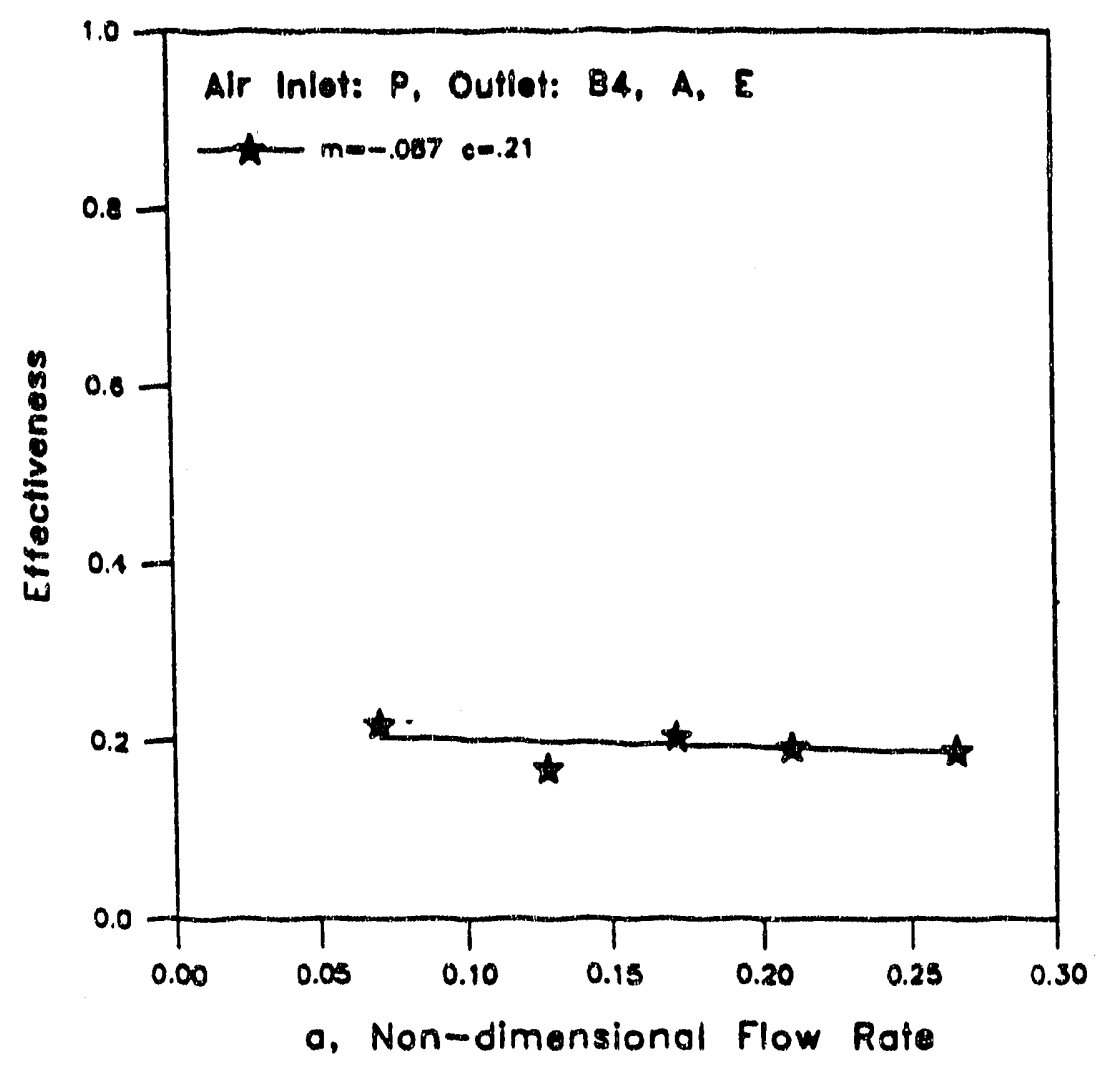

Fig. 28. IHEE vs. a for Concentrated (P) Inlet and Mixed (A, B4 \& E) Outlet 
slope is much larger than for concentrated flow; however, the range of a measured was small for these cases since the cell was tight and larger values of flow would have required pressures above $60 \mathrm{~Pa}$, the upper limit used in the tests.

2. In about half the cases, the slope $m$ is less than the value of $\epsilon(0)$. On physical grounds, it is expected that $m$ will be less than $\epsilon$ for large values of flow and hence expect that the dependence of $\epsilon$ on a would become non-linear at larger flow rates.

\section{Dependency of $\epsilon$ on Flow Exponent}

The values of $\epsilon$ at a particular value of $a$, as obtained from the best fit linear regression, were correlated to the average values of $n$ obtained from the pressurization tests. Each pair of $\epsilon$ and $n$ corresponds to a particular air flow pattern which is characterized by a configuration identification and hole opening.

Figures 29 and 30 present the results of these correlations for the diffuse and concentrated entry configurations, respectively, in the low flow limit $(a=$ 0.05 ). Figures 31 and 32 likewise show the pattern of variation of $\epsilon$ with $n$ at moderate flow rates $(a=0.2)$. The important observation is that $\epsilon$ increases as $n$ increases. Kiel et al. [44] measured $n$ for a sample of 711 houses in Canada and the United States, and the flow exponent, $n$, appeared to have a normal distribution with a mean of 0.67 , confirming the common perception that the average flow exponent is between 0.65 and 0.68 . However, from a regression analysis of the IHEE data in Figures 29 through 32, $\epsilon$ assumes values ranging from 0.21 to 0.72 at $n=0.67$. Hence, comparison of this trend with the pressurization test data reported by Kiel et al. [44] indicates that for 
about half of all houses, a measured infiltration rate in a typical house probably changes the energy load to only 28 - 79 percent of the calculated value of the infiltration energy load.

To obtain greater insight into the correlation between the effectiveness, $\epsilon$, and the flow exponent, $n$, the slope, $m$, of the $\epsilon-a$ correlation is plotted as a function of $n$ in Figures 33 and 34 for diffuse and concentrated air entry configurations, respectively. Each pair $(m, n)$ corresponds to a particular air fiow pattern characterized by a configuration identification and a particular gate valve opening. A fairly strong correlation exists for 'concentrated' entry, but is less obvious for 'diffuse' entry. For hole configurations where air enters the cell through hole B2 or B4, the scatter in the data may have occurred due to the change in leakage characteristics of the test cell over the course of time and also may be due to measurement errors. The results suggest that the effectiveness, $\epsilon$, is probably correlated to the flow rate, $\dot{m}$, as expected from physical considerations. It remains to be seen whether these correlations will be observed in normal houses.

\section{EFFECT OF INFILTRATION PATH ON IHEE}

It may be observed that the heat exchange effectiveness, $\epsilon$, depends on the physical construction of the building and specially on the path along which air infiltrates into or exfiltrates out of the building. Five different configurations of the test cell (configurations 2 through 6 as mentioned before) were chosen to investigate the effect of leakage path length on $\epsilon$. For each configuration, a series of experiments were conducted to determine the $\epsilon-a$ variation. The values of $\epsilon$ measured range from 0.55 to 0.80 with the parameter a varying 


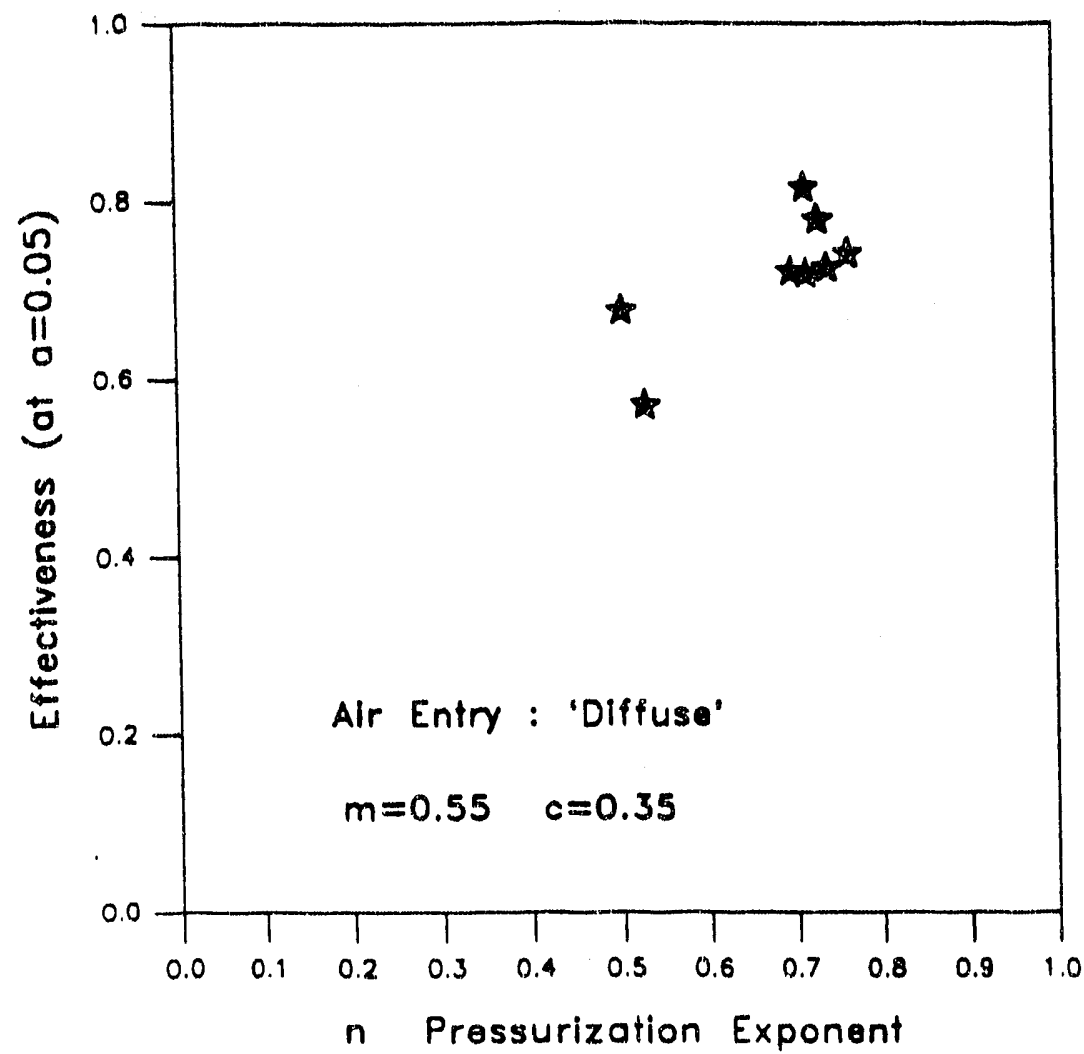

Fig. 29. IHEE vs. $n$ at Small Flow Rate for Diffuse Inlet 


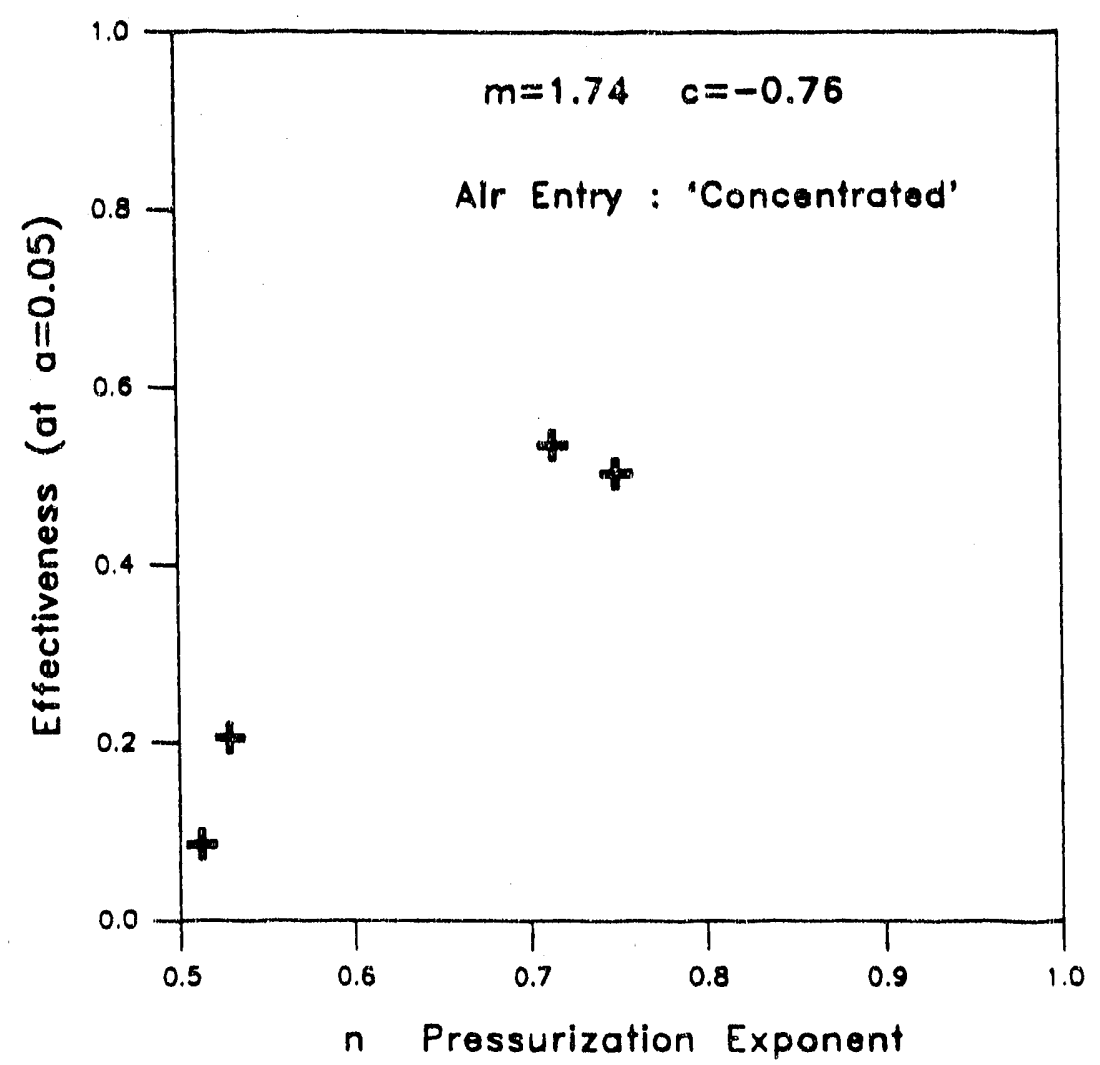

Fig. 30. IHEE vs. $n$ at Small Flow Rate for Concentrated Inlet 


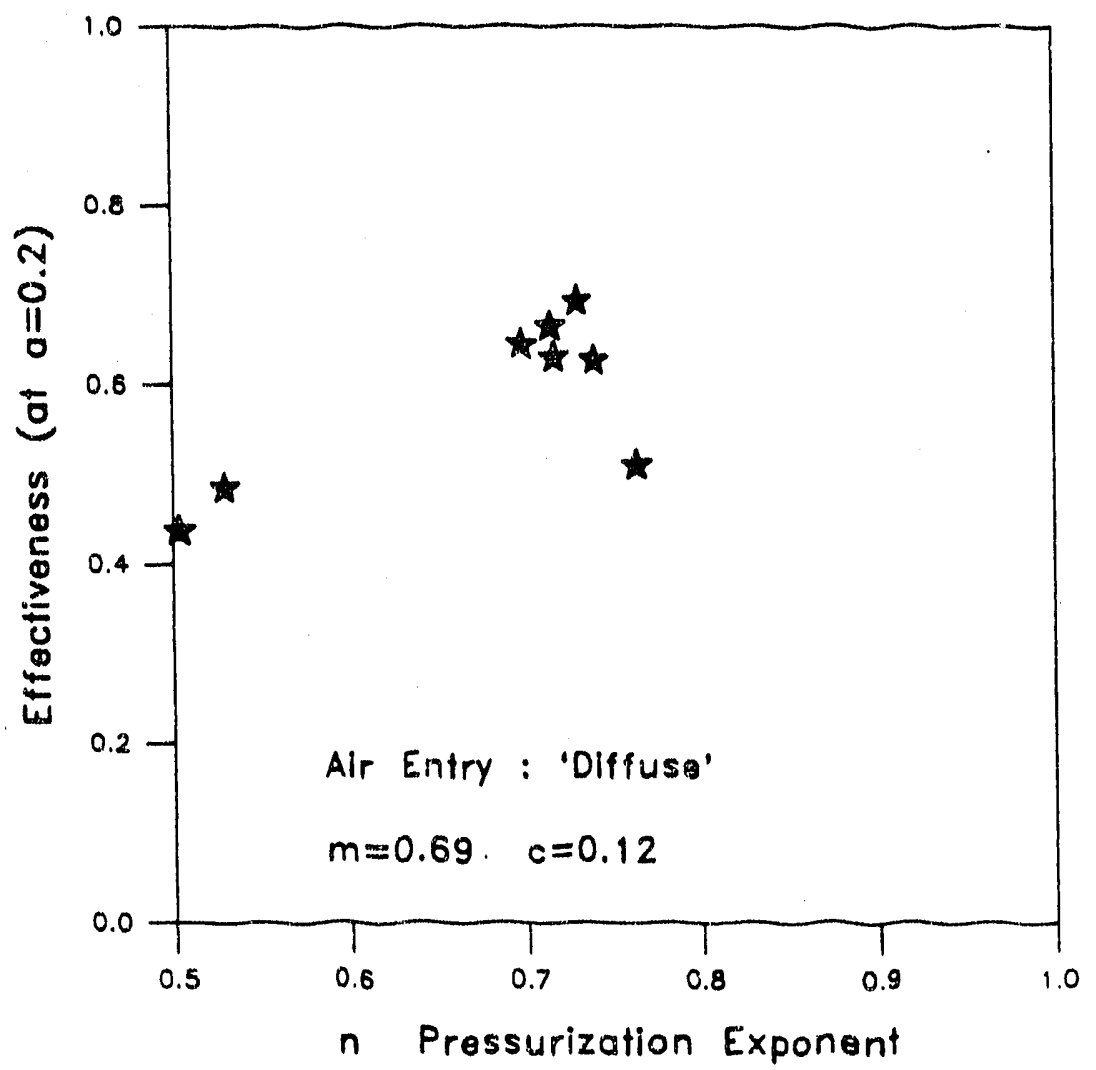

Fig. 31. IHEE vs. $n$ at Moderate Flow Rate for Diffuse Inlet 


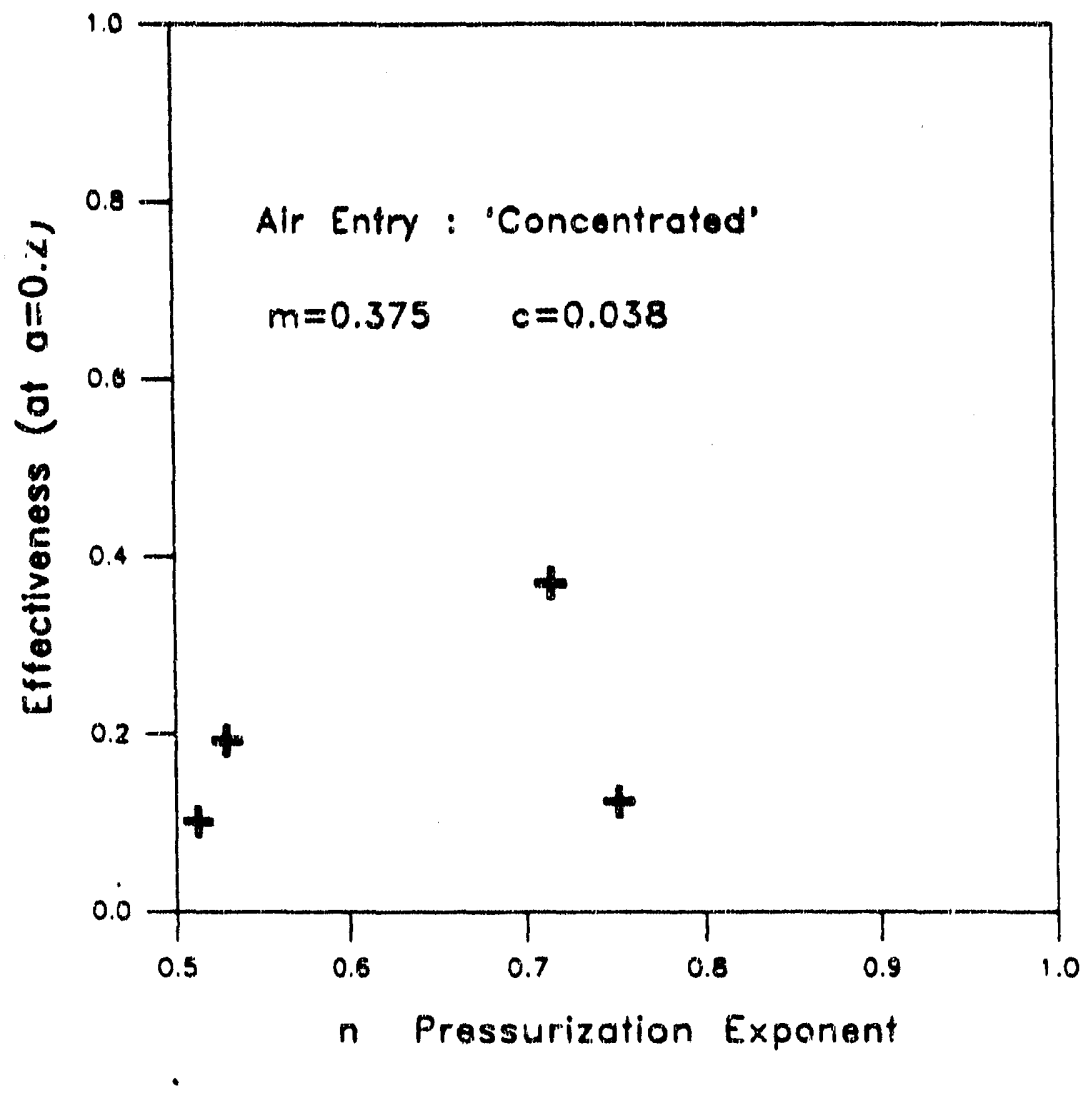

Fig. 32. HHEE vs. $n$ at Moderate Flow Rate for Concentrated Inlet 


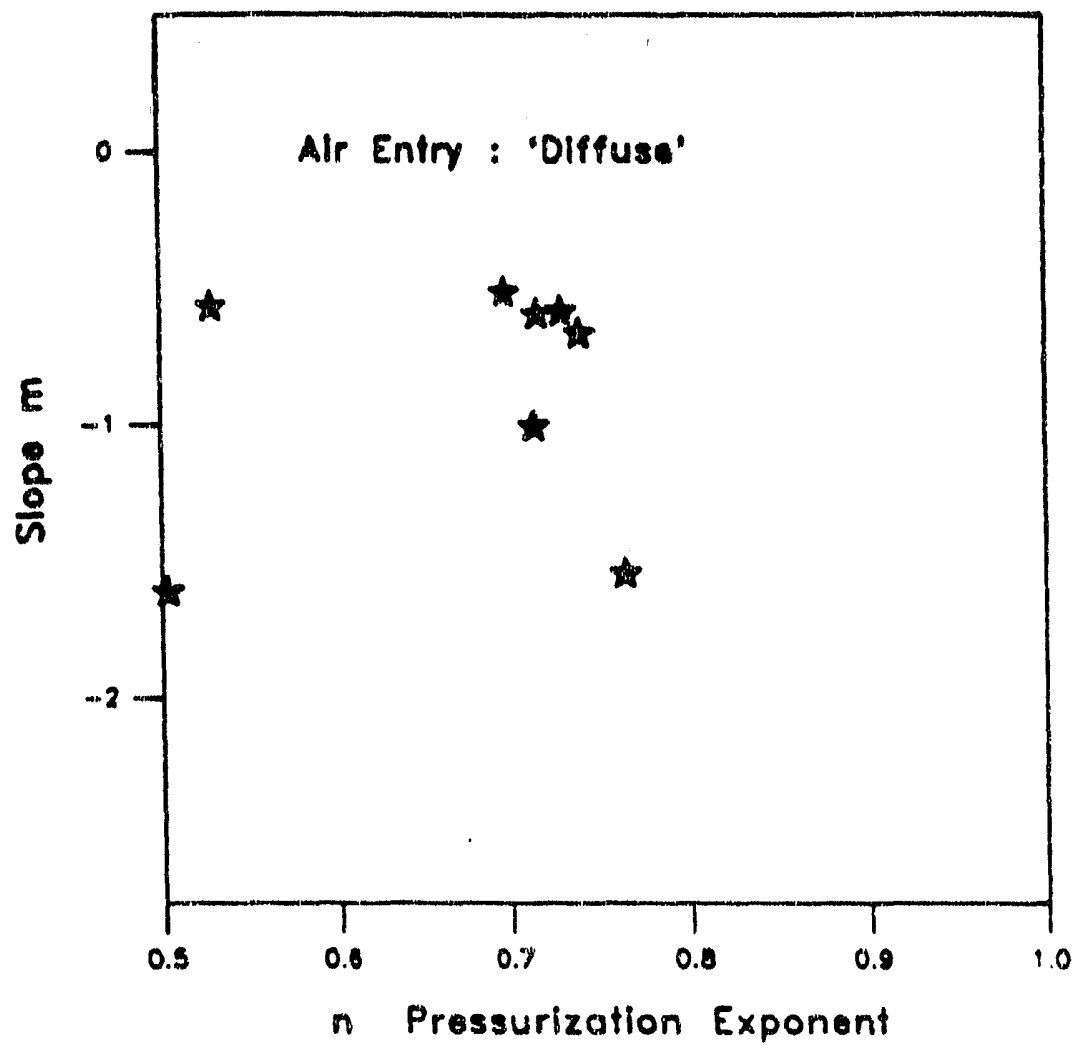

Fig. 33. $m$ vs. $n$ for Diffuse inlet 


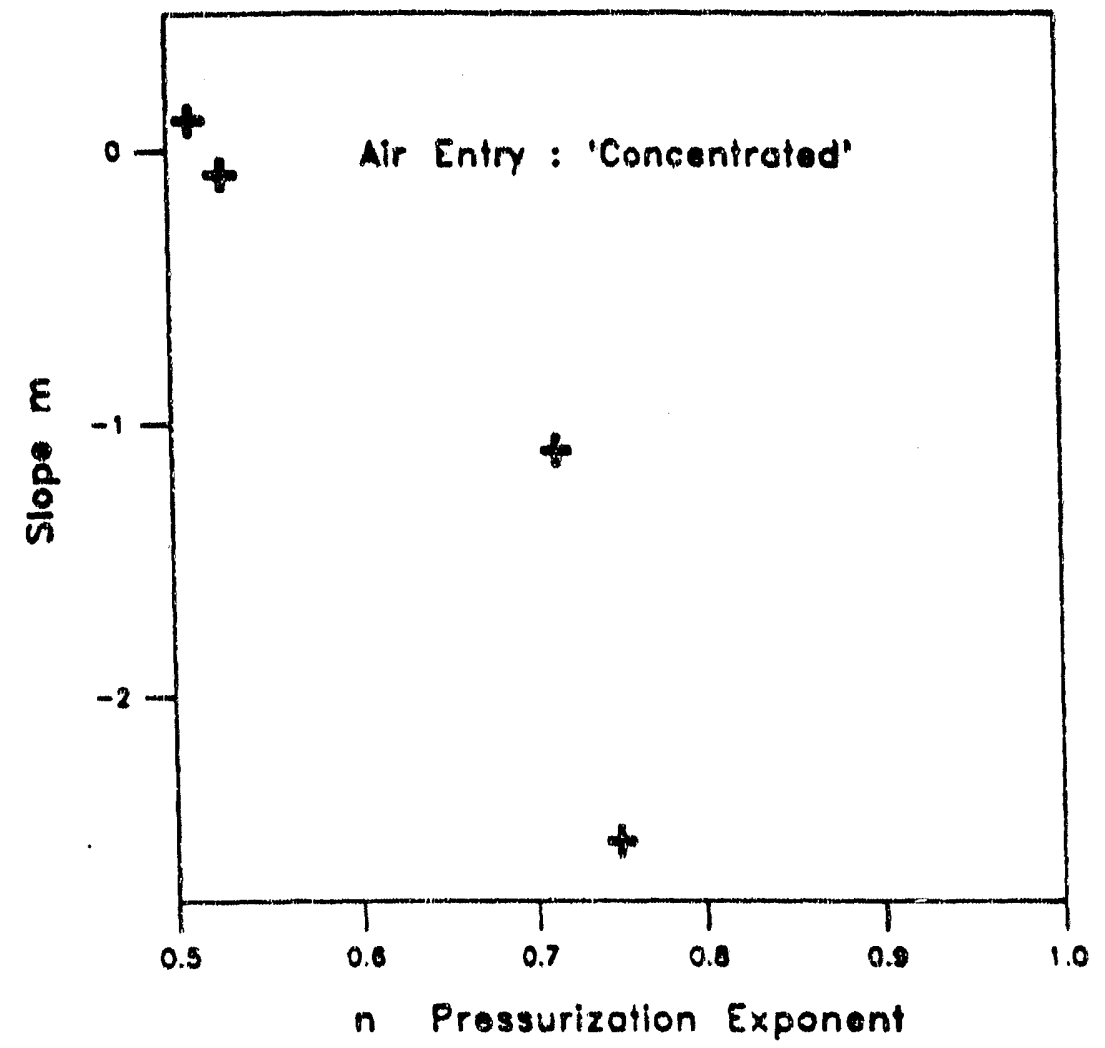

Fig. 34. $m$ v8. $n$ for Concentrated Inlet 
from 0.05 to 0.2 . As noted earlier, effectiveness decreases wh increasing a. But most importantly, $c$ increases with the leakage path length. This result is expected since the air flowing through the crack will have more contact with the warm surlaces (l.e. the leakage path) and increased heat transfer will occur for longer path lengths. Figure 35 shows this trend clearly where c is plotted agalnst a non-dimensional path length $L_{i} / L_{4}$ characterizing each configuration and for a constant value of $a=0$. The path length $L_{i}$ is defined the minimum distance between the exterior opening and the interior opening on the wall for a particular leakage path ' $i$ '; the normalizing parameter $L_{4}$ is the leakage path length for configuration B4. However, it is not obvious, at this stage, that this distance represents the actual length that air traveled before entering the test cell. It is simply assumed to be a parameter to quantity the length of the leakage path.

\section{HOLE-SIZE EXPERIMENT ON TEST CELL.}

To evaluate the effect of crack size (1.e. diameter of the hole in the currient context) on the IHEE, a series of steady-state tests were carried out on the test cell. Air was introduced through three wall surlaces and air escaperd out through the hules provided in the other three wall surfaces. All the six flows through the six wall, roof and wall surfaces were diffuse in nature, in the sense that air entered the wall insulation through the plywood, then it traveled along the surface dimensions and finally it left the wall through the other end of the wall. Four different hole sizes were attempted; diameter of the holes being 11/64 inch, 1/4 inch, 3/8 inch and 1/2 inch on all the six surfaces and the leakage path length remained the same in all the four configurations. The Infiltration Heat Exchange Effectiveness for the four hole sizes is presented in Figures 36- 


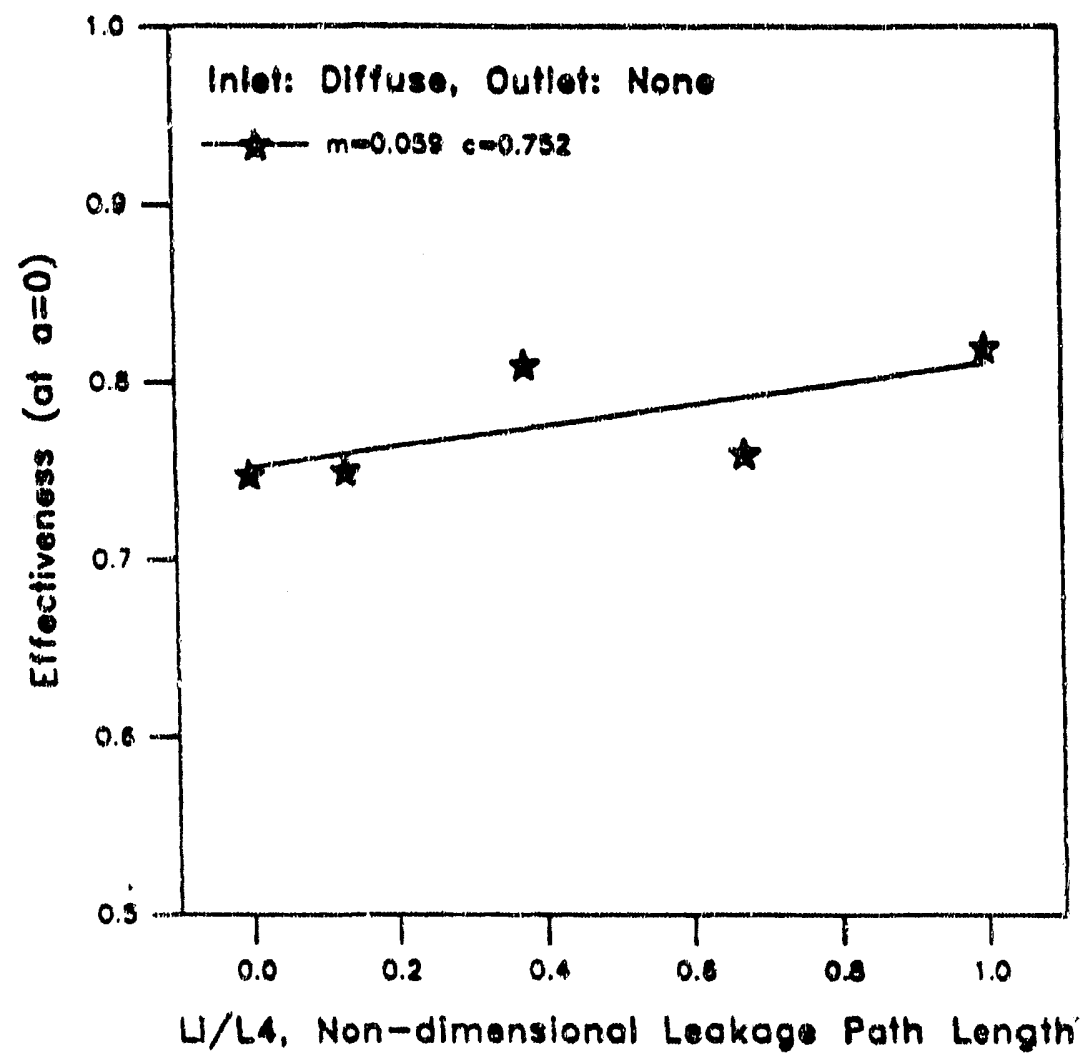

Fig. 35. IHEE vs. Leakage Path Length for Diffuse Configuration 
39. As is evident from the plots, the flow becomes less diffuse as the hole size increases and hence the effectiveness decreases. e at $a=0.25$ is shown against hole diameter in Figure 40 and the trend is clearly illustrated there. Also with the hole diameter increasing, the $\epsilon$ - a plots become flatter indicating the decreasingly difuse nature of the leakage path.

The results presented in this chapter clearty show that air now through trame construction can exhibit significant heat exchange, substantially reducing the energy requirements on the test cell due to infiltration. Infiltration heat exchange effectiveness increases as :
a) flow rate decreases;
b) flow path length increases;
c) hole/crack size decreases.

Infiltration Heat Exchange Effectiveness values as large as 0.8 have been measured, which indicate that for very tight construction, it is possible that conventional estimates of the infiltration load based on air exchange estimates could be in error by as much as a factor of 15. For the range of values of the pres. surization exponent, $n$, typically measured in houses, values of IHEE measured in the test cell were smaller but still suggest that estimates of infiltration load based on air exchange rates are likely to systematically overestimate infiltration loads by an average of 20 percent or more.

Examination of the dependence of IHEE on flow rate and flow exponent suggests that for typical flow rates, the fiow exponent may provide useful predictive information regarding the size of IHEE and can be incorporated into a procedure for modifying infittration load calculation procedures for houses after 


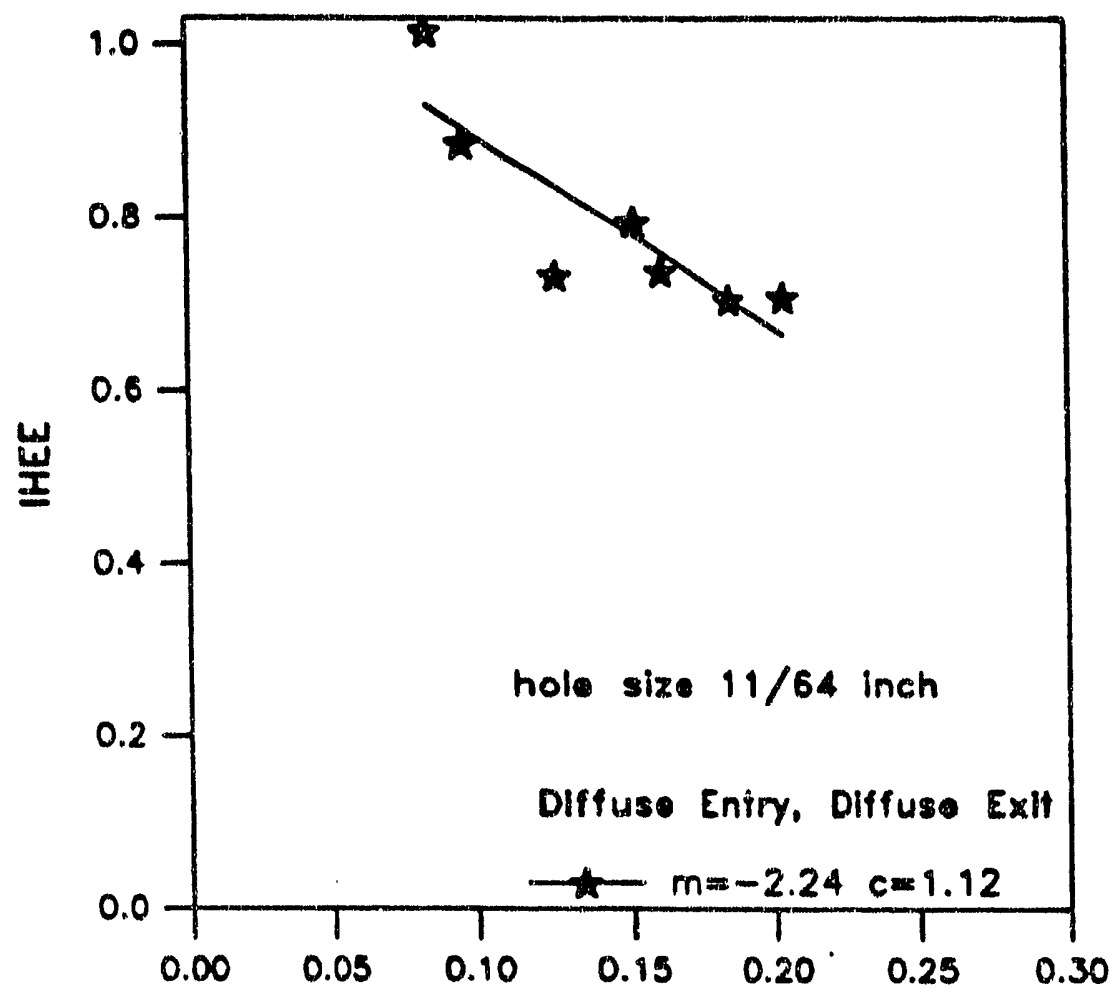

0 , Non-dimensional flowrate

Fig. 36. IHEE vs. a for 11/84 Inch Diffuse Inlei and Difiuse Outlet 


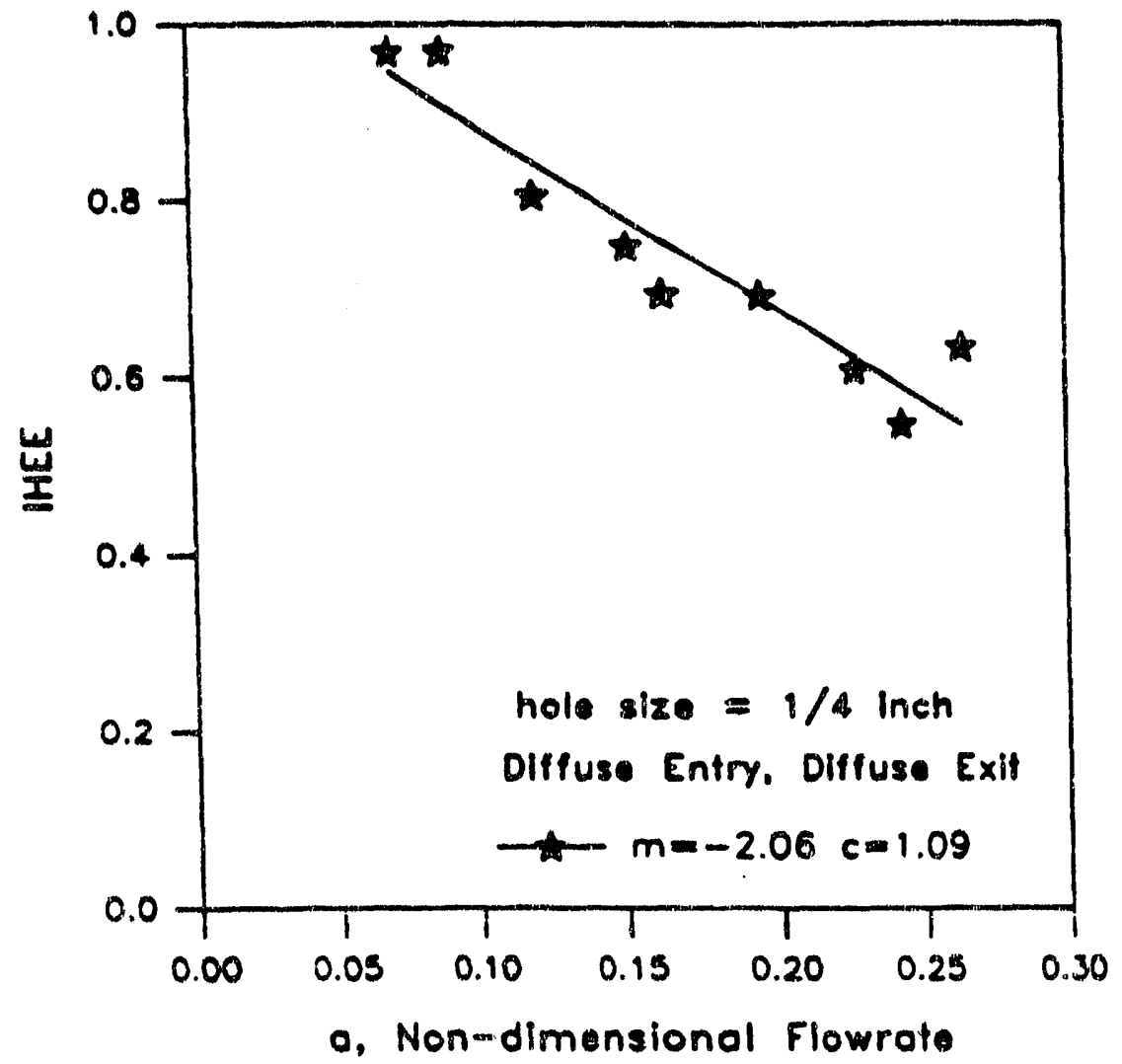

Fig. 37. IHEE vs. a for $1 / 4$ hch Dthuse Inlet and Diffuse Outtot 


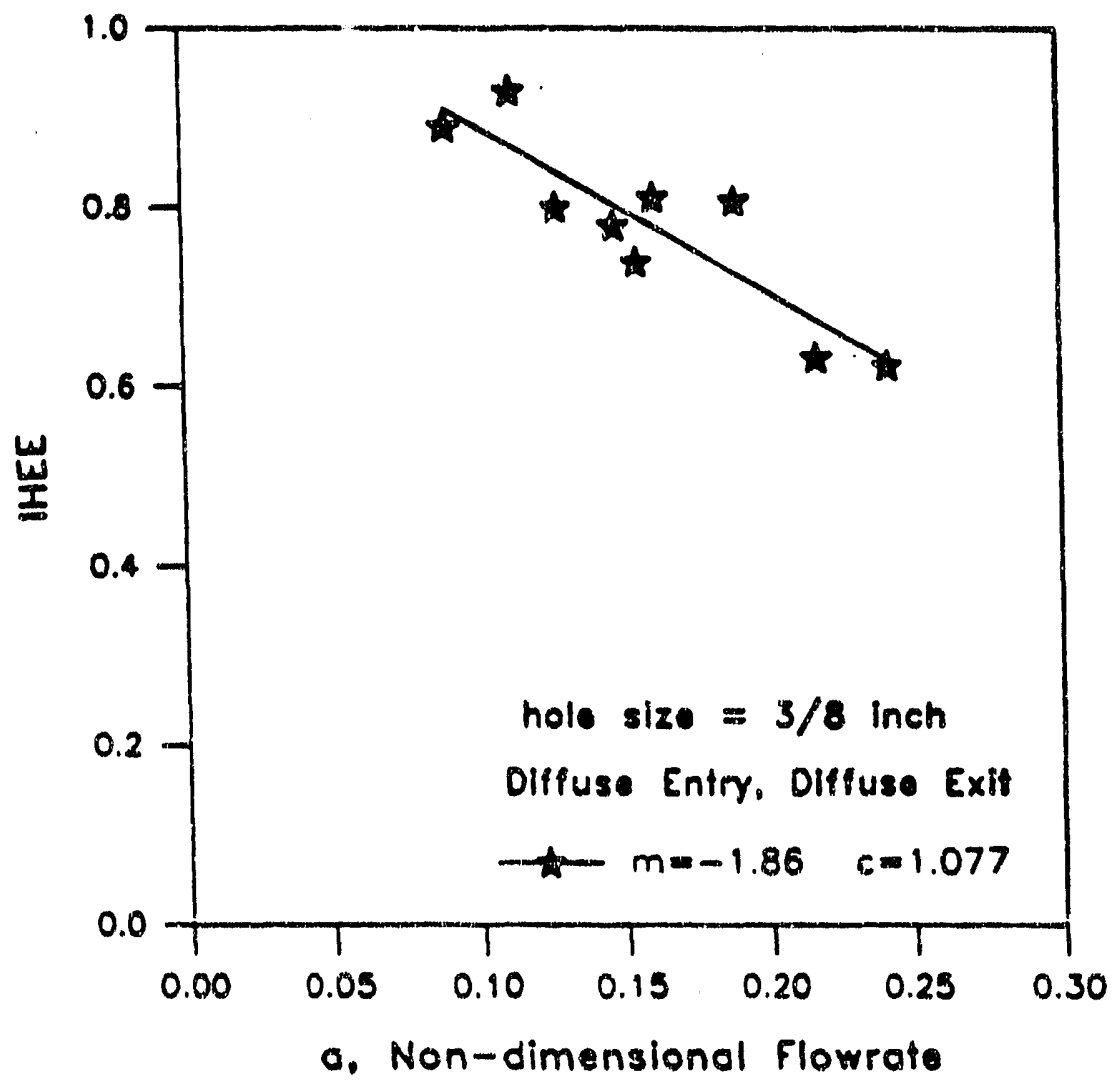

Fig. 38. IHEE vs. a for $3 / 8$ inch Diffuse Inlel and Difluse Outlet 


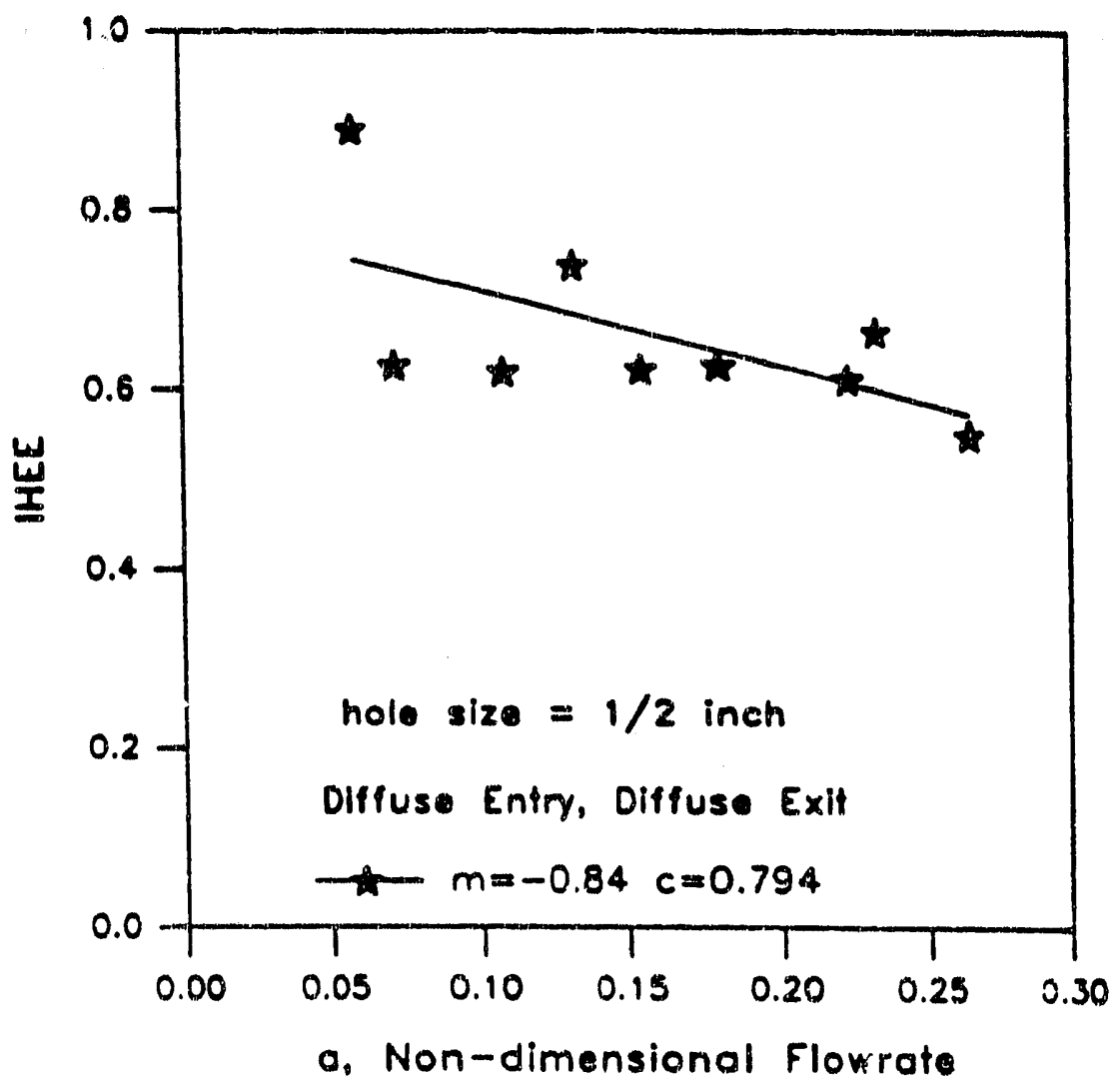

Fig. 39. IHEE vs. a for $1 / 2$ inch Diffuse Inlet and Diffuse Outlet 


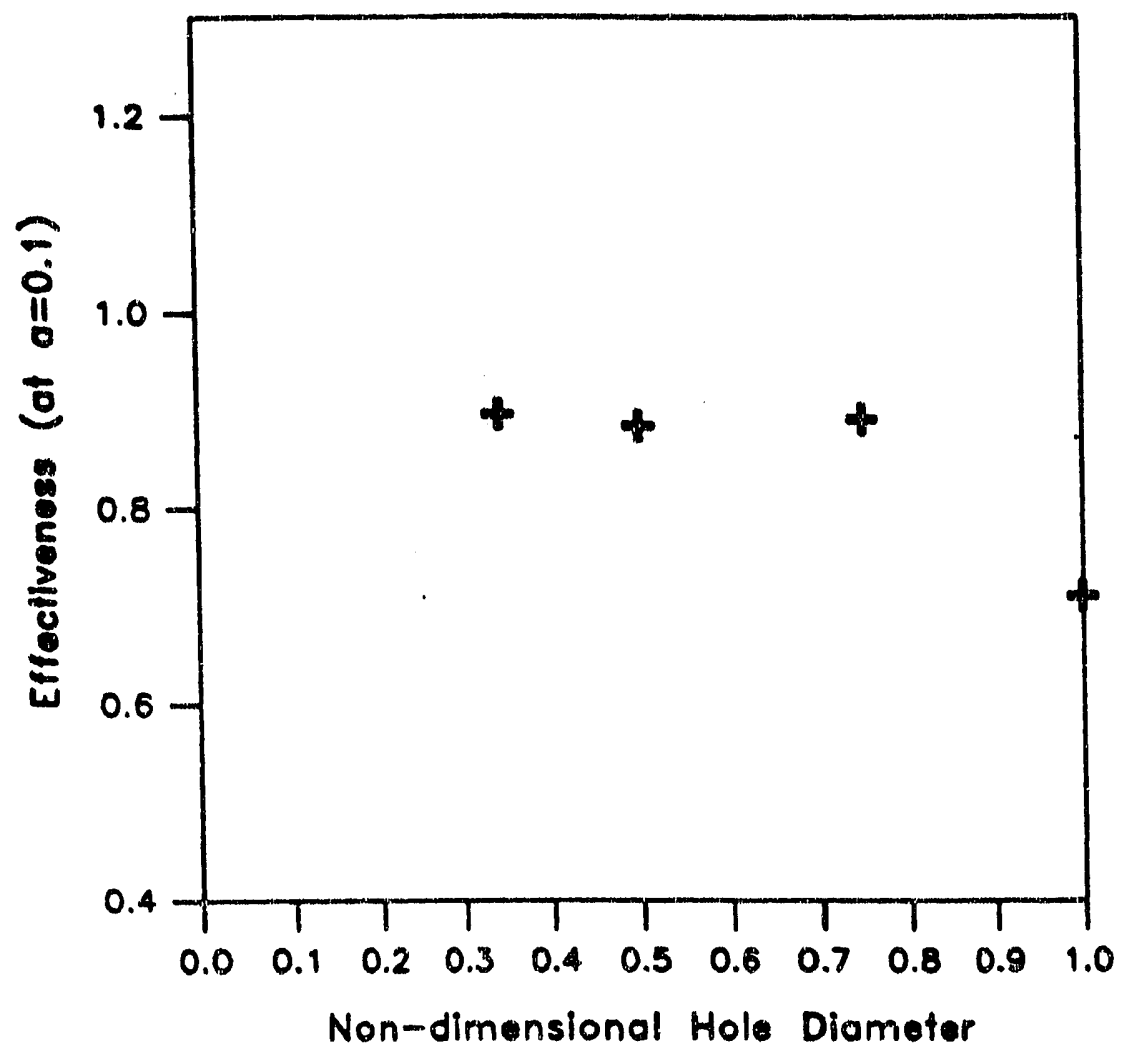

Fig. 40. IHEE vs. Inlet Size for Diffuse Air Entry 
86

further experimental and theoretical research. 


\section{CHAPTEK VI}

\section{RESULTS: STUD-CAVITY WALL SECTION}

This chapter discusses the results obtained from the stud-cavtly wall section. A parametric comparison of the simplified model and the data is also presented in this chapter. Steady state tests were run on a stud-cavity wall section which served as the test specimen; pressurization tests accumpanled each experiment for every configuration. The objective was to quanthattvely investigate the degree of diffuse behavior of the stud-cavity for several confligurationit. Five difterent configurations, each having unique air inlet and exti combination, were testad at various air flow rates and a base case experiment was pertormed with no air flow. Details of this experimental methodology have been presented in Chapter V.

A sensittuity and uncertainty analysis was carried out for the measured values of the Infiltration Heat Exchange Effectiveness and the detalls are outlined in Appendix A. It was found that the measurement of $e$ is quite sensitive to cold space temperature, hot space temperature, ambient temperature and the power input since the model of the callibrated hot box was developed for a particular set of parameters. Accordinghy, all these variables were kept within an extremely narrow band to minimize the blas caused by changes in these varlables. A typical operating condition would be a hot space temperature of $25.5 \mathrm{C}$, a cold space temperature of $1 \mathrm{C}$ and an ambient temperature of about $23 \mathrm{C}$. The heater power input and the temperature controller for the cooling system were manlpulated to achieve such operating conditions. Air flow rate was varled within a range, typlcally 4 SLPM (standard liters per minute) to 15 SLPM, where the 
pressure difference between the interlor of the stud-cavity and the cold/hot space was maintained below $60 \mathrm{~Pa}$. IHEE, $\epsilon$, is shown as a function of the air flow rate in Figure 41 for configuration $A$, where the air leaves the stud-cavity at a point diagonally across from the inlet location (hole 2 in Figure 16) and thus should utilize the whole vertical helght of the test specimen for heat exchange. It may be observed that $\varepsilon$ decreases with increase in air flow rate, as anticipated. At small flow rates, the measurement uncertainty increases dramatically coincident with a sudden increase in the $e$ value at 4 SLPM. The maximum theoretical value of $\epsilon$ is 0.5 for this configuration, so the large value obtained at 4 SLPM is apparently due to experimental error. Repeatability is quite good as evidenced by the two cases where measurements were repeated at the same flow rates.

In configuration B, exit hole 2 was plugged and a new exit hole 3, vertically above the air inlet, was used for the experiments. Since the test specimen wall section has a height which is much greater than its width, this configuration has about the same aif path length as compared to configuration $A$. The measured c values (Figure 42) are comparable to those from configuration $A$ and the dependence on flow rate is similar also; IHEE decreases with increasing air Now rate.

In conflguration $C$, exit holes 2 and 3 were plugged and a new hole 4 was opened up at the center of the wall section. This provides about half the air path length that was used before and hence a lower $\epsilon$ value is anticipated. Figure 43 shows the variation of $\epsilon$ with air flow rate and a significant drop in IHEE vaiues is noted. The flgure also shows a sharper gradient in the variation for flow rates above 8 SL.PM.

In the next configuration $(0)$ all the ext holes used so far, i.e., exit hole 2, 


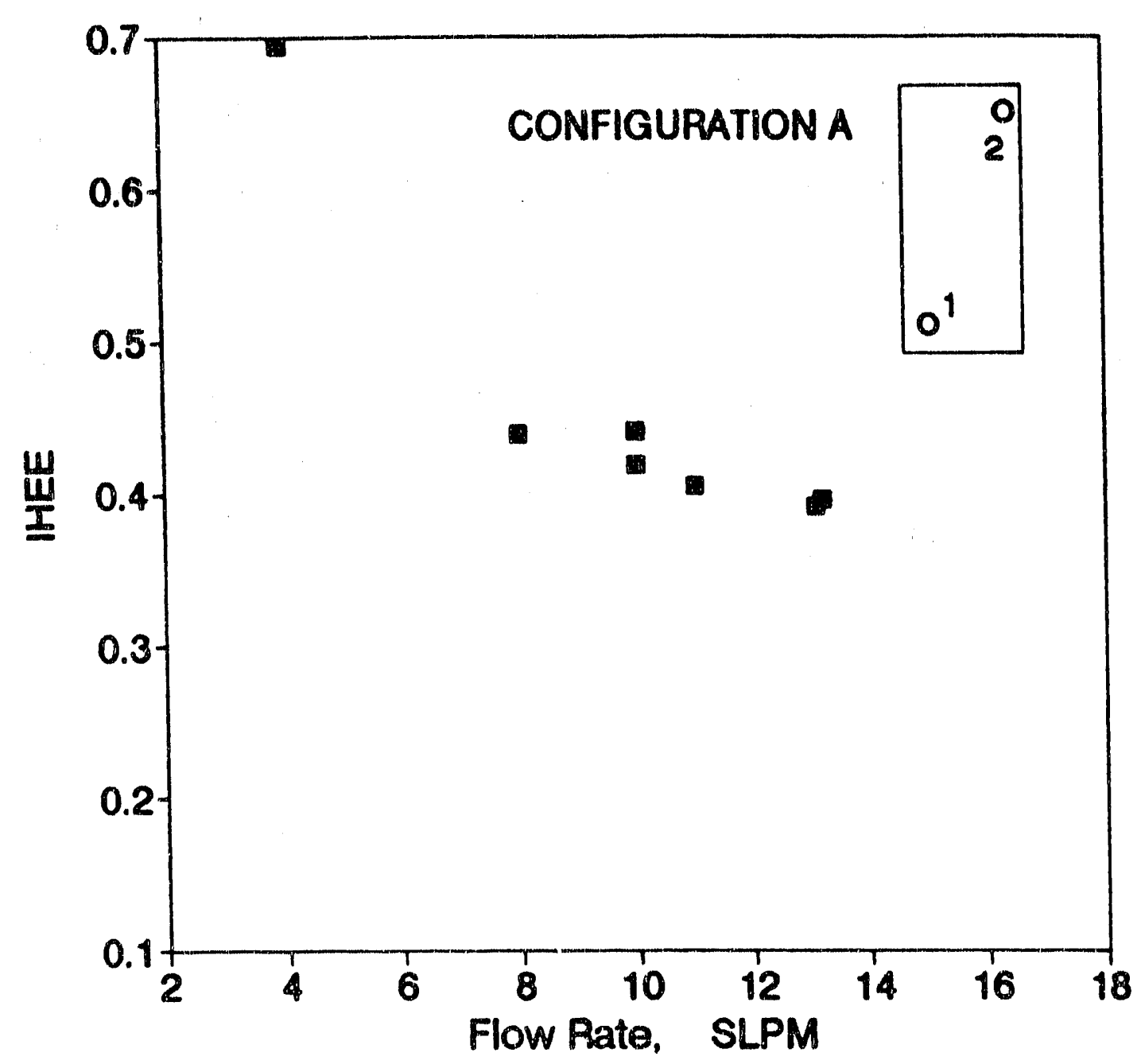

Fig. 41. Measured IHEE Values for Inlet at 1 and Outlet at 2 


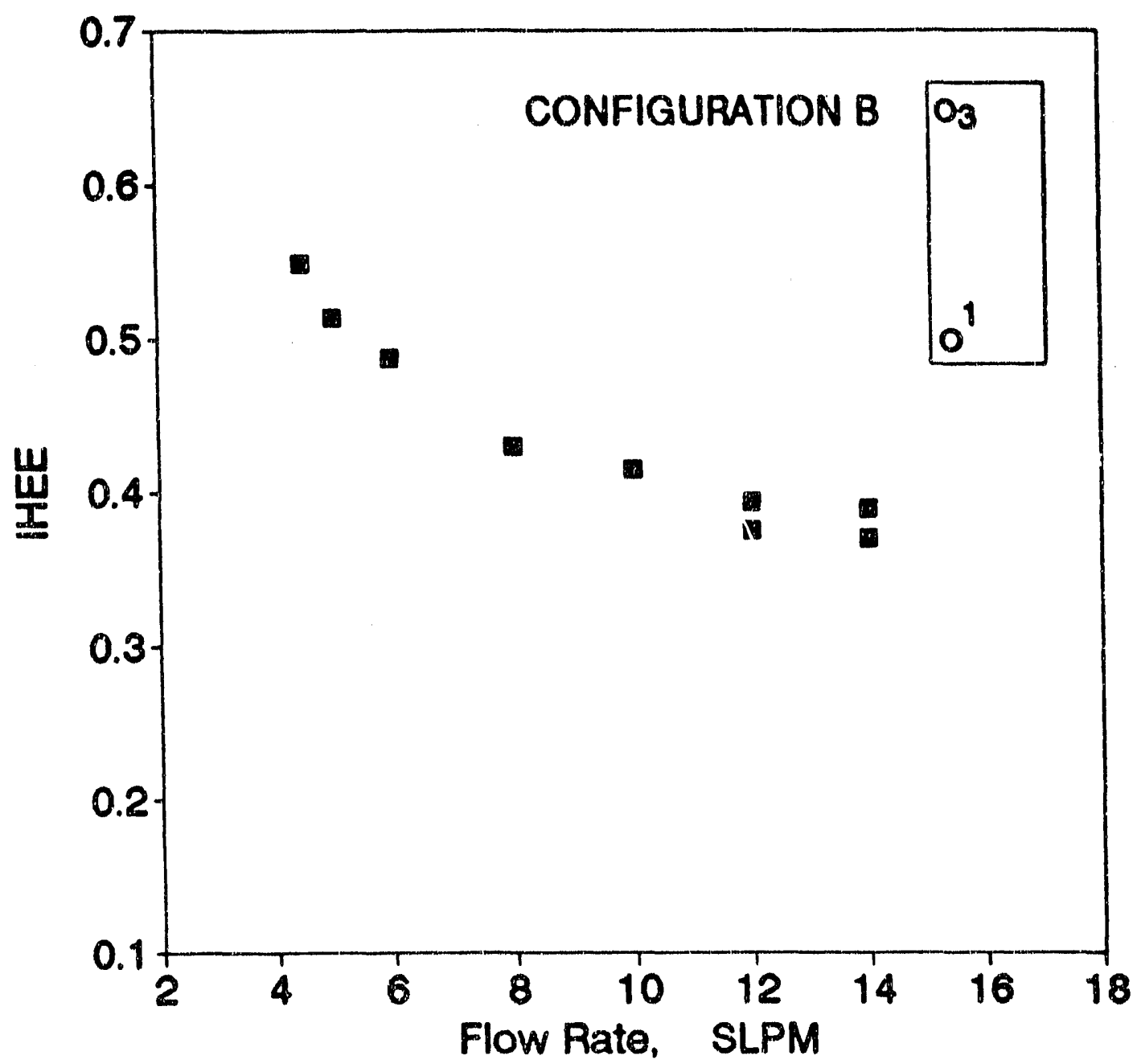

Fig. 42. Measured IHEE Values for Inlet at 1 and Outlet at 3 


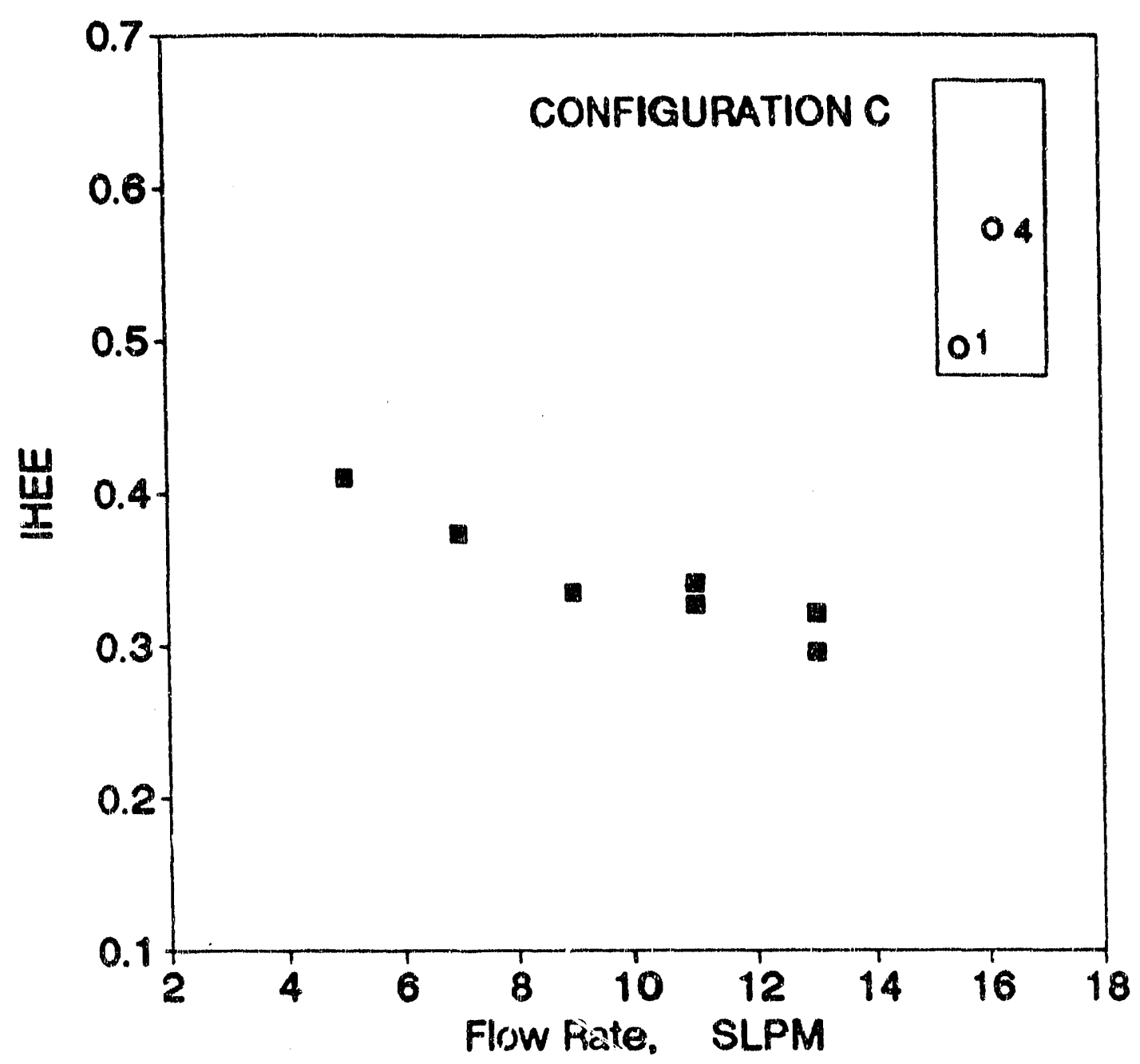

Fig. 43. Measured IHEE Values for Inket at 1 and Outtet at 4 
3 and 4 were opened and thus a 3-hole exit pattern was employed. Naturally, a higher air flow rate could be used within the stipulated 60 Pa pressure difference limit. A longer path length and/or more heat exchange area can be envisaged for this configuration which would cause a rise in IHEE values. Figure 44 illustrates the variation of $\epsilon$ with air flow rate for configuration $D$ and the general trend noted for conflgurations $A$ and $B$ is present, but s values are not appreclably different. The high measured value of $\epsilon$ at 4 SLPM again may be assurned due to measurement error.

Configuration E represents a very short path length with the air outlet located just across the thickness of the wall section from the air inlet. The measured values of $\epsilon$ with respect to air flow rate are illustrated in Figure 45. A sharp drop in IHEE values is observed relative to the previous configurations. This is anticipated as the flowing air gets much less opportunity to exchange heat with the porous insulation inside the stud-cavity giving rise to small $\epsilon$ values. However, the results for this configuration are counter-inturtive; for a flow situation with a straight-across outlet, a lower range of $\epsilon$ values might be expected since there appears to be little opportunity for the moving air to exchange heat. But the measured data exhibits values of IHEE near 0.2; a sharper gradient in the plot is also observed.

The results presented clearly show that air flow through a stud-cavity specimen can exhibit significant heat exchange, substantially reducing the energy requirements on the specimen due to infiltration.

Four of the 39 measurements made show values of $\epsilon>0.5$, the theoretical maximum value, and all occur fer flow rates near or below 5 SLPM. An uncertainty analysis was performed for the test data domain as outlined in Appendix 


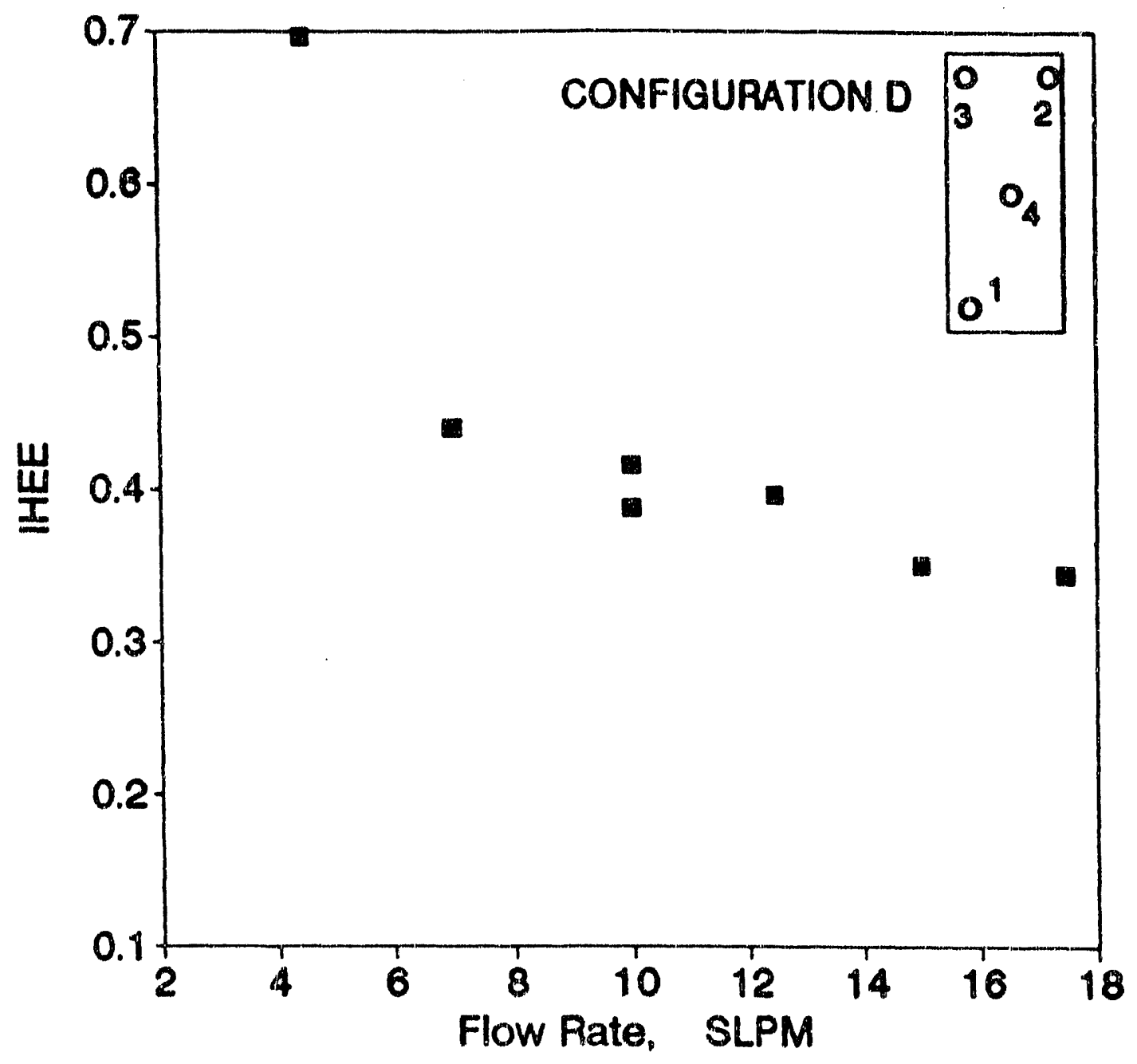

Fig. 44. Measured IHEE Values for Inlet at 1 and Outiet at 2, 3 and 4 


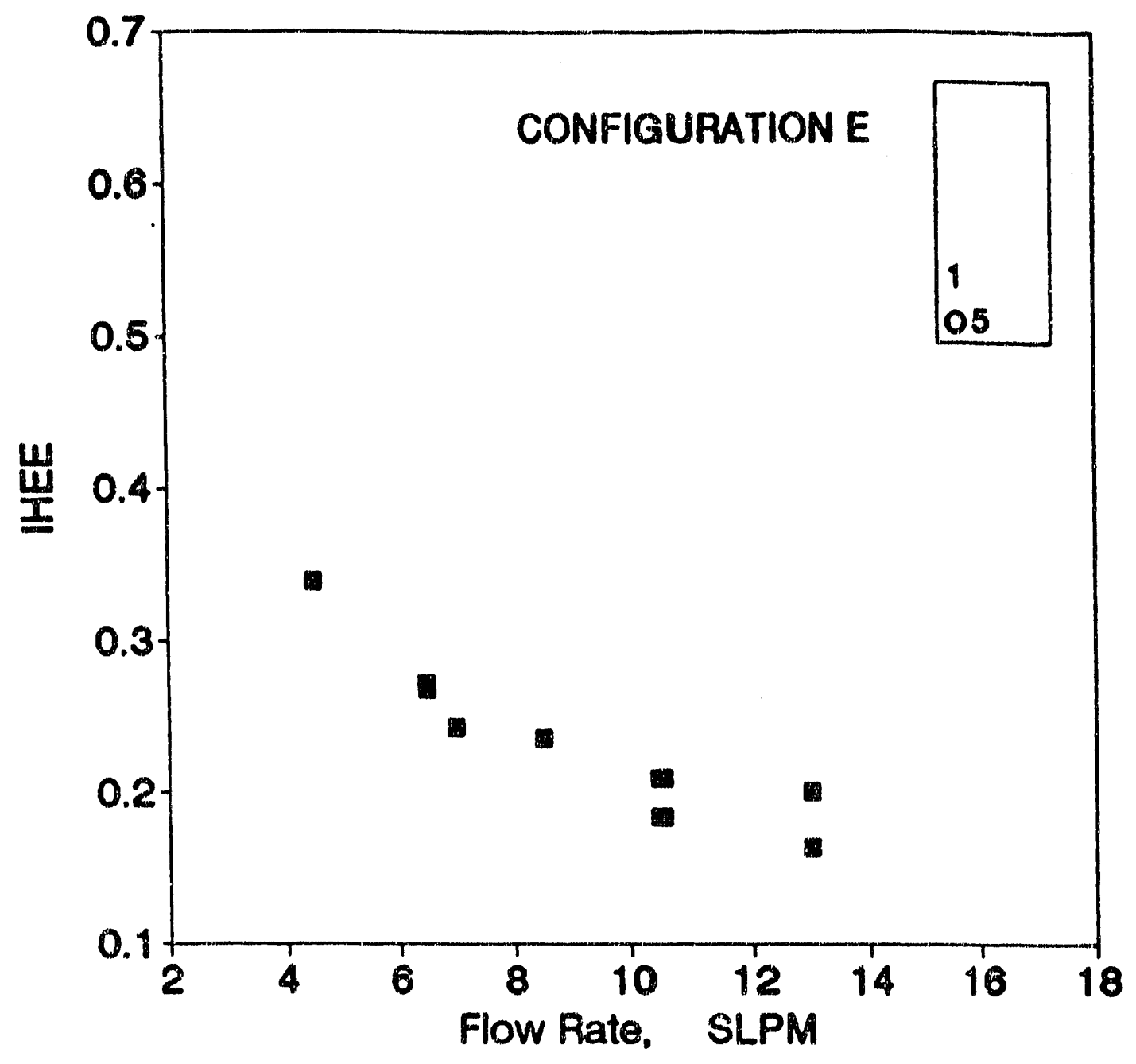

Fig. 45. Measured IHEE Values for Inlet at 1 and Outlet at 5 
A. The uncertainty for each measured $\epsilon$ is illustrated for each conflguration and air flow rate in Figure 46. The uncertainty is based on the maximum error specified for each measurement made in the experiment. The repeatability of individual data points and the consistent trend of $\epsilon$ values show that experimental error is generally less than the uncertainty values shown in Figure 46.

It may be observed from figure 46 that at low now rates (e.g. 4 SL.PM), the uncertainty increases rapidly. The $\epsilon$ values at low flow rates have been consistently at or above the expected values. This deviation is within the inherent large uncertainty present in the experimental measurement procedure at extremely low flow rates; however, it may reflect a systematic error at low flow rates.

\section{TEMPERATURE DISTRIBUTION INSIDE THE STUD-CAVITY}

The stud-cavity design incorporated 75 thermocouples embedded in the fiberglass insulation inside the stud-cavity to measure temperature at selected points forming a grid, in a $3 \times 5 \times 5$ matrix across the inside volume. A normalized 3-dimensional temperature distribution analysis was carried out to better understand the air path length for each inlet-exit configuration. For each air flow rate and each configuration, the measured temperature was subtracted from the temperature measured at the same thermocouple location, with zero air flow rate. This temperature difference is assumed to represent the effect of the intrusive air flow at that particular location inside the wall specimen. After studying the data for all nodes inside the stud-cavity, it was decided that the temperature differences measured at the five locations across the thickness of the stud-cavity can be averaged to give 15 temperature differences representing 

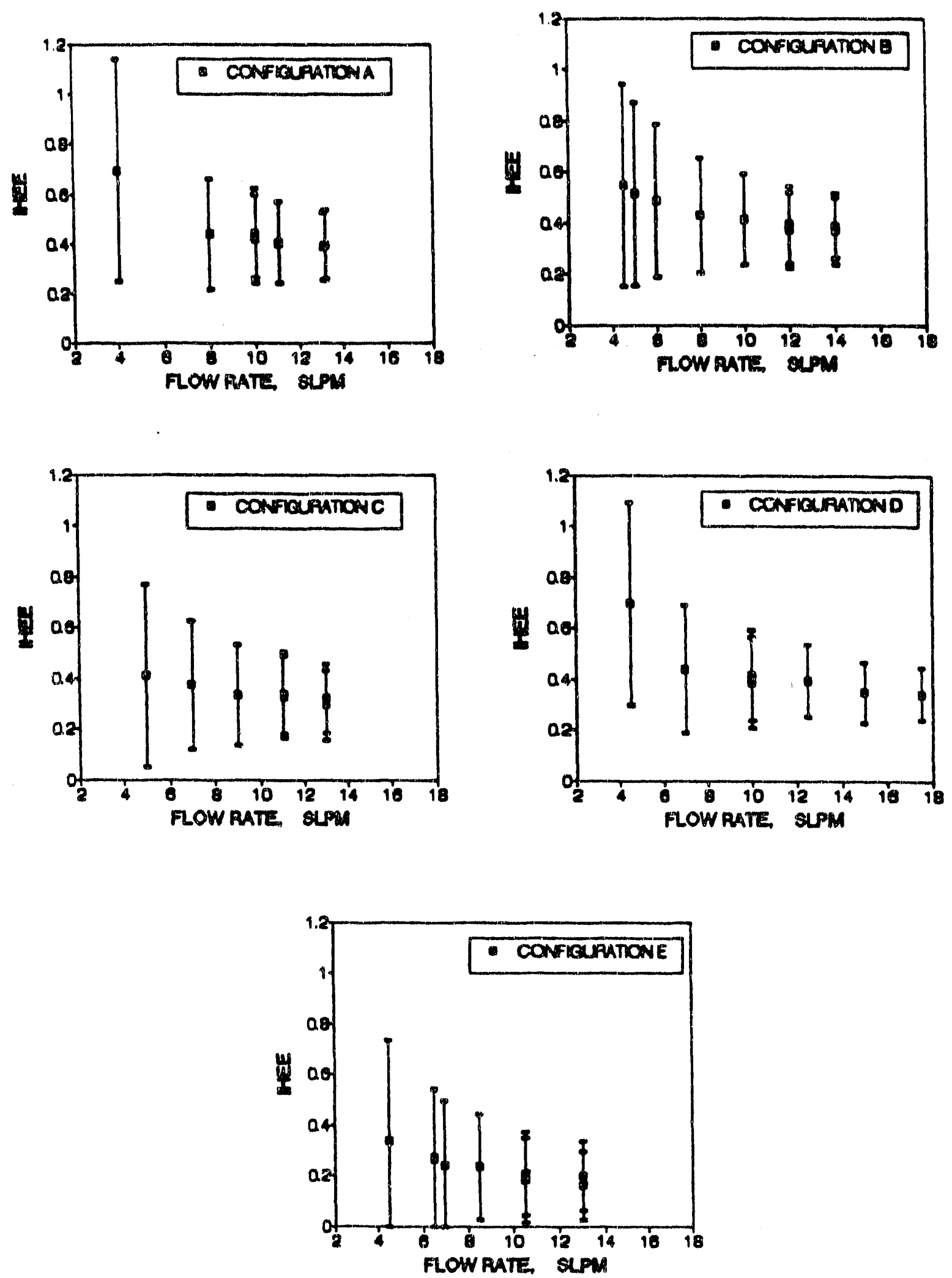

Fig. 46. Uncertainty Bars for Measured IHEE Values 
the influence of the air now and its variation along the width and along the height of the stud-cavity. A selection of these 3-D temperature distribution plots has been included in this chapter and the rest of them appear as Appendix $\mathbf{B}$.

Figures 47 and 48 show the temperature difference distributions for 11 SLPM and 13 SLPM respectively for configuration A. The height of the bars in these plots depicts the influence of the air flow through the stud-cavity. In this configuration the air inlet is near location 1C and the outlet is near location 5A. Those locations register strong changes due to the air flow; otherwise locations 1A, 1B, 2A and 2C, near the inlet, clearly show air flow around them. Around the exit, nodes $4 A, 5 B$ and $5 C$ show noticeable temperature differences. Node $3 A$, at the middle elevation, shows a small change due to air flow. A clear path is not completely apparent from the plot and a possible bypass around the thermocouple stations at $2 B, 3 B$ and $3 C$ is suggested. The temperature differences increase with an increase in flow rate, as can be observed from the plots. The locations where no change is observed may have experienced natural convection flows around them in the zero air flow rate configuration and these plots simply superimpose the air flow experiments onto the base case; this is a possible explanation for those locations which show no temperature change.

These graphs have been plotted to reveal the distribution of temperature changes due to air flow in the stud-cavity when subjected to an intrusive cold air flow and to obtain a length parameter to serve as the effective air path length to be used in the simplified model, described in Chapter IV. An effective path length, $L_{\text {eff, }}$ can be defined as:

$$
\boldsymbol{L}_{\text {eff }}=\text { (area affected / total area) } \times \text { (cavity length) }
$$


Thus, for example, if 5 of the 15 temperature differences are significant, then the effective air path length for that particular configuration is one-third $(5 / 15)$ the total height of the test section. This definition was actopted after careful Intuittive and quantitative examination of the measured data and the simplified 1-dimensional model being employed. Following this procedure, 11 of the 15 temperature bars in Figures 47 and 48 seem to be influenced by the air flow, and hence, the effective path length $0.733 \times 8 n=5.87 n$.

Figures 49 and 50 show the temperature difference plots for configuration $B$ at air flow rates of 12 and 14 SLPM respectively. This pair of plots is very similar to those described above for configuration A. But the change in location of the air outlet to node $5 \mathrm{C}$ is evident. Some of the nodes again seem to be unaffected by the fluid flow. On inspection, this configuration also yields an effective air path length of $5.87 \mathrm{ft}$. Appendix B clearly shows that the perturbation is much smaller at lower flow rates.

Configuration C uses a mid-elevation air outlet which is clearly evident in Figures 51 and 52 which show the temperature differences inside the studcavity for flow rates of 11 and 13 SLPM respectively. The upper half of the wall section does not seem to have participated in the heat exchange process as the traveling air escapes through the mid-exit without moving further up. The temperature bars are most prominent around the inlet and outlet and 8 locations out of 15 appear to be influenced by the cold air flow. Accordingly, the effective path length is calculated to be $4.3 \mathrm{ft}$. A notable omission among the unaffected cells is $2 B$ which, though surrounded by affected cells, does not register any temperature change from the zero flow situation.

Marginally higher flow rates were used in Configuration $D$ as noted earlier. 


\section{Configuration A 11 SLPM}
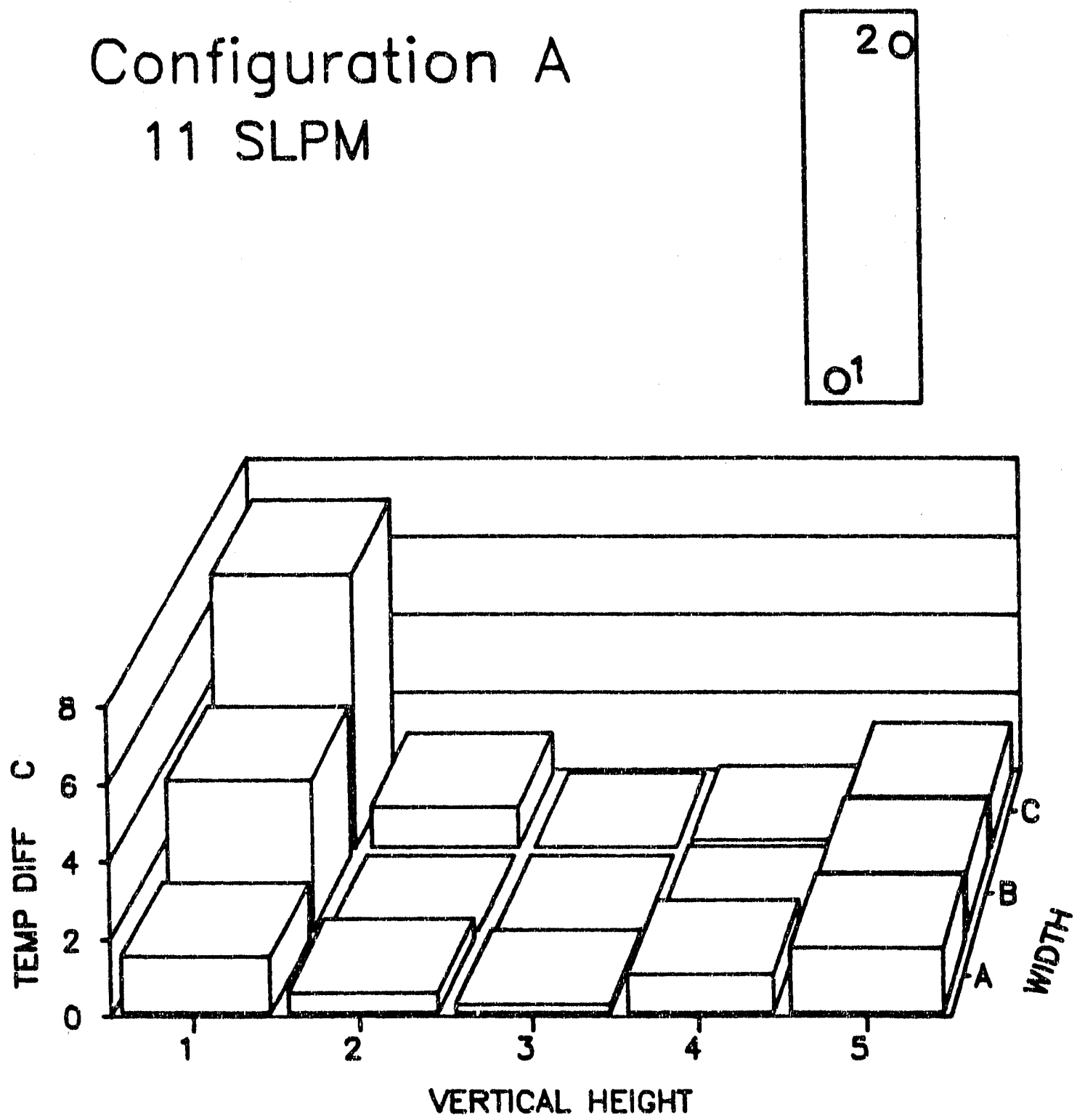

Fig. 47. Temperature Difference Plot for Configuration A at 11 SLPM 


\section{Configuration A 13 SLPM}

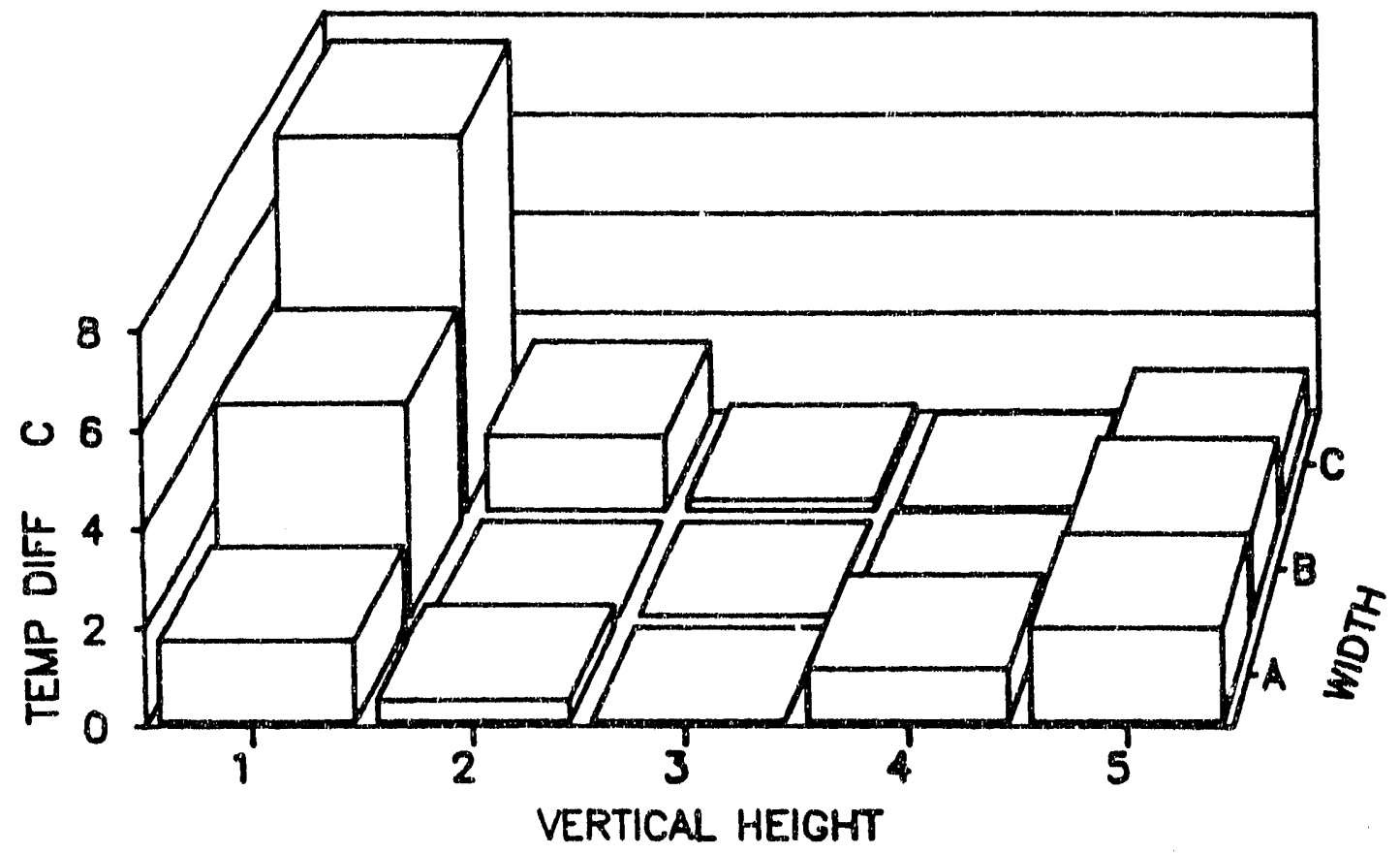

Fig. 48. Temperature Difference Plot for Configuration A at 13 SLPM 

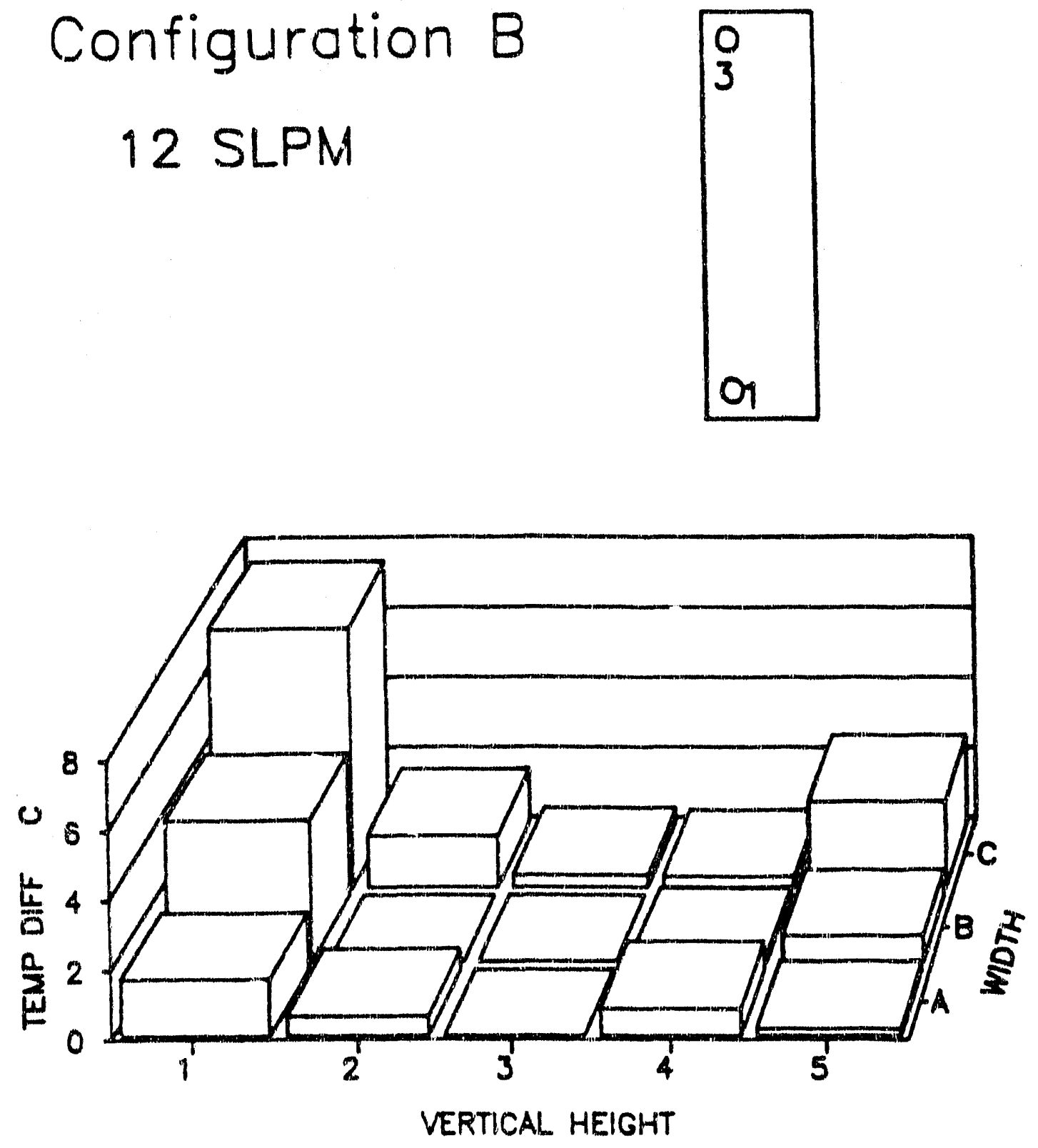

Fig. 49. Temperature Difference Plot for Configuration B at 12 SLPM 

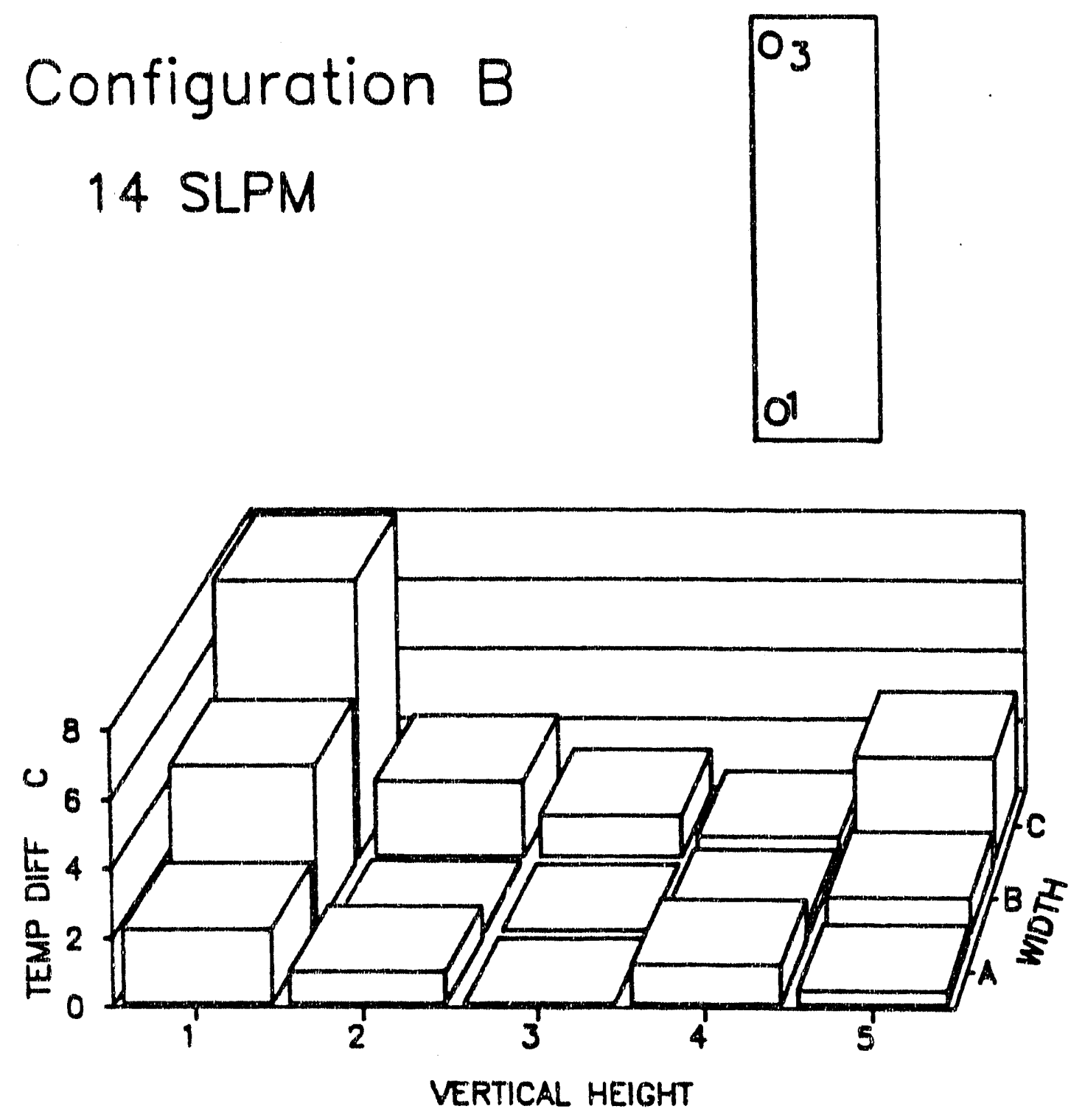

Fig. 50. Temperature Difference Plot for Configuration B at 14 SLPM 
Configuration $\mathrm{C}$ 11 SLPM

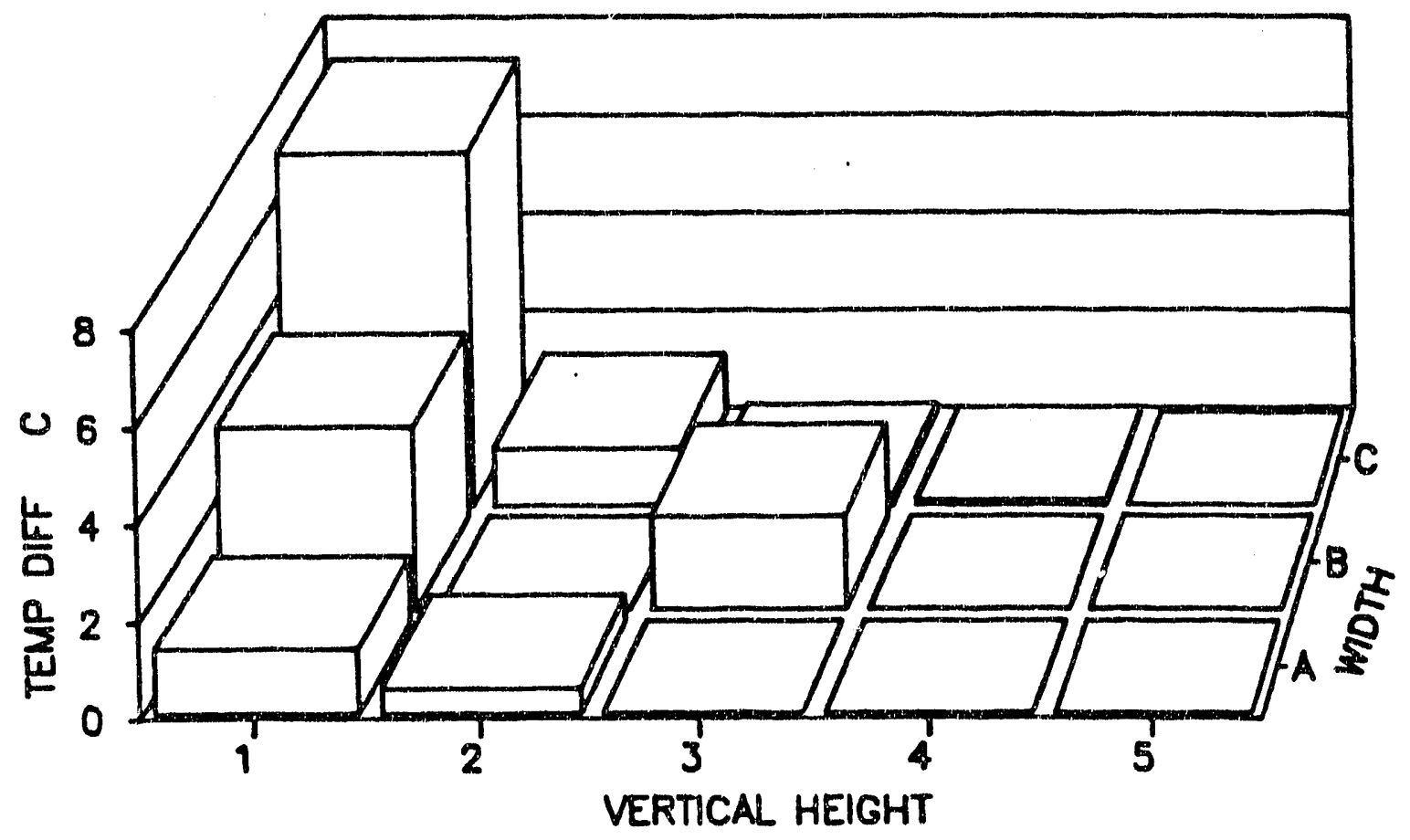

Fig. 51. Temperature Difference Piot for Configuration C at 11 SLPM 
Figures 53 and 54 show the temperature difference plots for this arrangement and the three different outlet locations can be identified in the plot. The entire stud-cavity seems to be influenced by the flow and hence the total height of the stud-cavity $(8 \mathrm{ft}$.) is used as the effective path length for this conflguration.

Finally, in configuration E, a short path length is encountered by the traveling air before lf flows out through hole 5 located directly across the cavity from the inlet. Figures 55 and 56 show the temperature influence of the fluid flow at flow rates of 10.5 and 13 SLPM respectively. It may be noted that all three nodes 1A, IB and 1C are significantly influenced and hence the effective path length is assumed to be equal to the inside width (the insulation filled width) which is $1.22 \pi$

COMPARISON OF EXPERIMENTAL. RESULTS WITH MODEL

In this section the experimental results are compared to those predicted by the analytical model. For this comparison, the hot-space and the cold-space temperature is assumed to be $78 \mathrm{~F}$ and $33.8 \mathrm{~F}$ respectively to match the test conditions. The measured U-value of the stud-cavity was used and the surface area of the wall specimen is taken as $(8 \times 1.5)$ or 12 square feet. Surface heat transfer coefficients have been used at the air-insulation interface and also at the external surfaces of the stud-cavity. The surface heat transfer coefficients are determined from forced convection correlations using the proper air velocity on the corresponding surface; for the interior surface coefficient, a value of $h_{i}=2.5$ Btu/hr-sq.ft..F has been used whereas for the external surface coefficient a value of $h_{0}=4.0 \mathrm{Btu} / \mathrm{hr}$-sq.ft. $-\mathrm{F}$ has been used. 
Configuration $D$
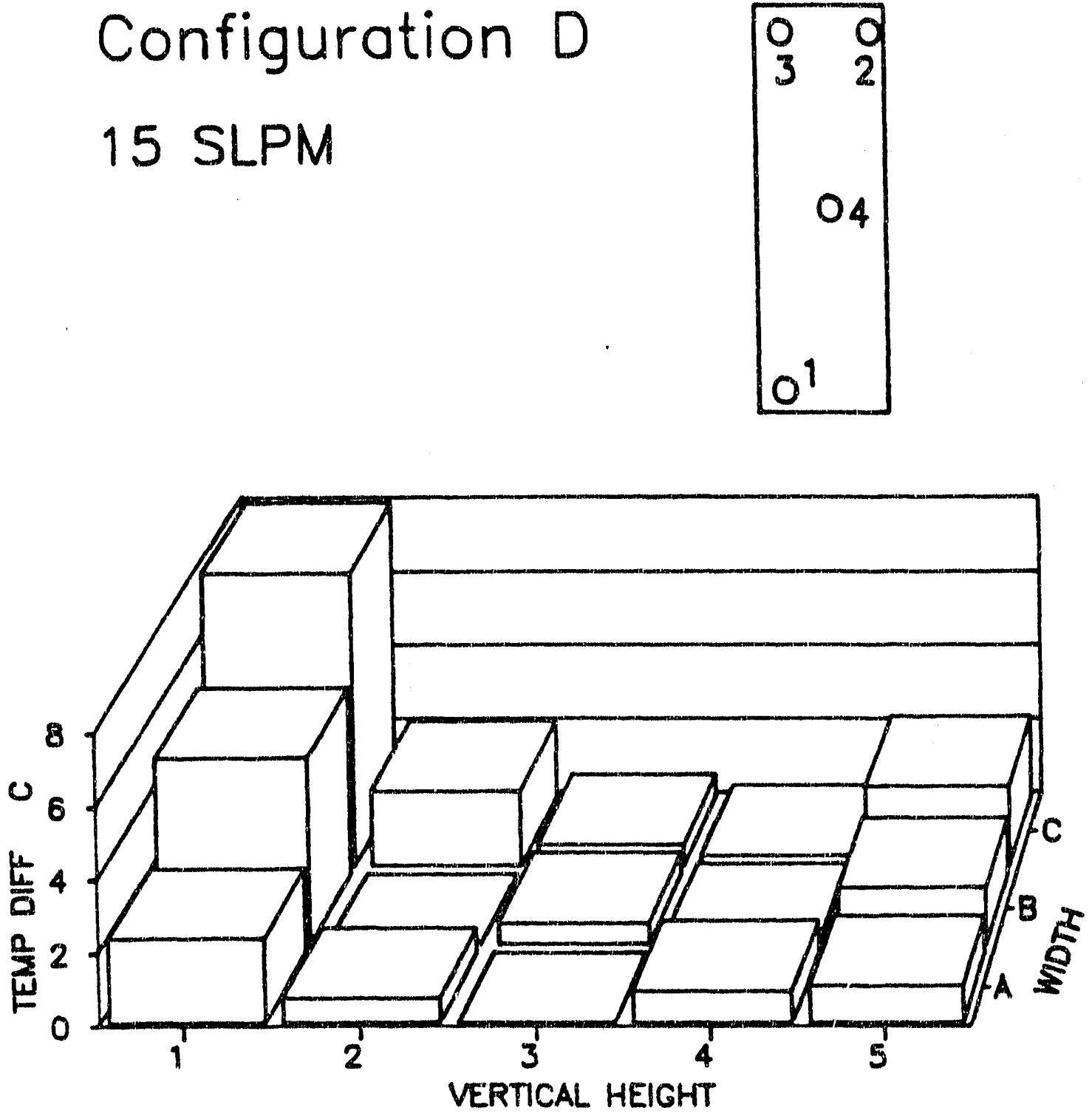

Fig. 53. Temperature Difference Plot for Configuration D at 15 SLPM 


\section{Configuration $E$ 10.5 SLPM}

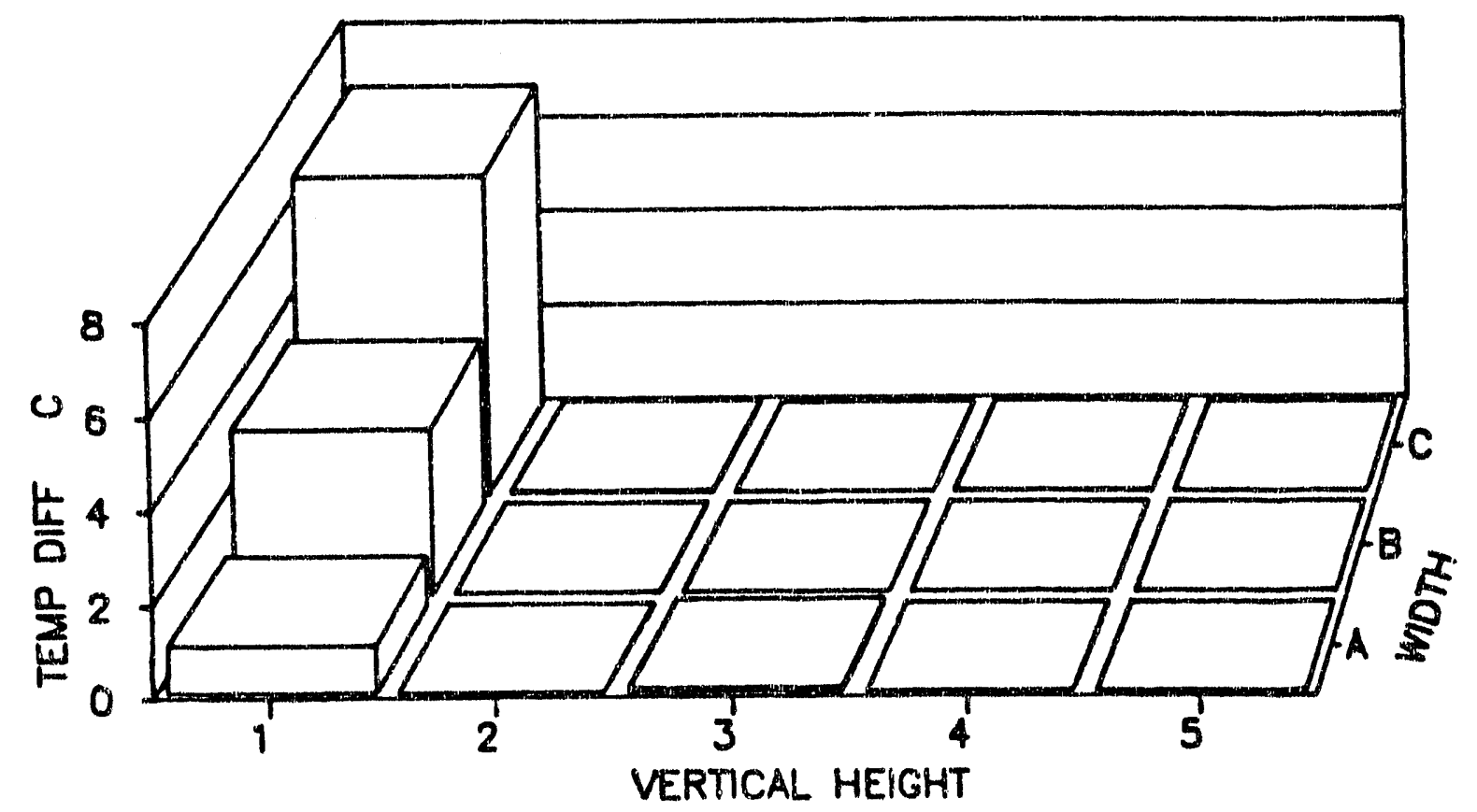

Fig. 55. Temperature Difference Plot for Configuration E at 10.5 SLPM 


\section{Configuration $E$ 13 SLPM}

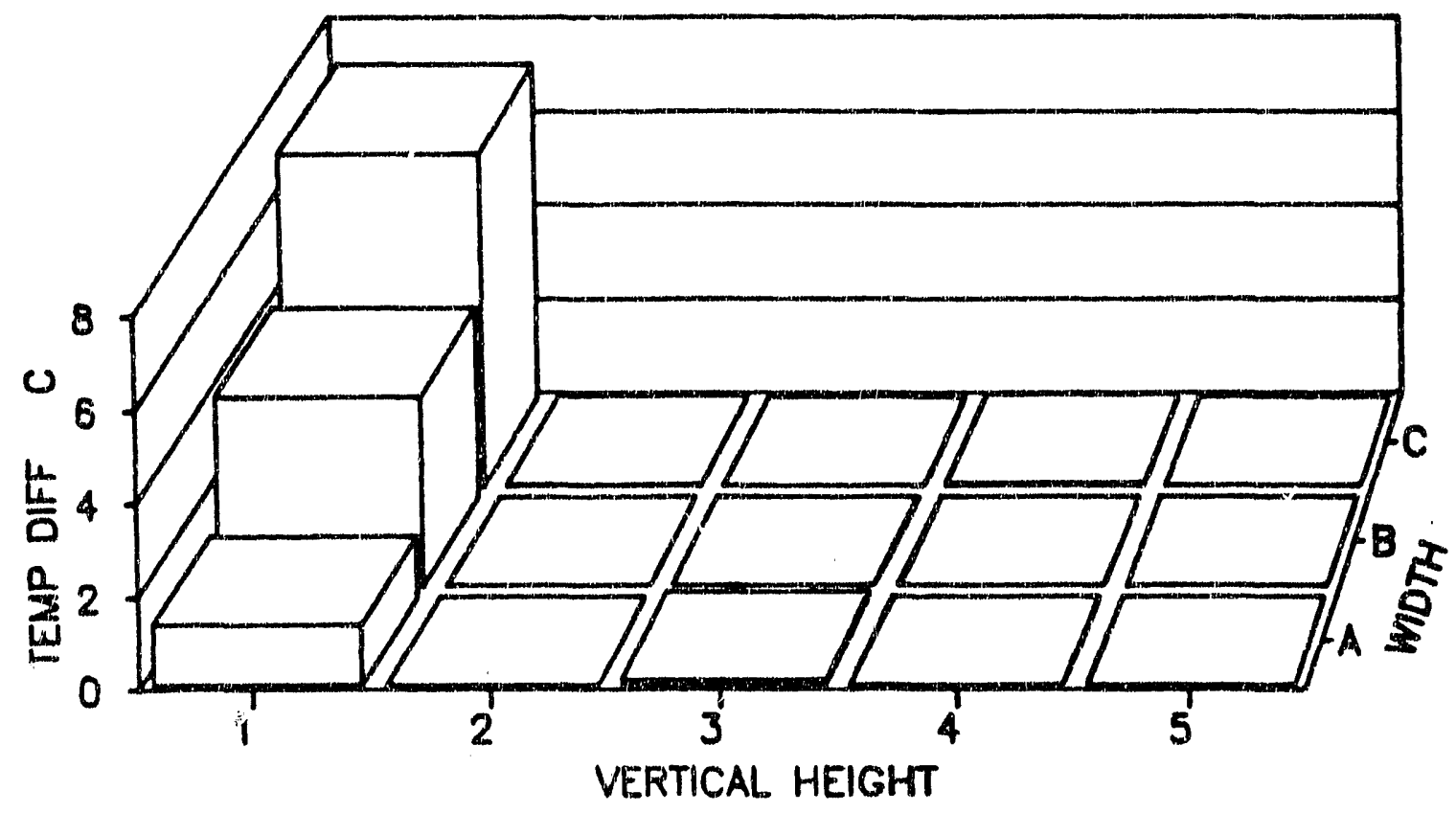

Fig. 56. Temperature Difference Plot for Configuration E at 13 SLPM 
Figures 57 through 61 show the model predictions compared with the measured values of Infiltration Heat Exchange Effectiveness, $\epsilon$, for conflgurations A through $E$ respectively. The model shows the tendency of a to decrease in value with an increase in flow rate. For configuration $A$ and conflguration $B$ the model underpredicts $\epsilon$ appreclably. The model shows excellent agreement with the measurements for the other three configurations, namely $C, D$ and $E$. In configuration $E$, where small values of IHEE were intultively expected, model predictions using the effective path length are very close to the measured values.

It may be noted that the IHEE prediction by the model is controlled by two primary parameters: the air flow rate, which is measured directly in the experiment; and the effective air path length, which is estimated from the temperature difference data. Although this heat and mass transfer problem is clearly 3dimensional in nature, the simple 1-dimensional analytical model has performed remarkably well. 


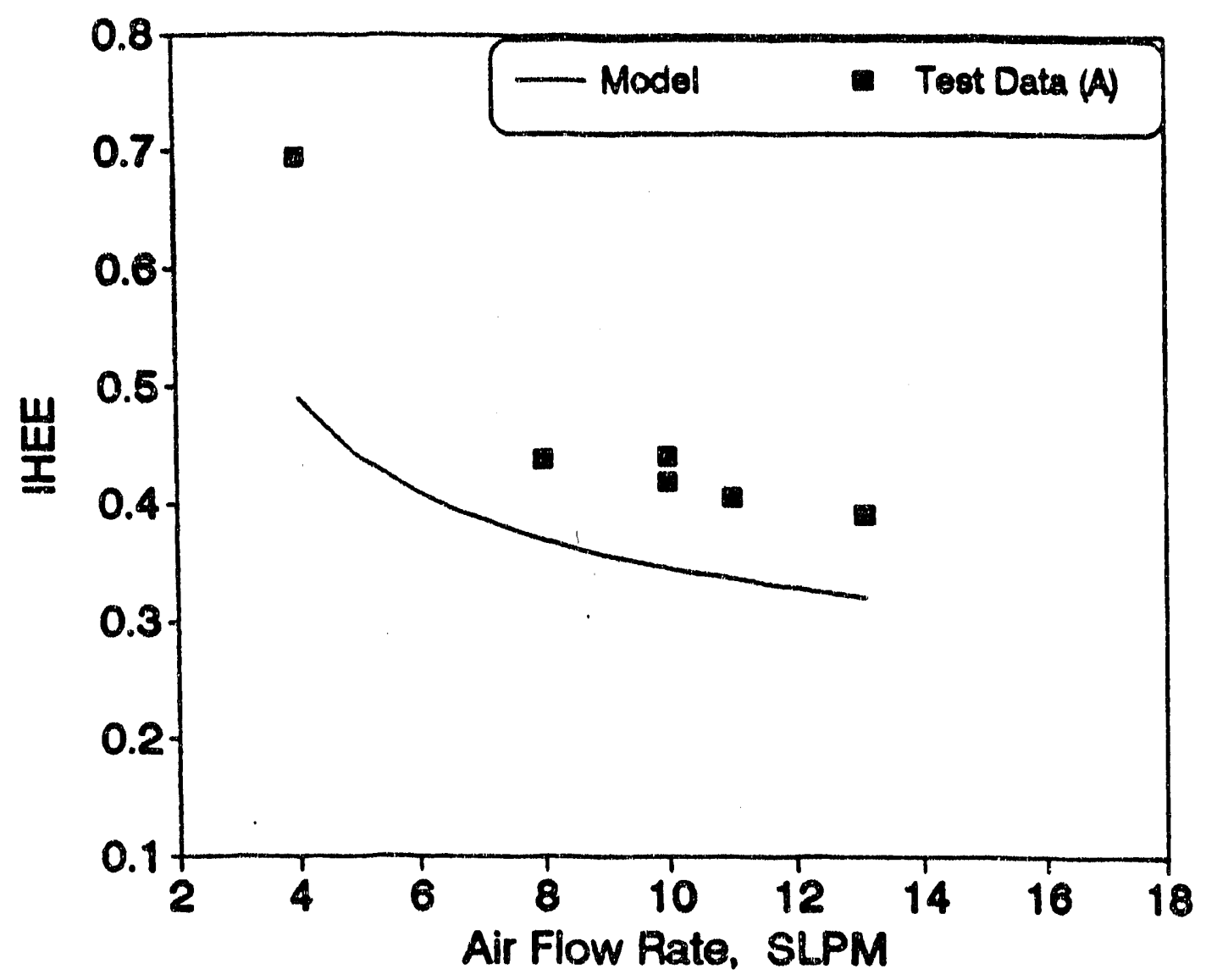

Fig. 57. IHEE for Configuration A: Comparison Between Model and Experiment 


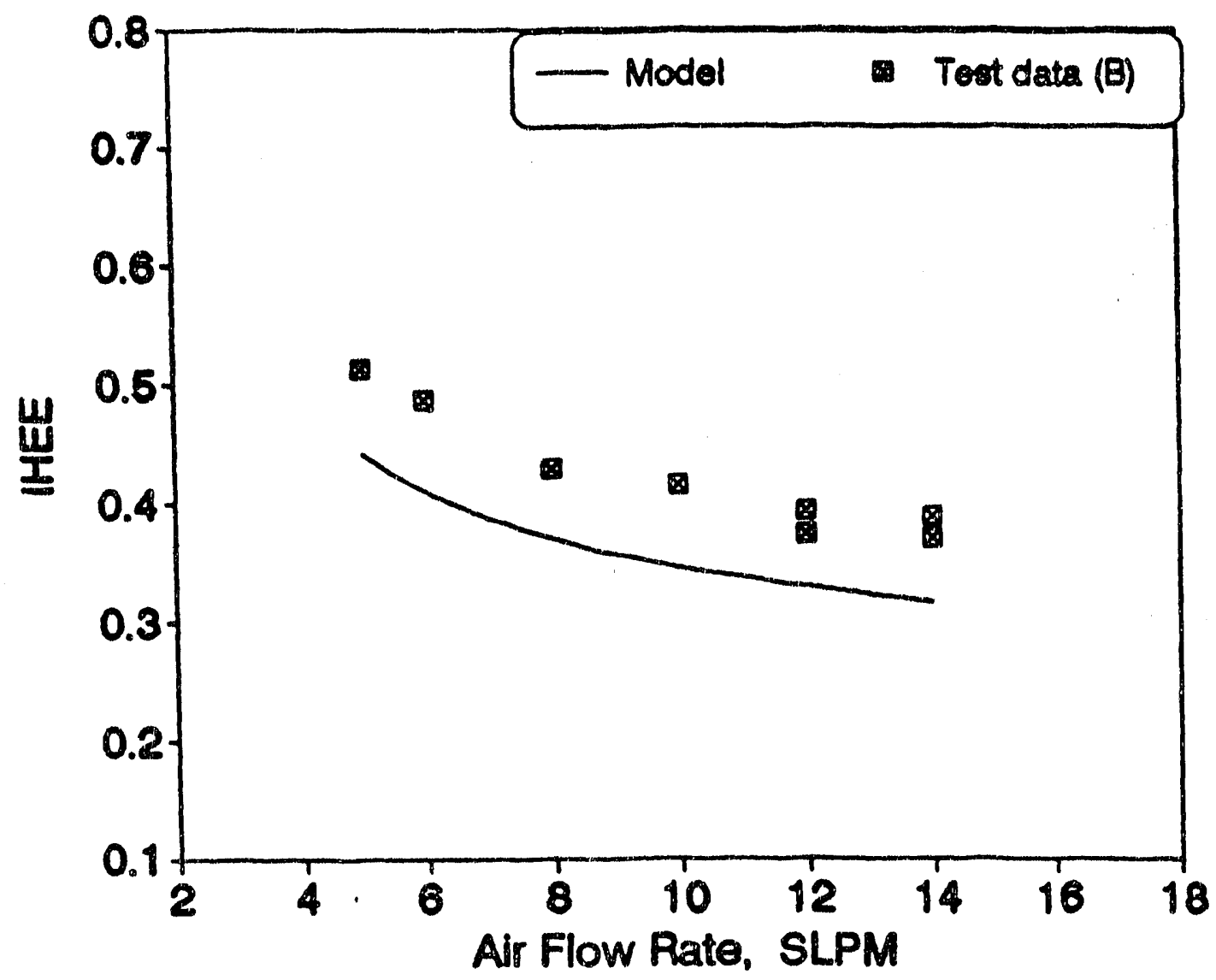

Fig. 58. IHEE for Configuration B: Comparison Between Model and Experiment 


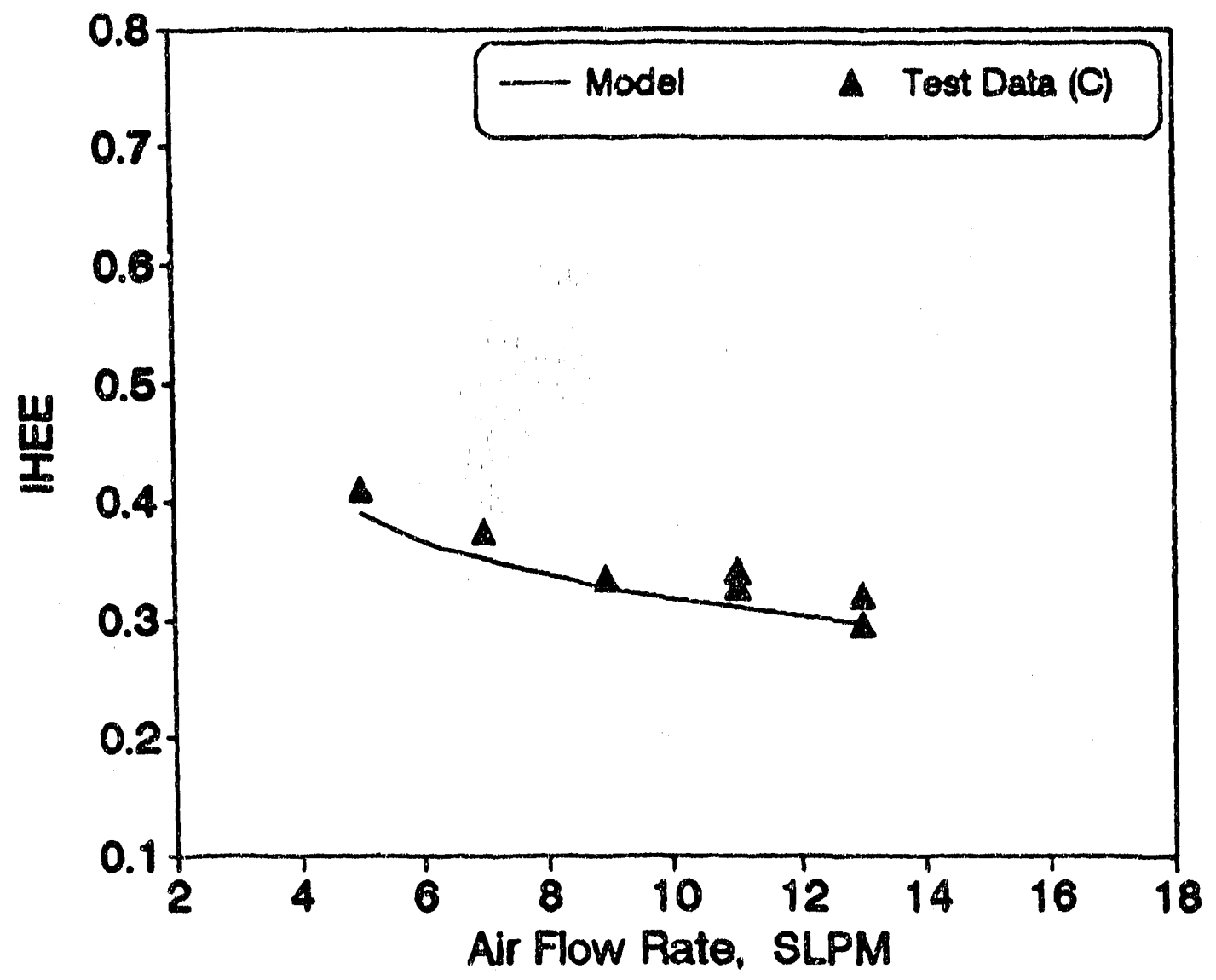

Fig. 59. IHEE for Configuration C: Comparison Between Model and Experiment 


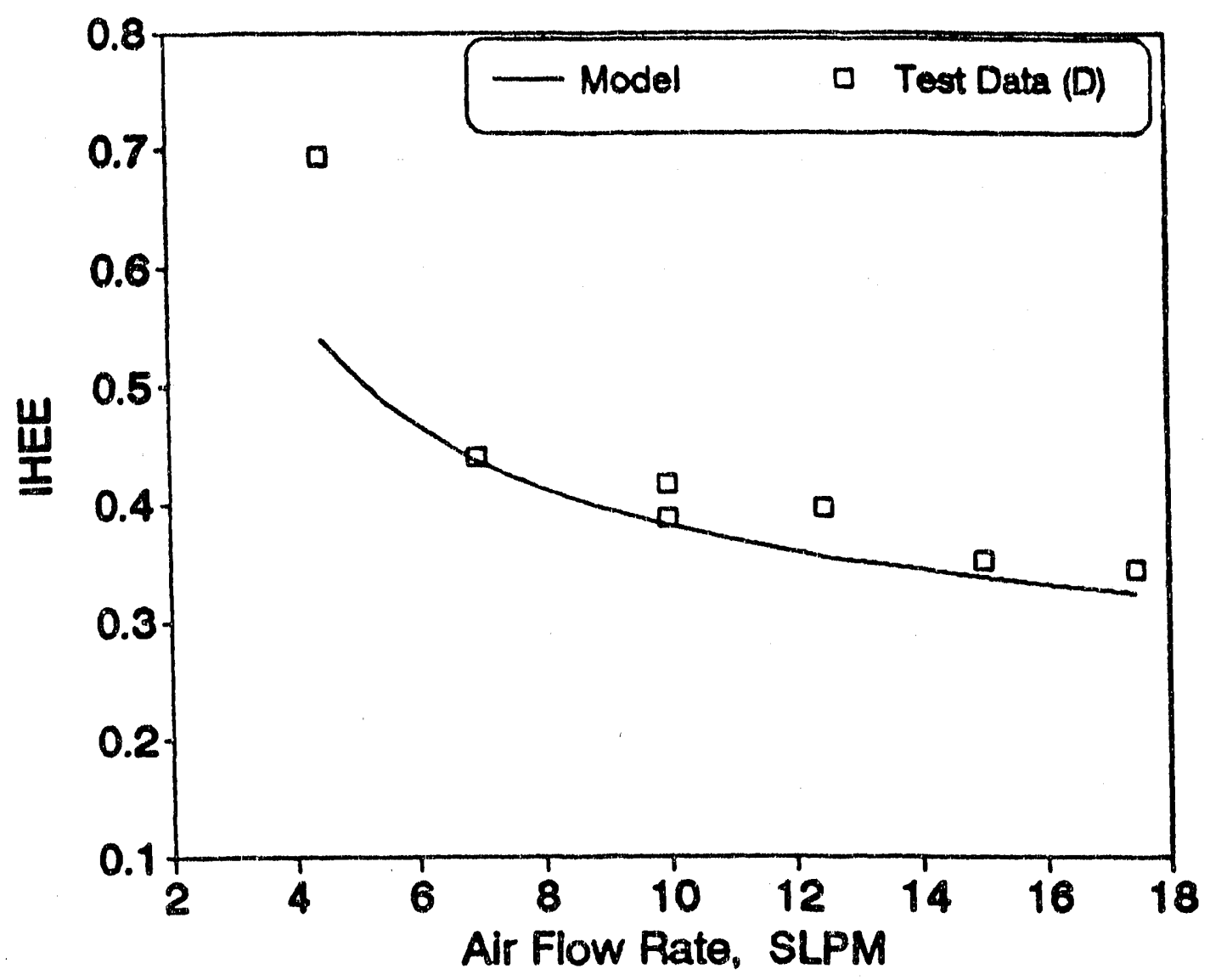

Fig. 60. IHEE for Configuration D: Comparison Between Model and Experiment 


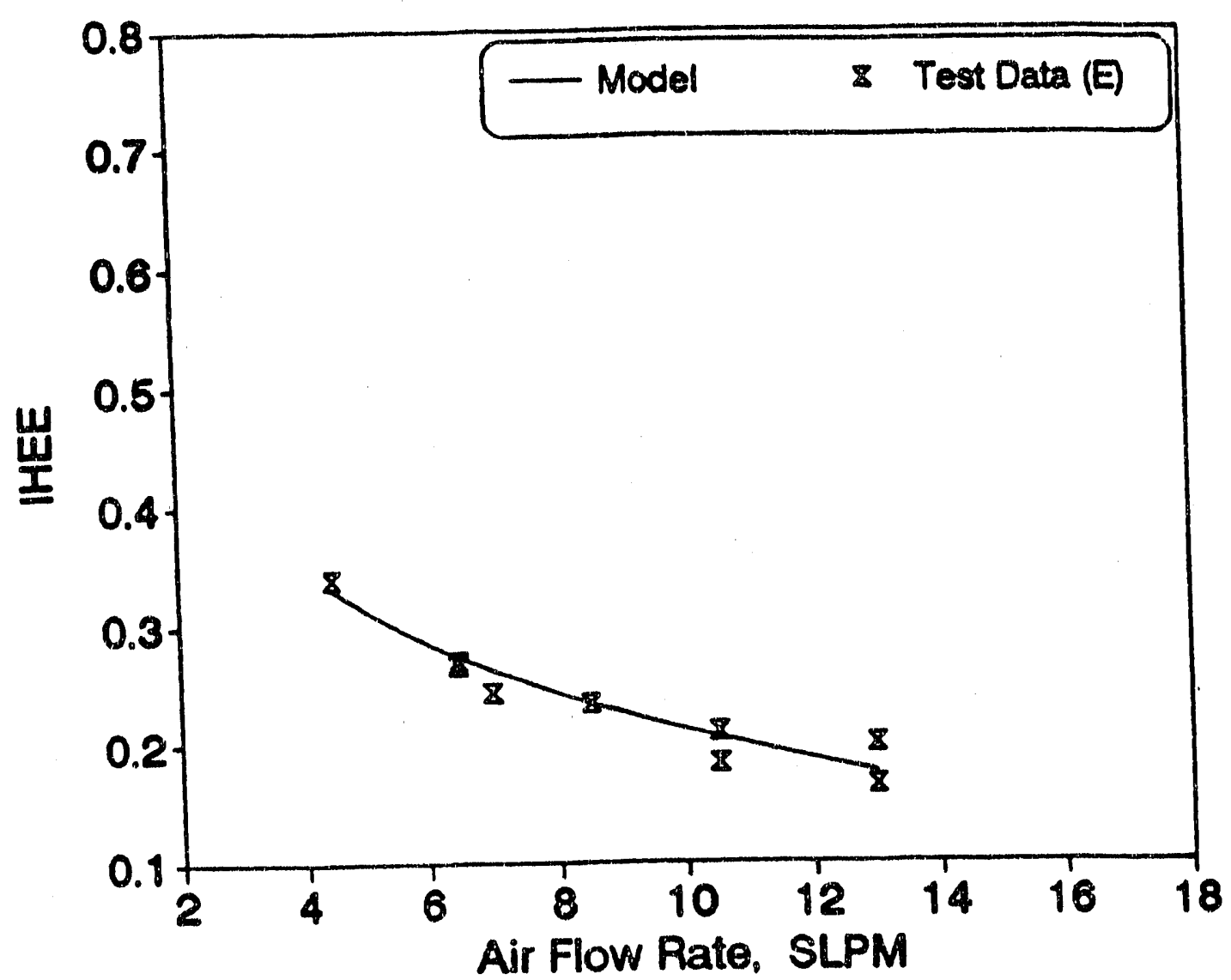

Fig. 61. IHEE for Configuration E: Comparison Between Model and Experiment 


\section{CHAPTER VIII}

\section{CONCLUSIONS AND RECOMMENDATIONS}

The actual energy consumption due to air infiltration in a test cell and in a well-characterized stud-cavity wall specimen has been studied experimentally and analytically. The conclusions drawn from this investigation are presented and discussed in this chapter. The benefits and limitations of this study as weil as recommendations for future work are presented.

\section{CONCLUSIONS}

Infiltration is customarily assumed to increase the heating and cooling load of a building by an amount equal to the mass flow rate of the infiltration times the enthalpy difference between the inside and outside air - with the latent portion of the enthalpy difference sometimes neglected. Calorimetric measurements conducted on a small test cell and a single stud-cavity wall test specimen with measured amounts of infiltration introduced under a variety of conditions show convincingly that infiltration can lead to a much smaller change in the energy load than is customarily calculated. The data also suggest that the phenomenon occurs in full-sized houses as well.

Infiltration Heat Exchange Effectiveness (IHEE), $\epsilon$, is introduced as a measure of the effectiveness of a building envelope in recovering heat otherwise lost (or gained) due to infiltration. Measurements clearly show that air flow through frame construction can exhibit significant heat exchange, substantially reducing the energy requirements on a test cell due to infiltration. Infiltration Heat Exchange 
Effectiveness increases as :
a) flow rate decreases;
b) flow path longth increases;
c) hole/crack size decreases.

There is a clear corrolation between large values of $e$ and large values of the exponent, $n$, so fan presstirization results may be usoful in predicting $\epsilon$ for buildings.

Infiitration fisat Exchange Effoctiveness values as large as 0.8 have been measured, which indicate that for very tight construction, it is possible that conventional estimates of the infiltration load based on air exchange estimates could be in error by as much as a factor of 5 . For the range of values of the pressur. ization exponent n typically measured in houses, values of IHEE measured in the test cell were smaller but still suggest that estimates of infiltration load based on air exchange rates are likely to systematically overestimate infittration loads by an average of 20 percent or more. Examination of the dependence of IHEE on flow rate and flow exponent suggests that for typical flow rates, the flow exponent may provide useful predictive information regarding the size of IHEE and can be incorporated into a procedure for moditying infiltration load calculation procedures for houses after further experimental and theoretical research.

Measurements for various air flow rates, and incorporating a variety of inlet and outlet conflgurations on the stud-cavity test specimen, indicate similar generalized trends for c. Infittration Heat Exchange EHectiveness increases as:
a) flow rite decreases;
b) flow path length increases. 
A careful study of the experimental data indicated clear correlation between $\epsilon$ and the air flow rate along with the effective path length for the flow. A procedure has been developed for defining the effectlve path length for typical alr flow conflgurations in terms of the changes in the interior temperature distribution within the insulation filled wall section.

A simplified model which incorporates macroscopically observable and a characterizable feature of wall structures, viz., effecttve path length etc., was investigated to complement the experimental study. The objective was to improve the ability to predict the energy penaity associated with air infiltration in a building envelope. A simplified model based on fundamental heat and mass transfer principles has been developed; 1-dimenslonal flow with idealized conditions was assumed. The model predicts the IHEE values as a function of air flow rate and effective path length. The predicted dependence of $\epsilon$ on air flow rate and effective path length for the configurations tested was consistent with the experimental results, although the model under-predicted the IHEE values for two of the configurations. For shorter path lengths the agreement between the model and the test data was much closer. At small flow rates disagreement between the model and the experimental data increased; however, the experimental uncertainty increased rapidly at extremely small flow rates. For a flow arrangement with a very short path length, the IHEE values measured were larger than expected (intuitively), but were in agreement with the model predictions. This counter-intultive phenomenon occurred for configuration $E$ where a straight-across flow outtet was incorporated. 


\section{BENEFITS}

The benefits and impact of the outcome of such an investigation are expected to be quite significant in building science and in the HVAC area. They include:

(a) better prediction of heating and cooling loads of building systems;

(b) more accurate equipment sizing;

(c) improved building tightening criteria;

(d) more insight into the fundamental understanding of

(I) attlc behavior (and radiant barriers);

(ii) Insulation behavior;

(e) economics of ventilation air heat exchangers vs. exhaust fans;

(f) potential indoor air quality issues;

(g) better accuracy in calibrated hot box measurements due to modified infiltration load.

\section{RECOMMENDATIONS}

The experiments on the well-characterized stud-cavity were quite sensitive to the space temperatures; closer control over these temperatures is desirable in future tests. More accurate measurement of the temperature of the air exiting 
the stud-cavity should be undertaken. The current mothod introduced a signiffcant bias toward the hot space temperature. For convenience:

i) the space around the wall section needs to be increased so that access to several areas, viz. the In!et and outlet locations, cold side thermocouples, clrculating fans, etc., becomes easier,

ii) the sealing arrangement at the front of the calibrated hot box using polyethylene sheet, caulk and plywood planks bolted into the edges needs to incorporate a different design so opening and closing of the test apparatus become easier, quicker and more airtight.

There are several limitations of the model that can be noted; the physical flow pattern inside the stud-cavity wall specimen is 3-dimensional in nature and future simulation work should incorporate a more elaborate multi-dimensional approach. The mathematical model in its present form assumes no heat exchange during the horizontal travel of air inside the wall section. This needs to be modified to a more realistic assumption. The effect of the crack size does not appear in the current model; this needs to be introduced.

Studies on different building components have to be continued followed by measurements on real houses and test houses in the open to confirm the findings of this dissertation and also to extend the knowledge on the effect of other parameters on $\epsilon$. The effects of seasonal variation and also of the simultaneous presence of infiltration and exfiltration at varying temperature differences across the walls are some of the parametric studies that can be undertaken in the future. Future studies should also include extensive dynamic testing starting from simple components and then moving on to more complex assemblies. 


\section{REFERENCES}

[1] Etheridge, D.W., "Crack Flow Equations and Scale Effect," Bullding and Environment, vol. 12, no. 3, 1977, pp. 181.189.

[2] Caffey, G.E., "Residential Air Infiltration." ASHRAE Transactions, vol. 85, part 1, 1979, pp. 41-57.

[3] Persily, A., "Understanding Air Infiltration in Homes," Report PU/CEES * 129. Princeton University Conter for Energy and Environmental Studies, NJ, February, 1982, 335 pp.

[4] Baker, P.H., Sharples, S. and Ward, I.C., "Air Flow Through Cracks," Bullding and Environment, vol. 22, no.4, 1987, pp. 293-204.

[5] Foustel, H.E. and Kendon, V.M., "Infiltration Models for Multicellular Structures - A Literature Review," Energy and Buildings, vol. 8, 1988, pp. 123-136.

[6] Liddament, M. and Allen, C., "The Validation and Comparison of Mathematical Models of Air Infiltration," Technical Note AIC 11, Air Infiltration Centre, Berkshire, England, 1983.

[7] Claridge, D.E. and Bhattacharyya, S., "The Measured Energy Impact of Infiltration in a Test Cell," Journal of Solar Energy Engineering, vol. 112, 1990, pp. 132-139.

[8] Anon., "Dynamic Insulation : the Next Step?", Australian Refrigeration, Air Conditioning and Heating. November, 1984, pp.47.

[9] Arquis, E. and Langlais, C., "What Scope for 'Dynamic insulation'?," Batiment International Building Research and Practice, vol. 19, 1986, pp. 84-93.

[10] Guo, J. and Liu, M.S." "The Energy Saving Effect of Double Frame Windows," Proceedings of the CLIMA 2000 World Congress on Heating, 
Ventllating and Air-Conditioning, vol. 2, Copenhagen, Denmark, 1985, pp. 84-97.

[11] Timusk, J., Seskus, A.L., and Lio, M., "Performance Evaluation of the Dynamic Wall House," Project Report prepared by Centre for Bullding Science, University of Toronto, Toronto, Canada, 1987, 51 pp.

[12] Bailly, N.R., "Dynamic Insulation Systems and Energy Conservation in Buildings," ASHRAE Transactlons, vol. 93, part 1, 1987, pp. 447-466.

[13] Dubois, P., "Energy Efficient Building Walls," Proceedings of the First E.C. Conference on Solar Collectors in Architecture, Venice, Italy, 1983, pp. 144-158.

[14] "ASHRAE Handbook: 1985 Fundamentals," American Soclety of Heating, Refrigerating and Air-Conditioning Engineers, Atlanta, GA, 1985, Chap. 28.

[15] "DOE-2 Reference Manual," Los Alamos Sclentific Laboratory, Los Alamos, NM, 1980.

[16] "SERI-RES : Solar Energy Research Institute Residential Energy Simulator," version 1.0, Solar Energy Research Institute, Golden, CO, 1982.

[17] Beyea, J., Dutt, G. and Wotecki, T., "Critical Significance of Attics and Basements in the Energy Balance of Twin Rivers Townhouses," Energy and Bulldings, vol. 1, 1977, pp. 261-269.

[18] Harrje. D.T., Dutt, G. and Beyea, J., "Locating and Eliminating Obscure but Major Energy Losses in Fiesidential Housing," ASHRAE Transactions, vol. 85, part 2, 1973, pp. 521-59.

[19] Claridge, D.E., Jeon H. and Bida, M., "Performance Analysis of the Colorado 50/50 Retrofit Program." vol. I. Submitted to the sutwar Energy Research Institute by the University of Colorado. Dept. of Civil, Env. \& Arch. Engineering, February, 1984, 82 pp. 
[20] Claridge, D.E., Jeon H. and Bida, M., "A Comparison of Traditional Degree-Day and Variable-Base Degree-Day Predictions with Measured Consumption of 20 Houses in the Denver Area," ASHRAE Transactions, vol. 91, part 2, 1985, pp. 865-874.

[21] Anderlind, G., "Energy Consumption Due to Air Infiltration," Proce日dings of the 3rd ASHRAE/DOE/BTECC Conference on Thormal Performance of the Exterlor Envelopes of Bulldings, Clearwater Beach, FL, 1985, pp. 201-208.

[22] Anderlind, G. and Johansson, B., "Dynamic Insulation : A Theoretical Analysis of Thermal Insulation through which a Gas or Fluid Flows," Document D8:1983, Swedish Councll for Bullding Research, Stockholm. Sweden, 1983, 69 pp.

[23] Kohonen, R., "Thermal Effects of Airflows and Molsture on Exterior Wall Structures," Proceedings of the 3rd ASHRAE/DOE/BTECC Conference on Thermal Performance of the Exterior Envelopes of Buildings, Clearwater Beach, FL, 1985, pp. 583-605.

[24) Kohonen, R. and Virtanen, M., "Thermal Effects of Air Leakages on the Thermal Performance of Building Structures," Technical Research Center of Finland, Laboratory of Heating and Ventilating, Espoo, Finland, 1985, 21 pp.

[25] Kohonen, R., Ojanen, T. and Virtanen, M., "Thermal Coupling of Leakage Flows and Heating Load of Buildings," 8th AIVC Conference on Ventilation Technology - Research and Application, Uberlingen, West Germany, 1987, pp. 10.1-10.22.

[26] Kohonen, R. and Virtanen, M., "Thermal Coupling of Leakage Flows and Heating Load of Buildings," ASHRAE Transactions, vol. 93, part 2, 1987, pp. 2303-2318.

[27] Berlad, A.L., Tutu, N., Yeh, Y.J., Jaung, R., Krajewski, R., Hoppe, R. and Salzano, F.J., "Air Intrusion Effects on the Performance of Permeable Insulation Systems," Thermal Insulation Performance, ASTM STP 718, 
American Society for Testing and Materials, Philadelphia, PA, 1980, pp. 181-194.

[28] Berlad, A L., Tutu, N., Jaung, R. and Yeh, Y.J., "Interim Progress Report on an Investigation of Energy Transport in Porous Insulator Systems," Department of Mechanical Engineering, SUNY, Stony Brook, NY, October, 1979, $37 \mathrm{pp}$.

[29] Berlad, A.L., Jaung, R., Joshi, N. and Westerinen, J., "Energy Transport in Porous-Insulator Systems - Performance of Vertical Enclosures," Oak Ridge National Lab., TN, August, 1982, 39pp.

[30] De Gids, W.F., "Influence of Different Parameters in Infiltration Heat Loss," Proceedings of the 2nd AIC Conference on Bullding Design for Minimum Air infiltration, Stockholm, Sweden, 1981, pp. 73-96.

[31] Michell, D. and Biggs, K.L., "Energy Savings Through Reduced Air In" filtration in Houses," Architectural Sclence Review, vol. 27, no. 1, 1984.

[32] Heidt, F.D., Haberda, F. and Trepte, L., "Impact of Air Infiltration and Ventilation on Ensrgy Losses of Buildings," Proceedings of International Congress on Building Energy Management, Povoa de Varzim, Italy, 1980, pp. 201-214.

[33] Nantka, M.B., "Air Infiltration and Ventilation in Relation to the Thermal Performance of Dwelling Houses in Poland," Bullding Service Engineering Research Technology, vol. 7, no. 1, 1986, pp. 11-18.

[34] Persily, A., "Evaluation of an Air-to-Air Heat Exchanger," Environment international, vol. 8, 1982, pp. 453-459.

[35] Nagda, N.L., Koontz, M.D. and Pastor, M.E., "Energy Use, Infiltration, and Indoor Air Quality in Tight, Well-insulated Residences," EPRI Report EAVM-4117, Electric Power Research institute, Palo Alto, CA, June, 1985.

[36] Lecompte, Jan G.N., "The Influence of Natural Convection in an Insulated Cavity on the Thermal Performance of a Wall," Insulation Materials, 
Testing, and Applications, ASTM STP 1030, American Society for Testing and Materials, Philadelphia, PA, 1990, pp. 397-420.

[37] Wolf, S., "A Theory for the Effects of Convective Air Flow through Fibrous Thermal Insulation," ASHRAE Transactions, vol. 72, part 2, 1966, pp. III 2.1-111 2.9 .

[38] Wolf, S., Solvason, K.R. and Wilson, A.G. "Convective Alr Flow Effects with Mineral Wool Insulation in Wood-Frame Walls," ASHRAE Transactions, vol. 72, part 2, i968, pp. III 3.1-III 3.8.

[39] Bankvall, C., "Heat Transfer in Fibrous Materials," Journal of Testing and Evaluation, vol. 1, no. 3, 1973, pp. 235-243.

[40] Burns, P.J., Chow, L.C. and Tien, C.L., "Convection in a Vertical Slot Filled with Porous Insulation," International Journal of Heat and Mass Transfer, vol. 20, 1977, pp. 919-926.

[41] "Standard Test Method for Thermal Performance of Building Assemblies by means of a Calibrated Hot Box," ASTM C976-82, American Society for Testing and Materials, Philadelphia, PA, 1982, 15 pp.

[42] "Standard Test Method for Determining Air Leakage Rate by Fan Pressurization ;" ASTM E779-87, American Society for Testing and Materials, Philadelphia, PA, 1987, 6 pp.

[43] Charlesworth, P.S., "Air Exchange Rate and Air Tightness Measurement Techniques - an Application Guide," Air Infiltration and Ventilation Centre, Berkshire, England, 1988.

[44] Kiel, D.E., Wilson, D.J. and Sherman, M.H., "Air Leakage Flow Correlations for Varying House Construction Types," ASHRAE Transactions, vol. 91, part 2, 1985, pp. 560-575.

[45] Kline, S.J. and McClintock, F.A., "Describing Uncertainties in Singlesample Experiments," Mechanical Engineering, January 1953, pp. 3-7. 


\section{APPENDIX A}

A precise method of estimating uncertainty in experimental results is avallable in the literature [45]. The procedure is based on a careful specification of the uncertainties in the various primary variables that have been measured during the tests. Our dependent variable is the Infiltration Heat Exchange Effectiveness, $\epsilon$, and the primary variables are the various temperatures, the flow rate and the heating power input.

The energy loss model which adequately describes the heat transfer from the hot-space to the ambient and to the cold space by paths outside the experimental sample (stud-cavity) is given by:

$$
Q_{\text {lose }}=1.0249\left(T_{h}-T_{c}\right)+2.3075\left(T_{h}-T_{a}\right)
$$

where $Q_{\text {loes }}$ is in Btu/hr and $T_{h}$ and $T_{c}$ are the hot and cold space temperatures in deg C. The base (UA) value (i.e. at zero flow rate) of the stud-cavity wall specimen is then given by:

$$
(U A)_{0}=\frac{\left(Q_{\text {in }}-Q_{\text {loos }}\right)}{\left(T_{h}-T_{c}\right)}
$$

where $Q_{\text {in }}$ is the total power input, which is the sum of the heater power and the fan power. The base case UA represents the steady-state conductive heat loss coefficient of the stud-cavity. For the base case, $U A=0.8698$ Btu/hr-sq.n.-deg F. The value of $\epsilon$ is calculated from the measured base case $U A$. value and the injected flow rate $\dot{m}$ as: 
TABLE A-1. Measurement Accuracy of Different Variables

\begin{tabular}{|c|c|c|c|}
\hline Variable & Unit & Absolute Uncertainty & Relative Uncertainty \\
\hline$T_{h}$ & deg C & \pm 0.5 & \pm 0.2 \\
\hline$T_{c}$ & deg C & \pm 0.5 & \pm 0.2 \\
\hline$T_{i}$ & deg C & \pm 0.5 & \pm 0.2 \\
\hline$T_{a}$ & deg C & \pm 0.5 & \pm 0.2 \\
\hline$Q_{\text {in }}$ & Watt & \pm 0.203 & \pm 0.203 \\
\hline$\dot{m}$ & SLPM & \pm 0.3 & \pm 0.3 \\
\hline$\epsilon$ (@ 4 SLPM) & & \pm 0.232 & \pm 0.0302 \\
\hline$\epsilon$ (@ 10 SLPM) & & \pm 0.093 & \pm 0.0122 \\
\hline
\end{tabular}

$$
\epsilon=1-\frac{Q_{\text {in }}-Q_{\text {lose }}-\left(T_{h}-T_{c}\right)(U A)_{0}}{\left(T_{h}-T_{i}\right)(U A)_{\text {inf }}}
$$

The numerator of the fraction represents the measured infiltration $U A$ value, while the term $(U A)_{\text {inf }}=\dot{m} C_{\mathrm{p}}$ is the infiltration loss coefficient as usually calculated and $T_{i}$ is the air inlet temperature in deg $\mathrm{C}$.

Let $w_{e}$ be the uncertainty in the result and $w_{T}, w_{Q}$ and $w_{m}$ be the uncertainties in the temperatures, heating power input and air flow rate respectively. Then the uncertainty in $\epsilon$ is given by :

$$
w_{\epsilon}=\left[\left(\frac{\partial \epsilon}{\partial T_{h}^{\prime}} w_{T}\right)^{2}+\left(\frac{\partial \epsilon}{\partial T_{c}} w_{T}\right)^{2}+\left(\frac{\partial \epsilon}{\partial T_{i}} w_{T}\right)^{2}+\left(\frac{\partial \epsilon}{\partial T_{a}} w_{T}\right)^{2}+\left(\frac{\partial \epsilon}{\partial Q_{i n}} w_{Q}\right)^{2}+\left(\frac{\partial \epsilon}{\partial \dot{m}} w_{m}\right)^{2}\right]^{1 / 2}
$$

The individual measurement accuracy of the different parameters is tabu- 
TABLE A-2. Sensitivity of Different Variables

\begin{tabular}{|c|c|c|}
\hline Sensitivity Derivative & (@4 SLPM) & (@10 SLPM) \\
\hline$\frac{\partial_{e}}{\partial T_{\mathrm{h}}}$ & 0.1315 & 0.031 \\
\hline$\frac{\partial T_{i}}{\partial T_{c}}$ & 0.2406 & 0.096 \\
\hline$\frac{\partial_{e}}{\partial T_{i}}$ & 0.0096 & 0.026 \\
\hline$\frac{\partial e}{\partial T_{e}}$ & 0.3684 & 0.147 \\
\hline$\frac{\partial e}{\partial Q_{i n}}$ & 0.1485 & 0.060 \\
\hline$\frac{\partial e}{\partial \dot{m}_{m}}$ & 0.0590 & 0.063 \\
\hline
\end{tabular}

lated in Table A-1 and it can be observed that the uncertainty of IHEE increases quite drastically at low flow rates. Absolute uncertainty is the maximum error specified in the manufacturers' specifications for the various measuring devices. For the thermocouples, calibration tests indicated a lower relative uncertainty and thus a relative uncerlainty of 0.2 for all the thermocouples was assumed. For power and flow rate measuring devices, the relative uncertainty was assumed to be the same as the absolute uncertainty. The sensitivity of different variables is listed in Table A-2 and ambient temperature seems to have the most influence on IHEE. 


\section{APPENDIX 9}

Some of the 3-dimensional temperature distribution plots were presented in Chapter VII; the rest of them are shown in this Appendix. 
Configuration A 4 SLPM

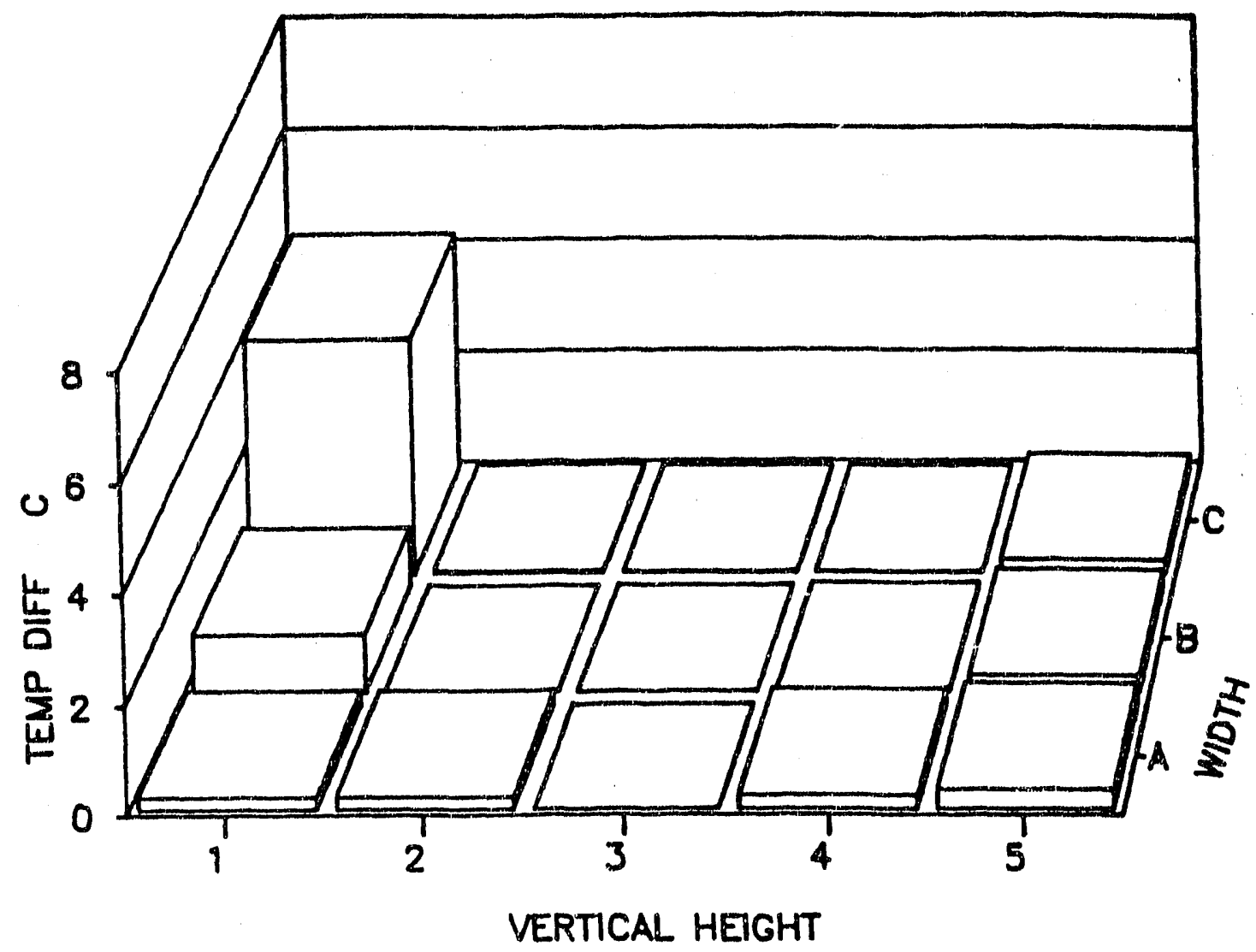




\section{Configuration A 8 SLPM}

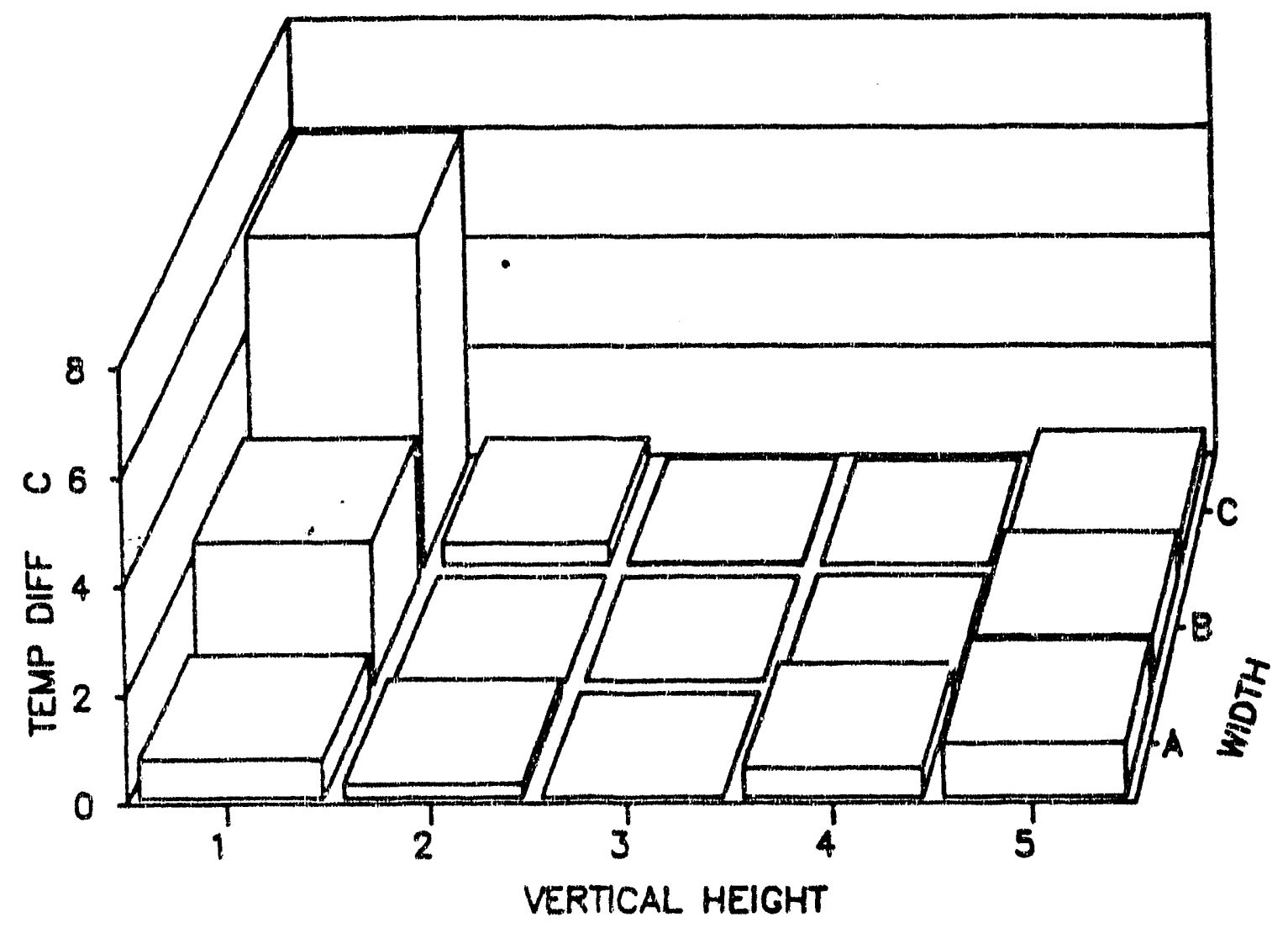


Configuration A 10 SLPM

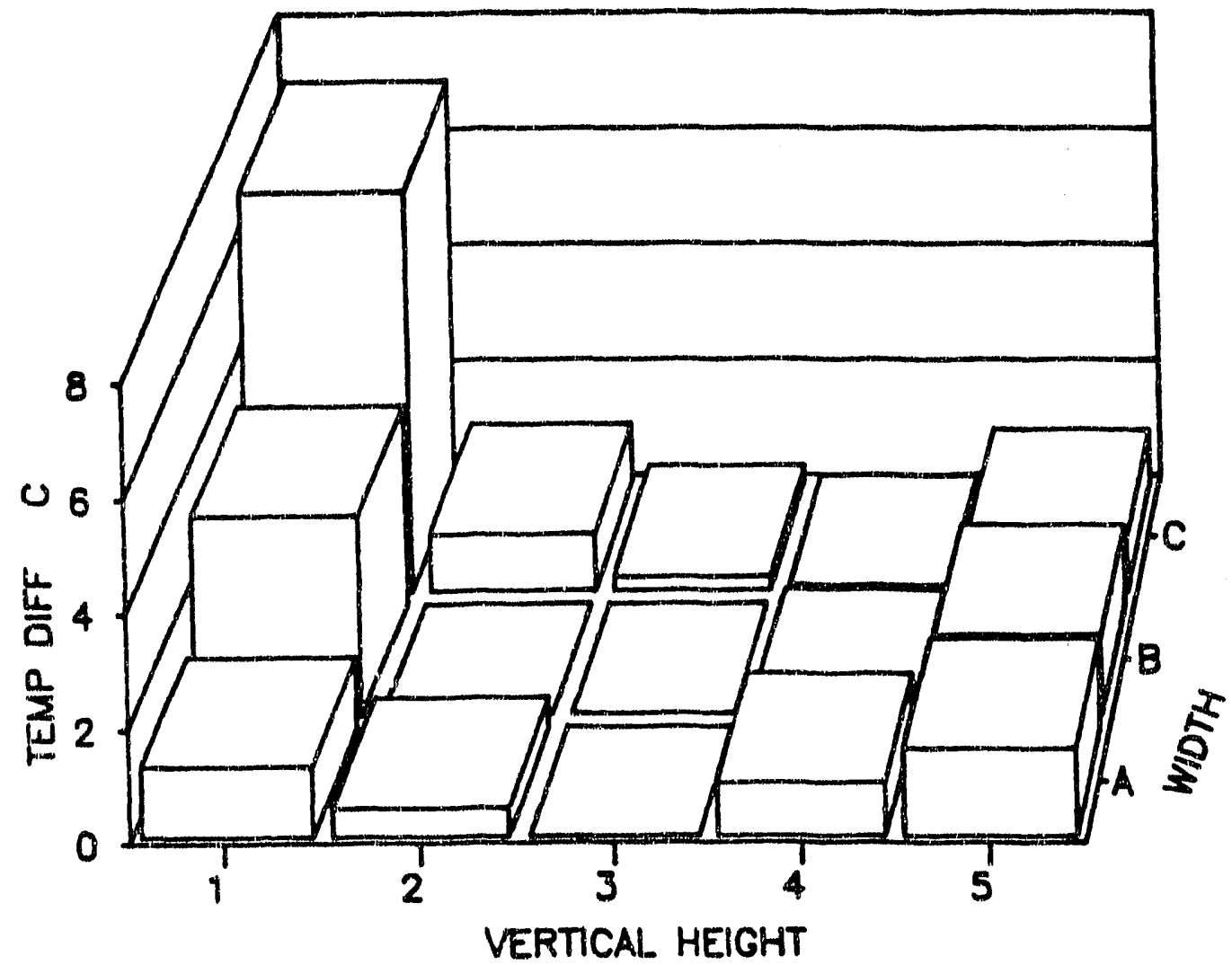




\section{Configuration B 4.5 SLPM}

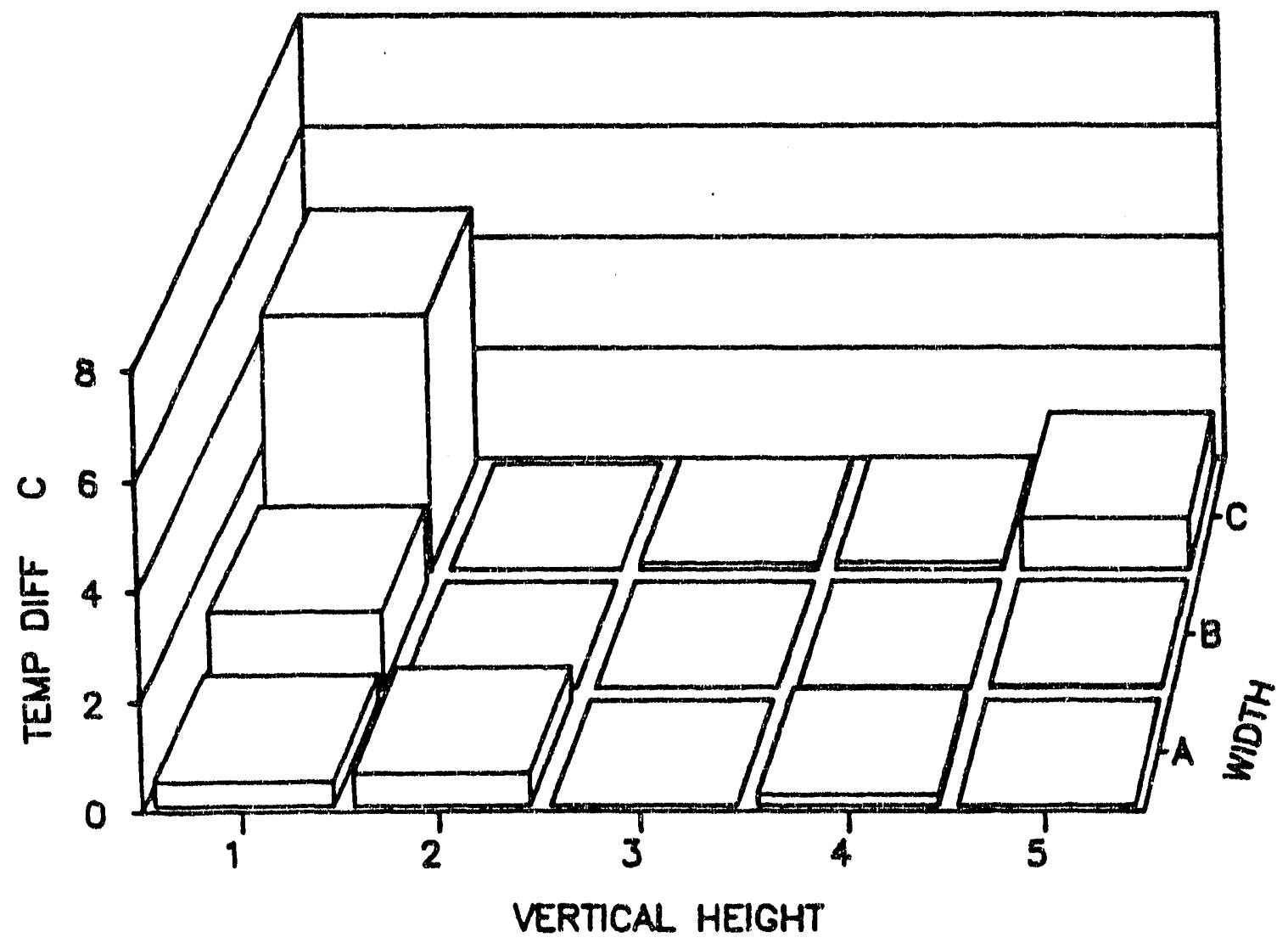


Configuration B 8 SLPM

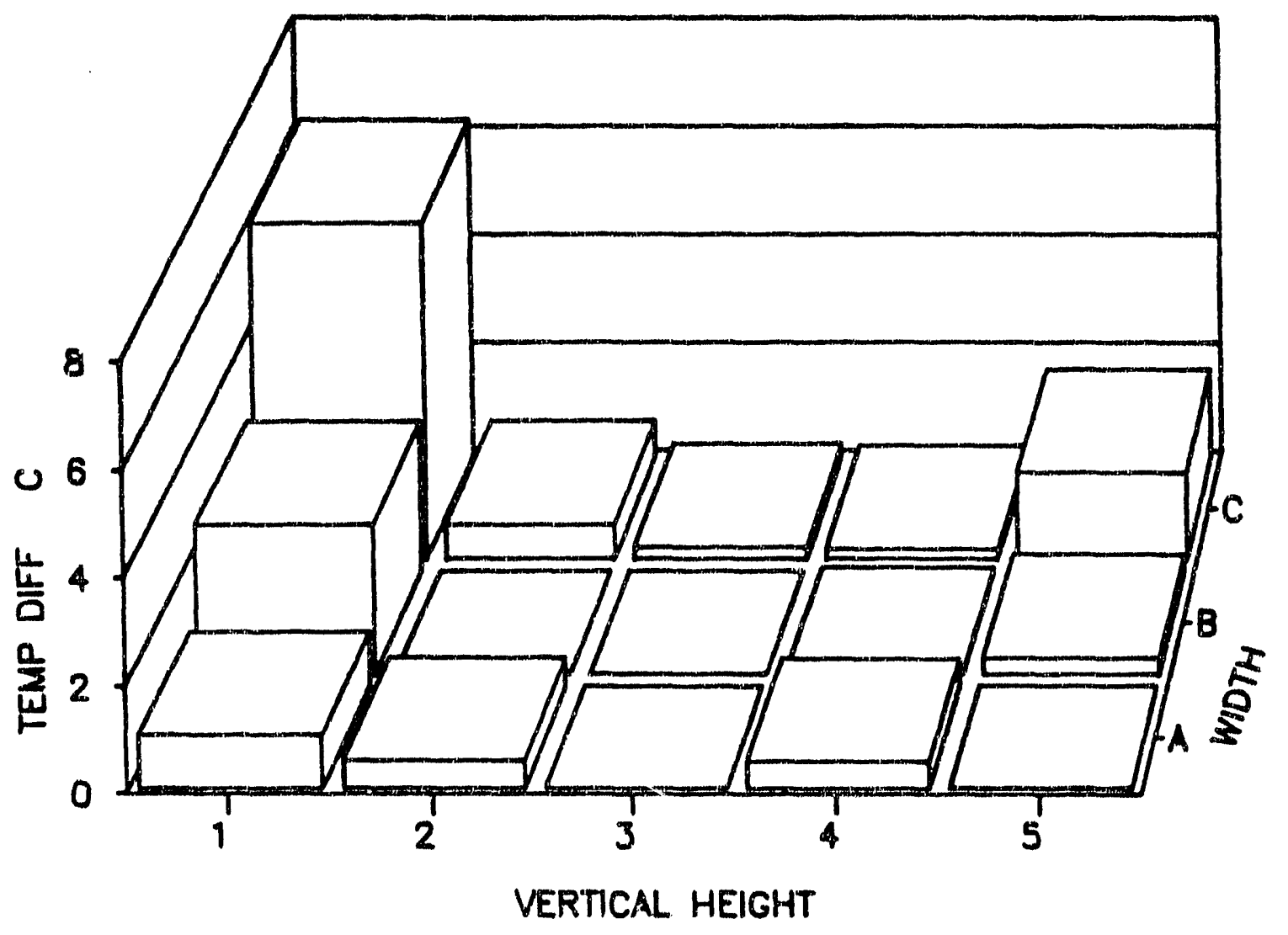




\section{Configuration B 10 SLPM}

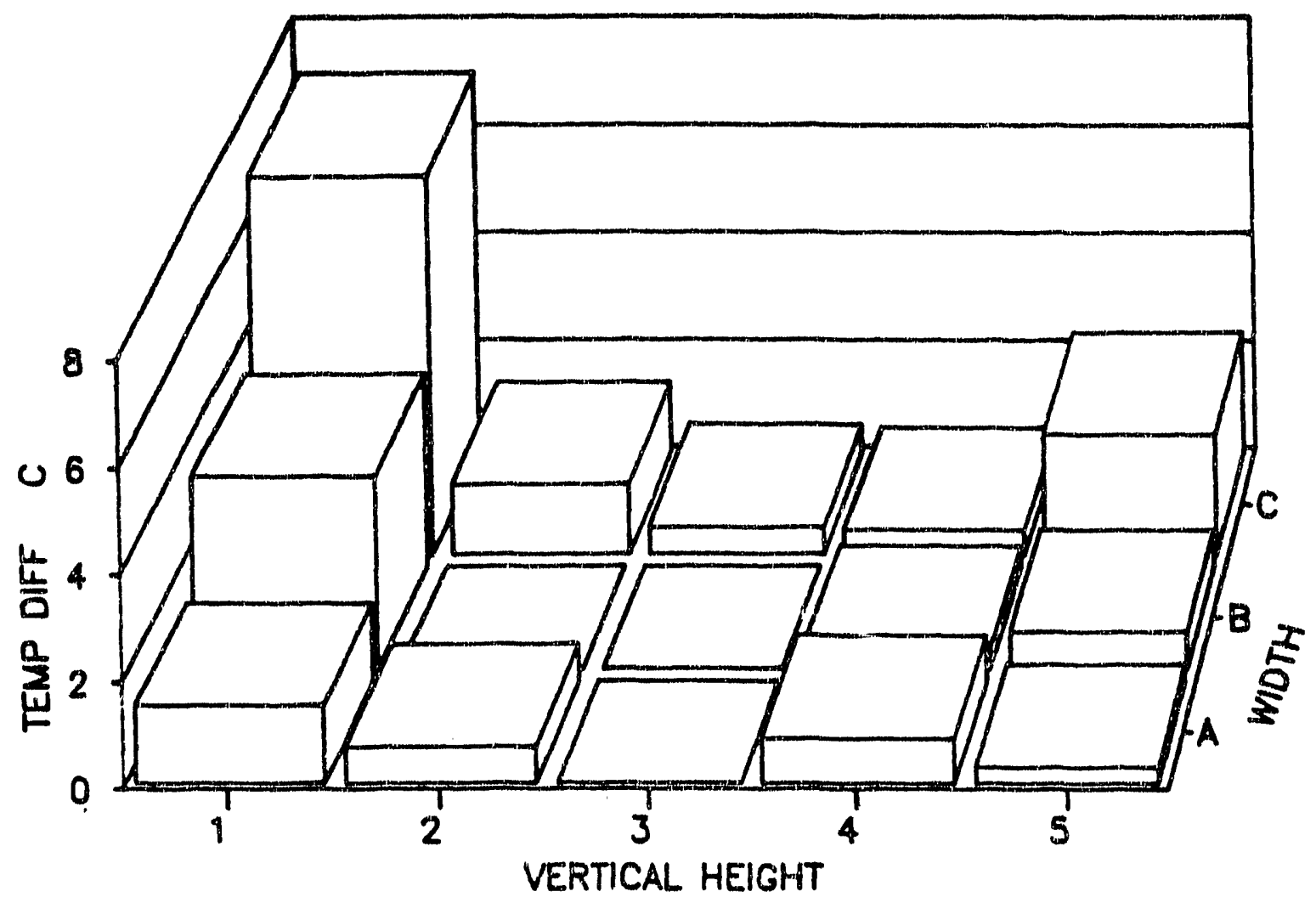


Configuration C 5 SLPM

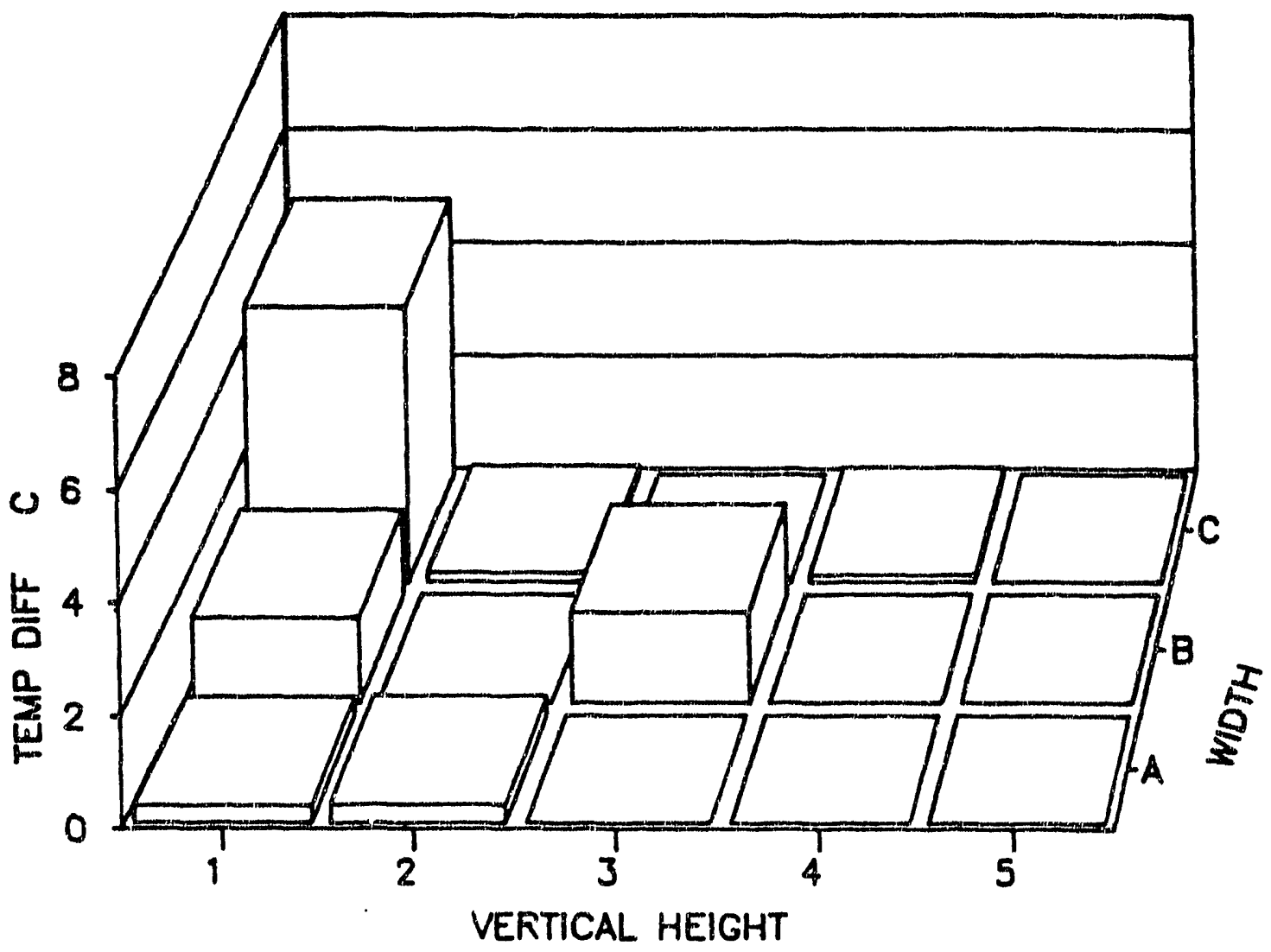


Configuration C 7 SLPM

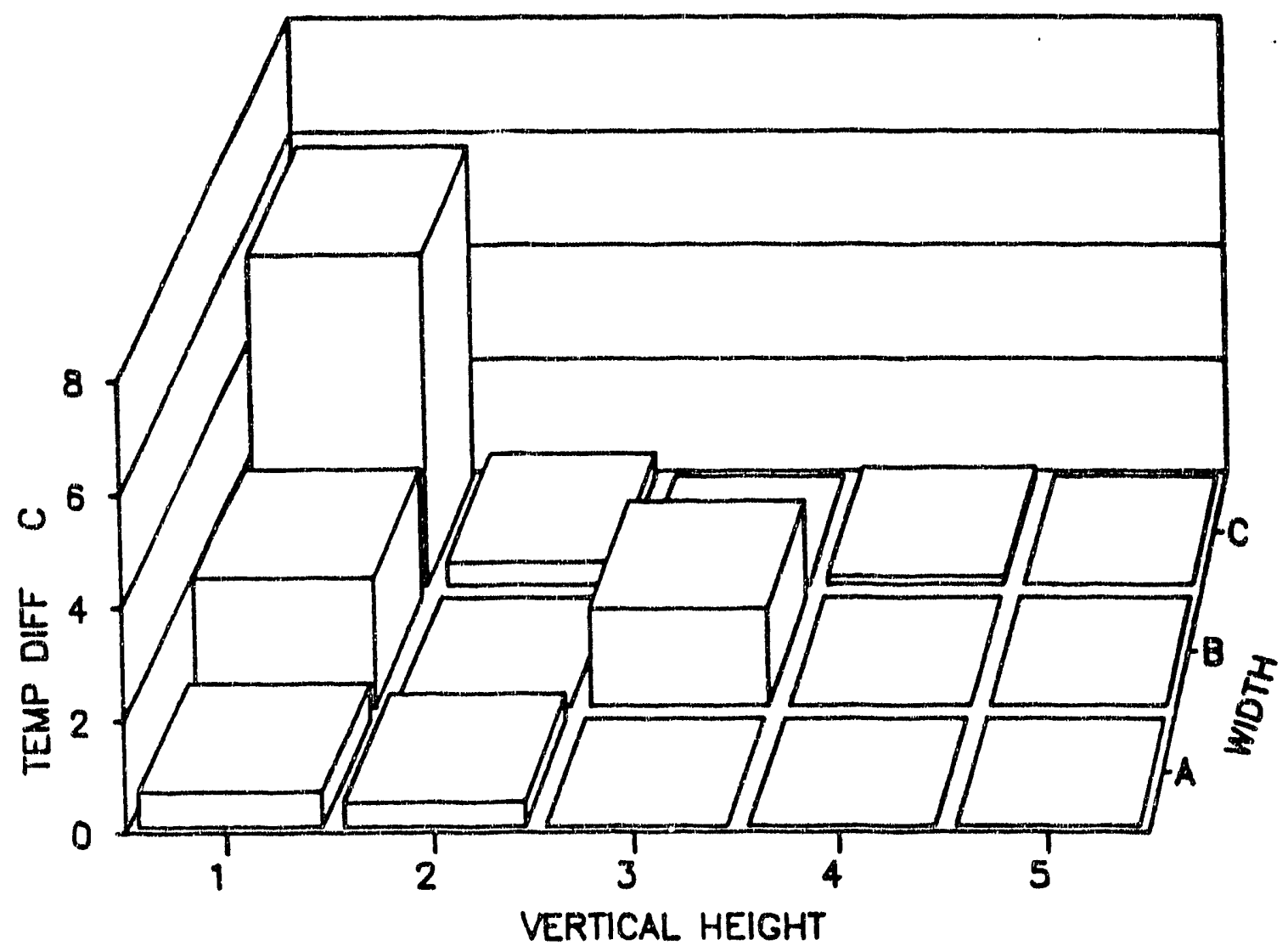




\section{Configuration C 9 SLPM}

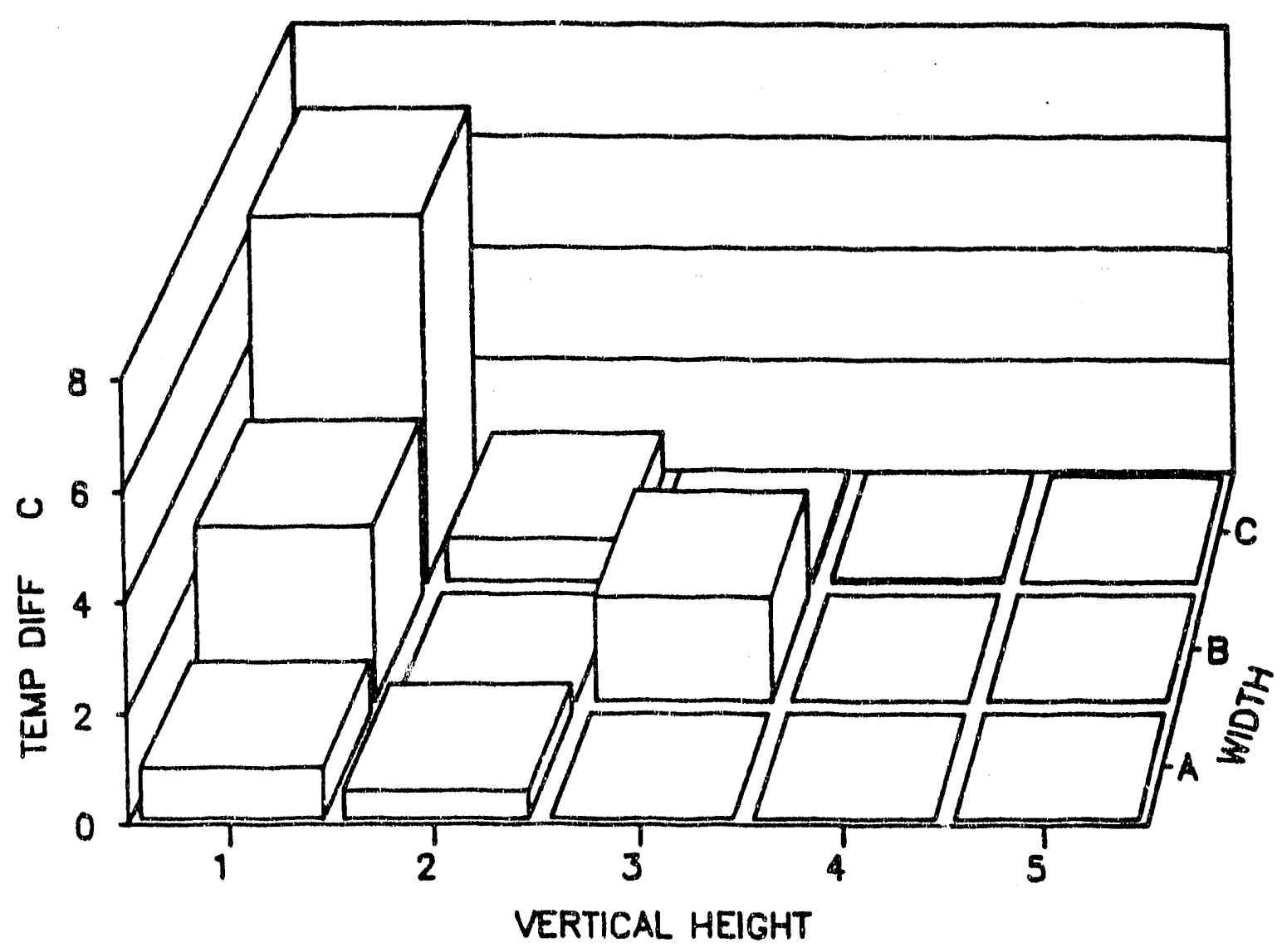


Configuration D 4.5 SLPM

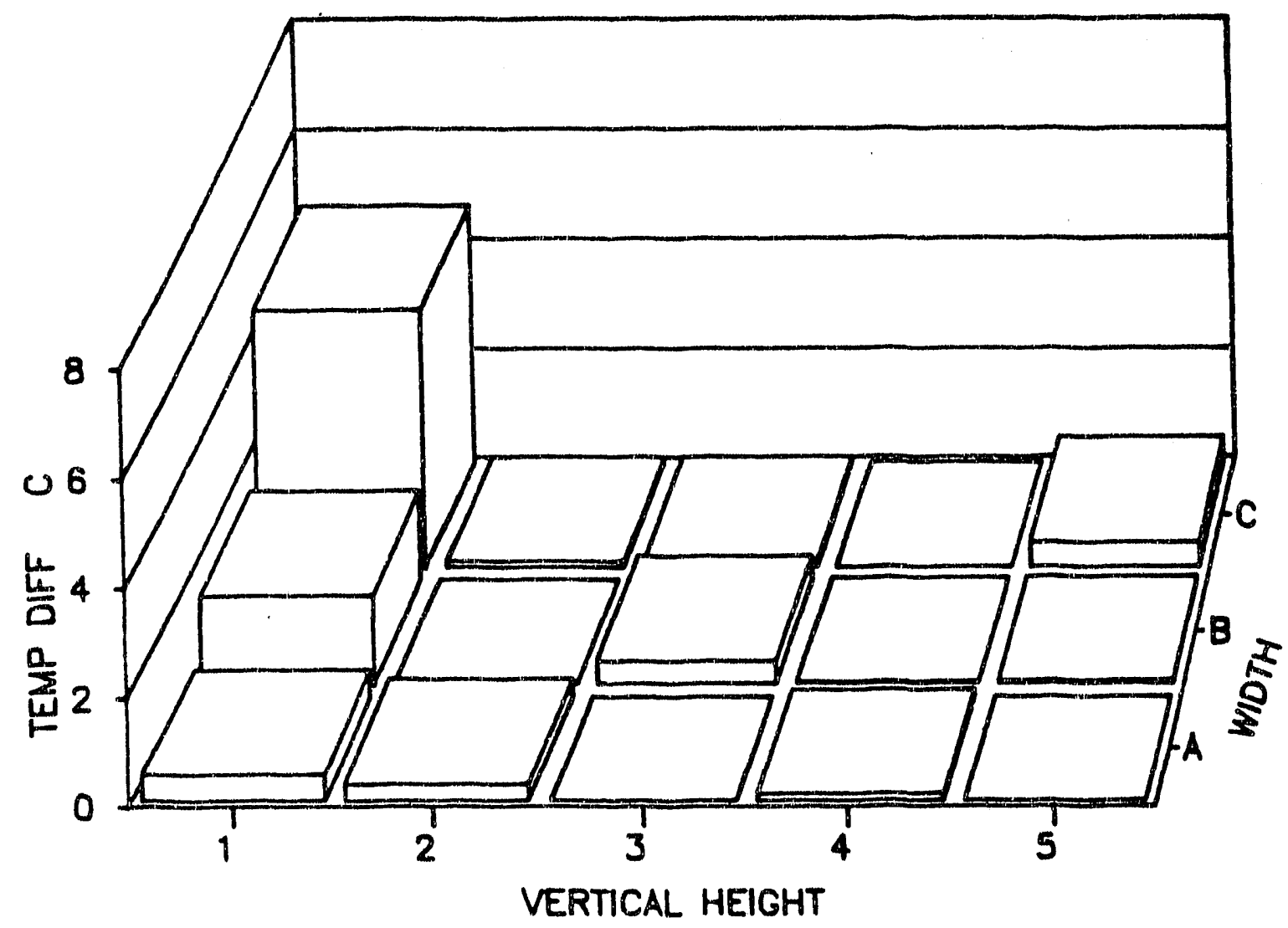




\section{Configuration D 7 SLPM}

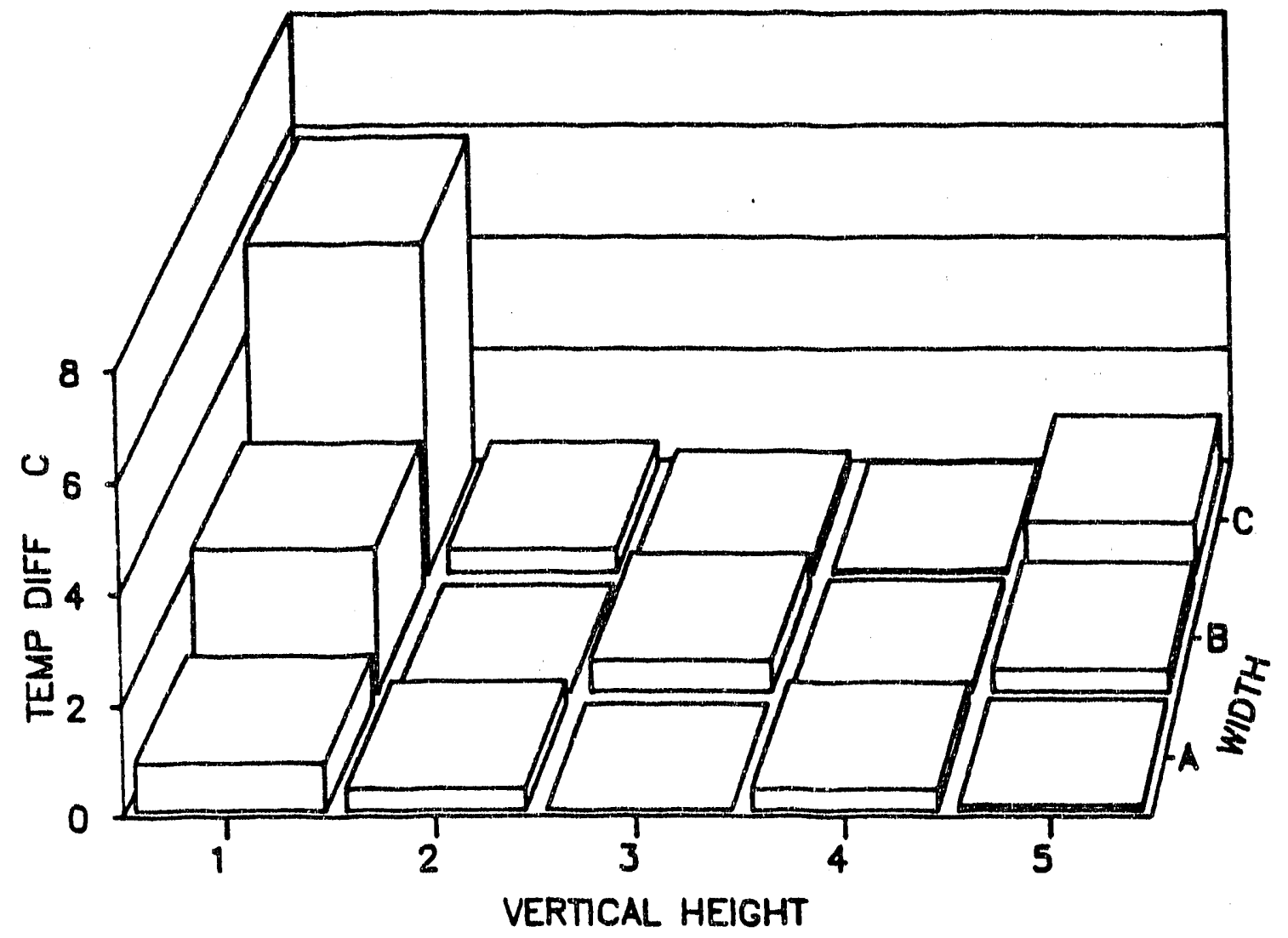




\section{Configuration D 10 SLPM}

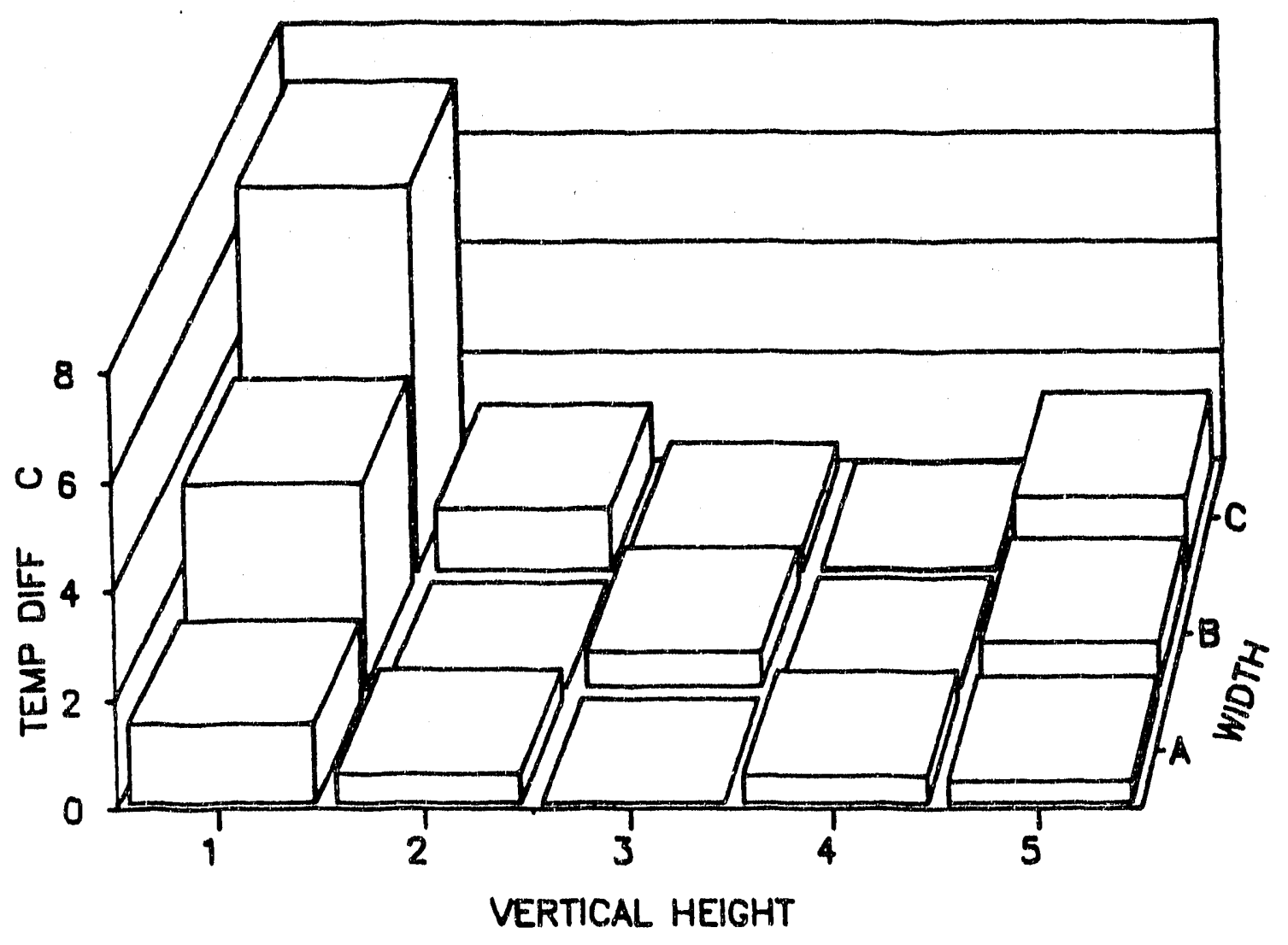




\section{Configuration D 12.5 SLPM}

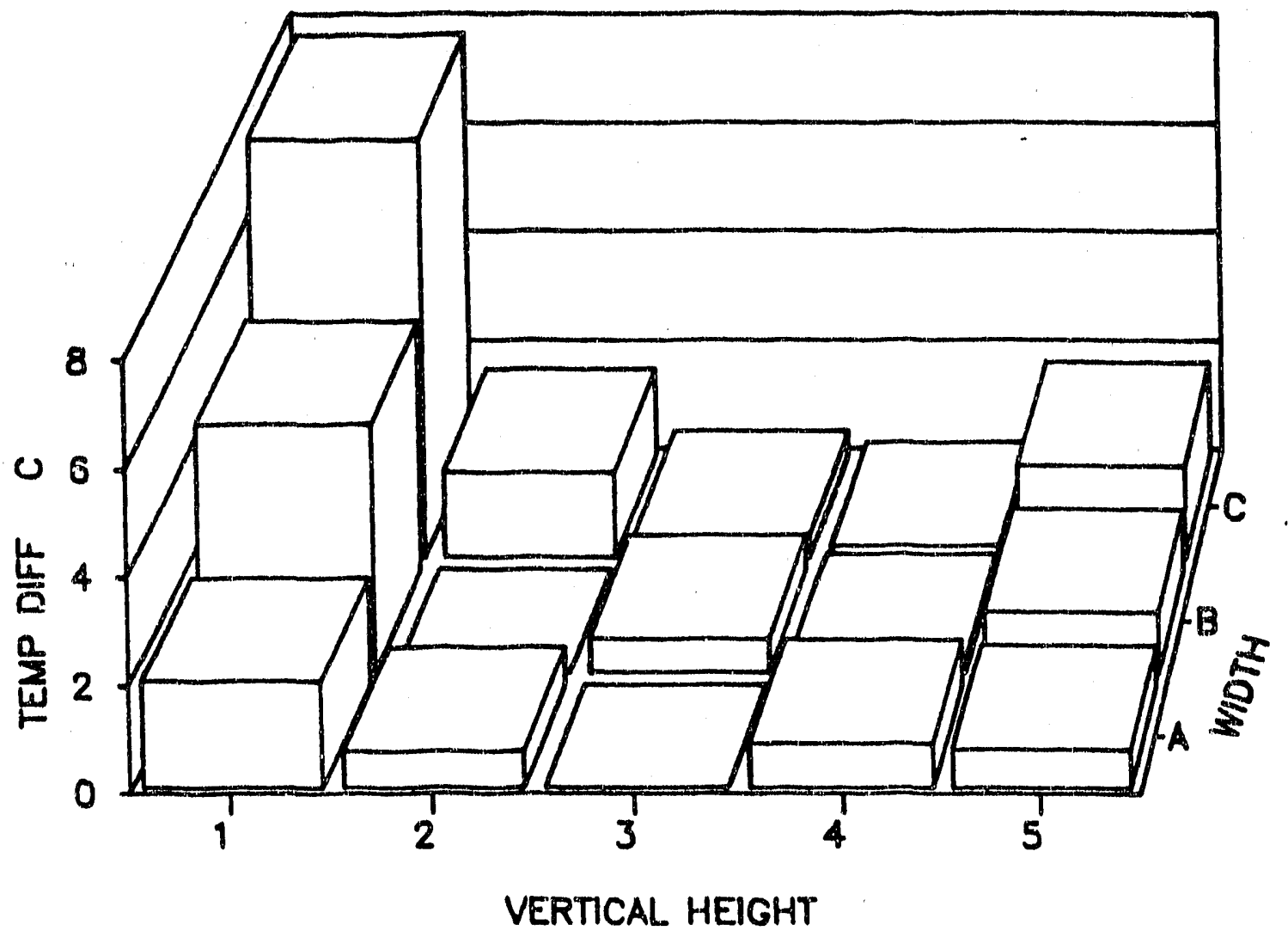


Configuration E 4.5 SLPM

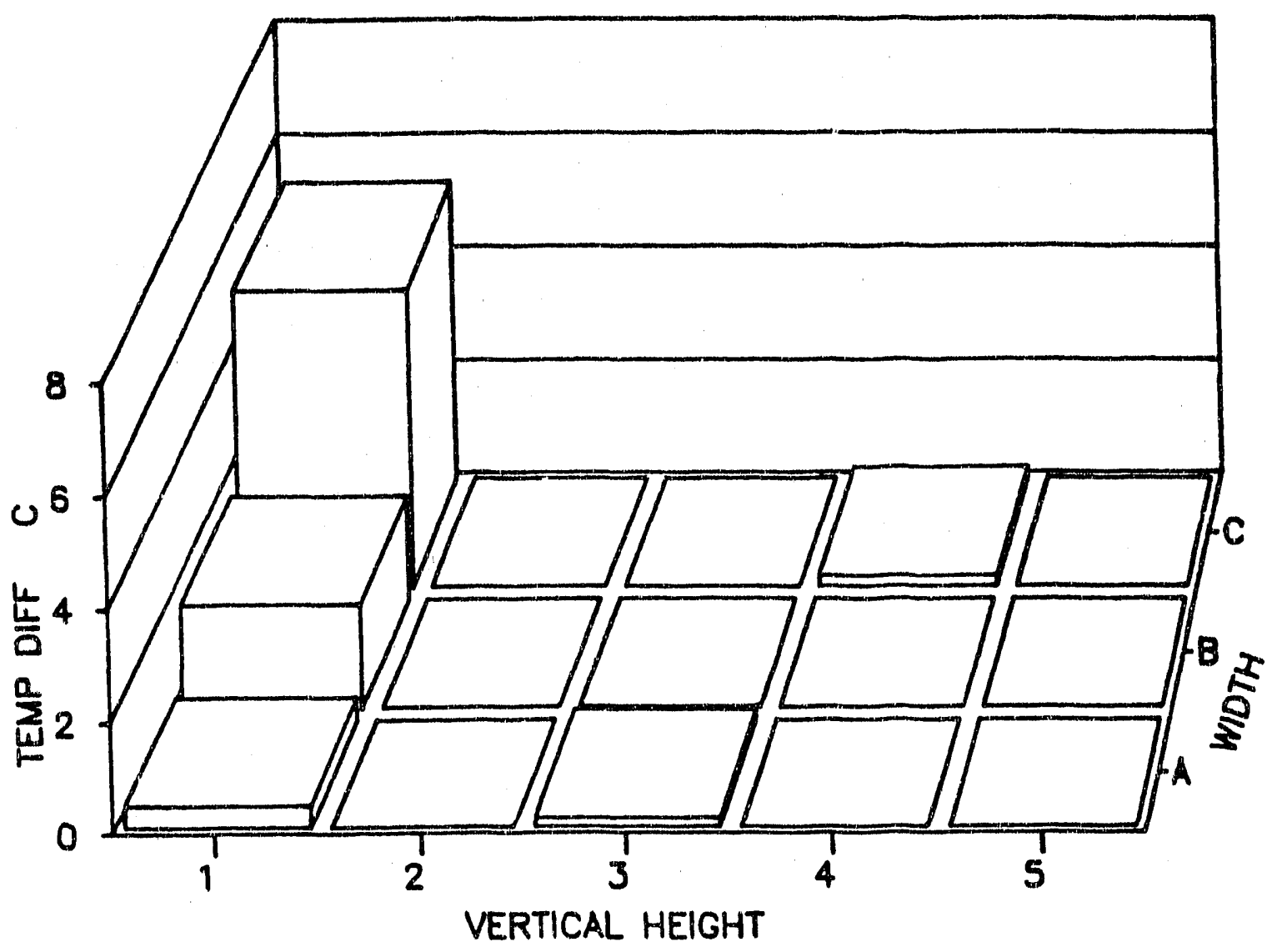


Configuration E 6.5 SLPM

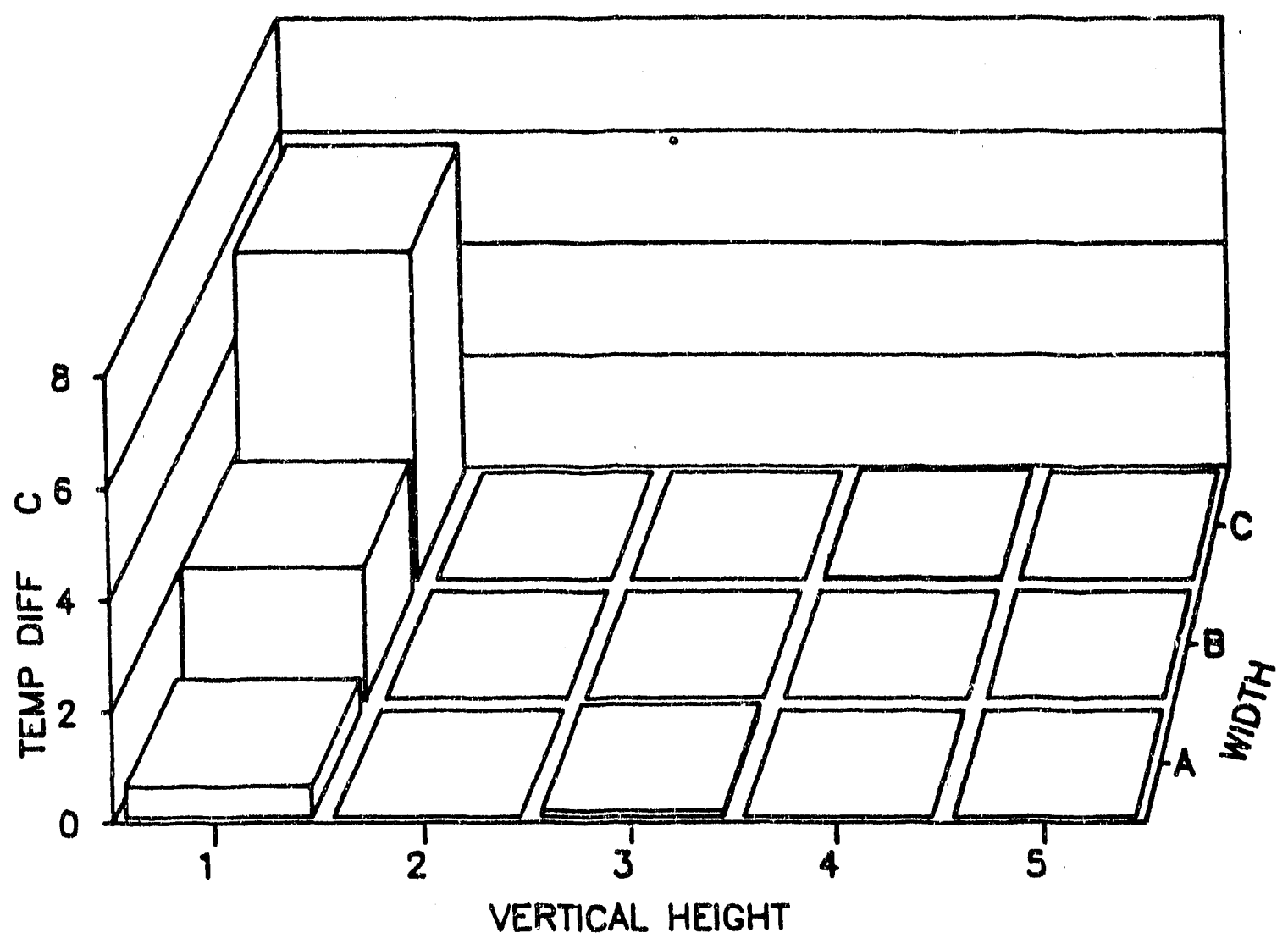


Configuration E 8.5 SLPM

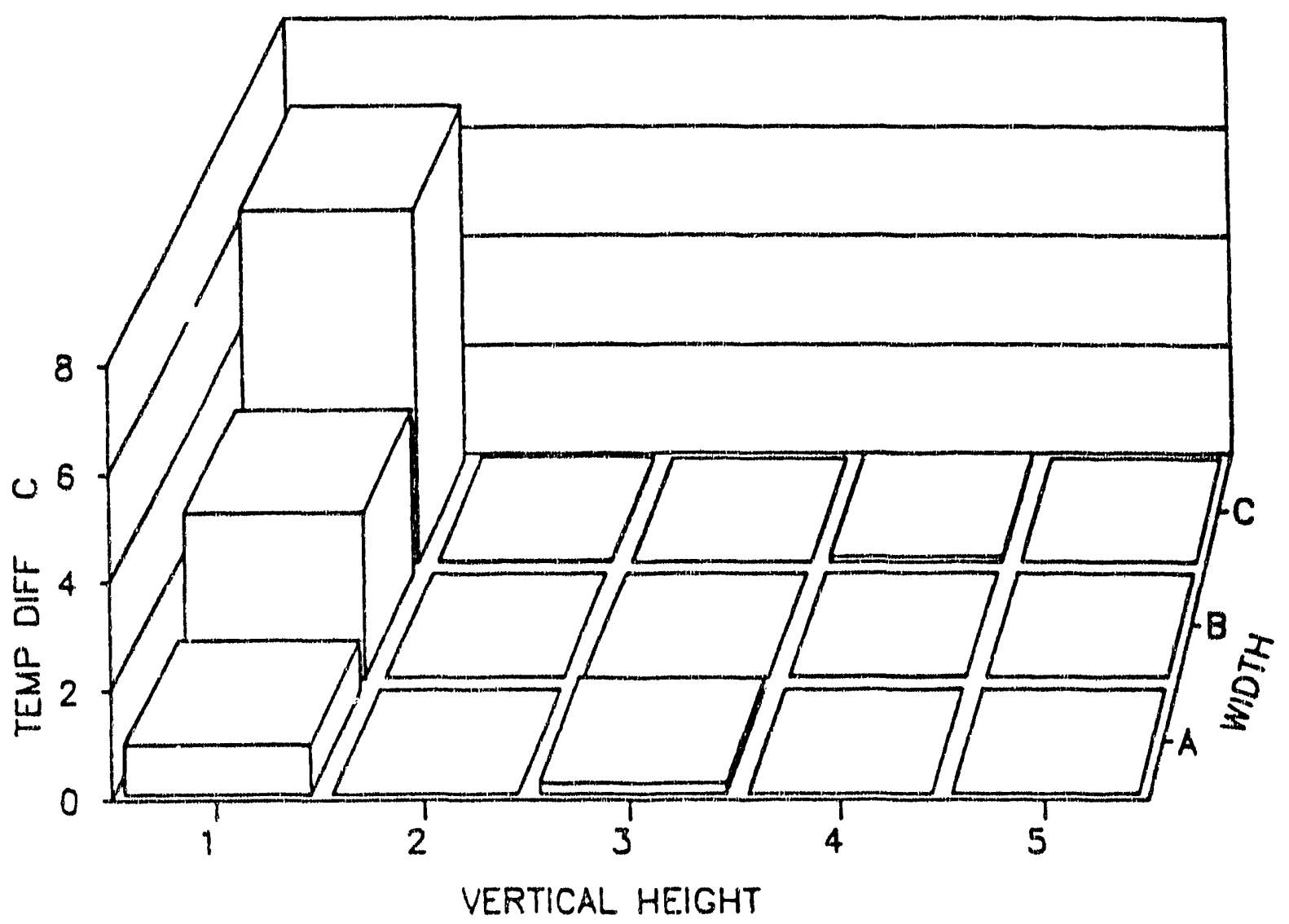




\section{APPENDIX C}

Raw data measured in the steady-state stud-cavity experiments is presented in this appendix. Each block of data is presented for a particular test corrosponding to a specific configuration and a specific flow rate, as mentioned at the top of the block. Each block of data is shown as a matrix consisting of 5 rows (A through $E$ ) and 20 columns. All temperatures are given in degree Celsius.

A1 through D15 are the temperatures measured by the thermocouples 10cated inside the stud-cavity. A1 through A5, A6 through A10 and A11 through A15 correspond to the temperatures measured by thermocouples at locations $A 1, B 1$ and $C_{1}$ in Figure 8. Similarly A16 through A20, B1 through B5 and B6 through $B 10$ correspond to the temperatures measured by the thermocouples at locations A2, 82 and C2 in Figure 8 . The rest of the temperatures are similarty shown.

D16 through E3 represent the lemperatures measured at 8 locations in the cold space and E4 through E11 represent the temperatures measured at 8 locations in the hot space. E12 represents the pressure difference between the stud-cavity interior and the hot/cold space in Pascal. E13, E14, E15 and E16 correspond to the ambient temperature, air inlet temperature, chilled water temperature and air exit temperature respectively. E18, E19 and E20 represent the hot space fan voltage (in Volts), fan current (in Amperes) and fan power (in Watts) respectively. 


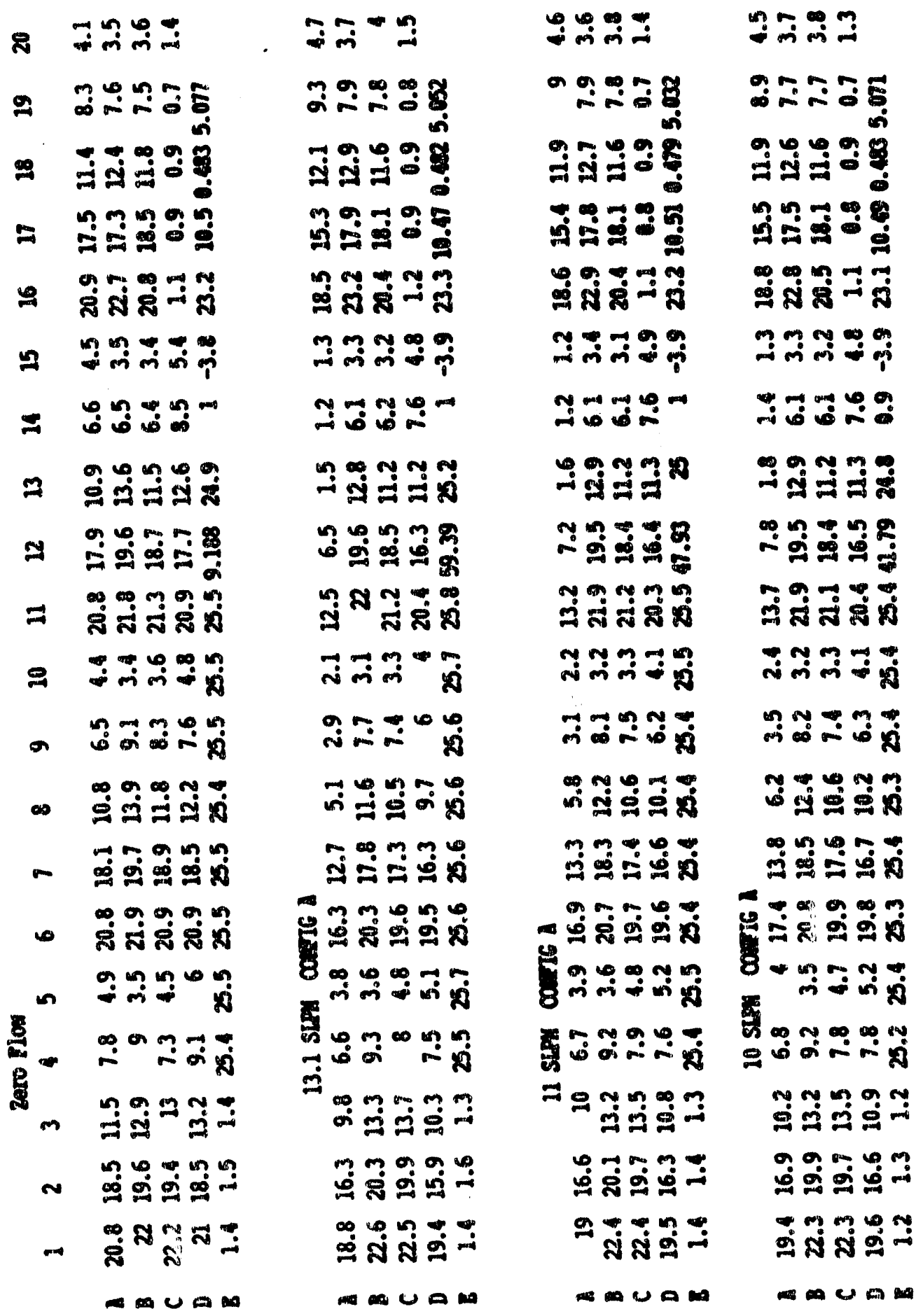


รูำำำ

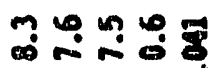

क्ष

ํㅓำㅇํㅇ

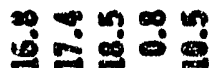

mon

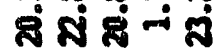

m m m m

$m$ m

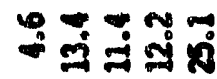

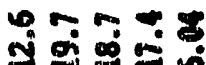

oma.

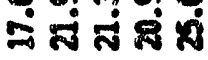

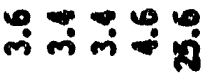

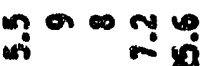

का

$\alpha \min$

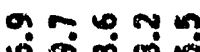

엄

จำ่ำ

แ

क्षे

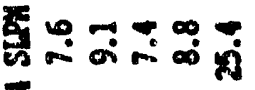

$\rightarrow$

ๆำำ

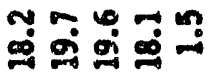

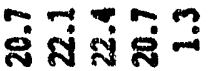

$\infty u$ m

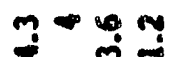

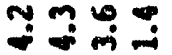

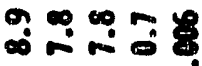

व $\infty$ -

ㅁำ

무용

กำ

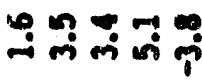

of

\%?

จं $\Rightarrow$

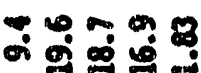

\%

IN?

ลี่

i in m

요

ํㅜㄹ

-

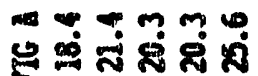

$8-m \infty \pi$

-

Exmm m

$\infty$ -

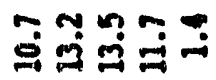

$\div 8 \%$ 용

มี่

- U⿴囗十⺝
๑ீํํ용

뭉요용

$=20 \%$

웅 90

$\mp \mathbf{N}$

mm m o ?

ดु की

ำ ำำ

ตำ

유ำ

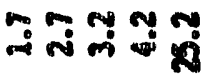

ํㅜㅇำำ

o. 09

- 里 0

ำ ำ

ํํㅇ $=x$

$\rightarrow$ on $\Rightarrow r$

혐

$8 m ? \div$

है

Fs $00 \% \pi$

$\approx \quad 0000$

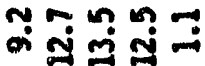

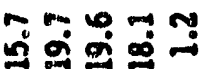

\% $\mathbb{2}$

-
ตั

ํㅜㅇำ용

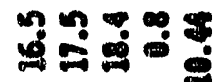

स⿻日月

in m

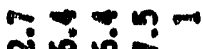

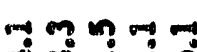

-

용요

$=0 \%$

त 8 N

m

as oำ ำ

무료

an on mo

అ

8ㅁำ की

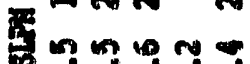

- 5 का

m

울 ํㅜㄹ

\%

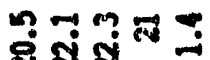

ภม 


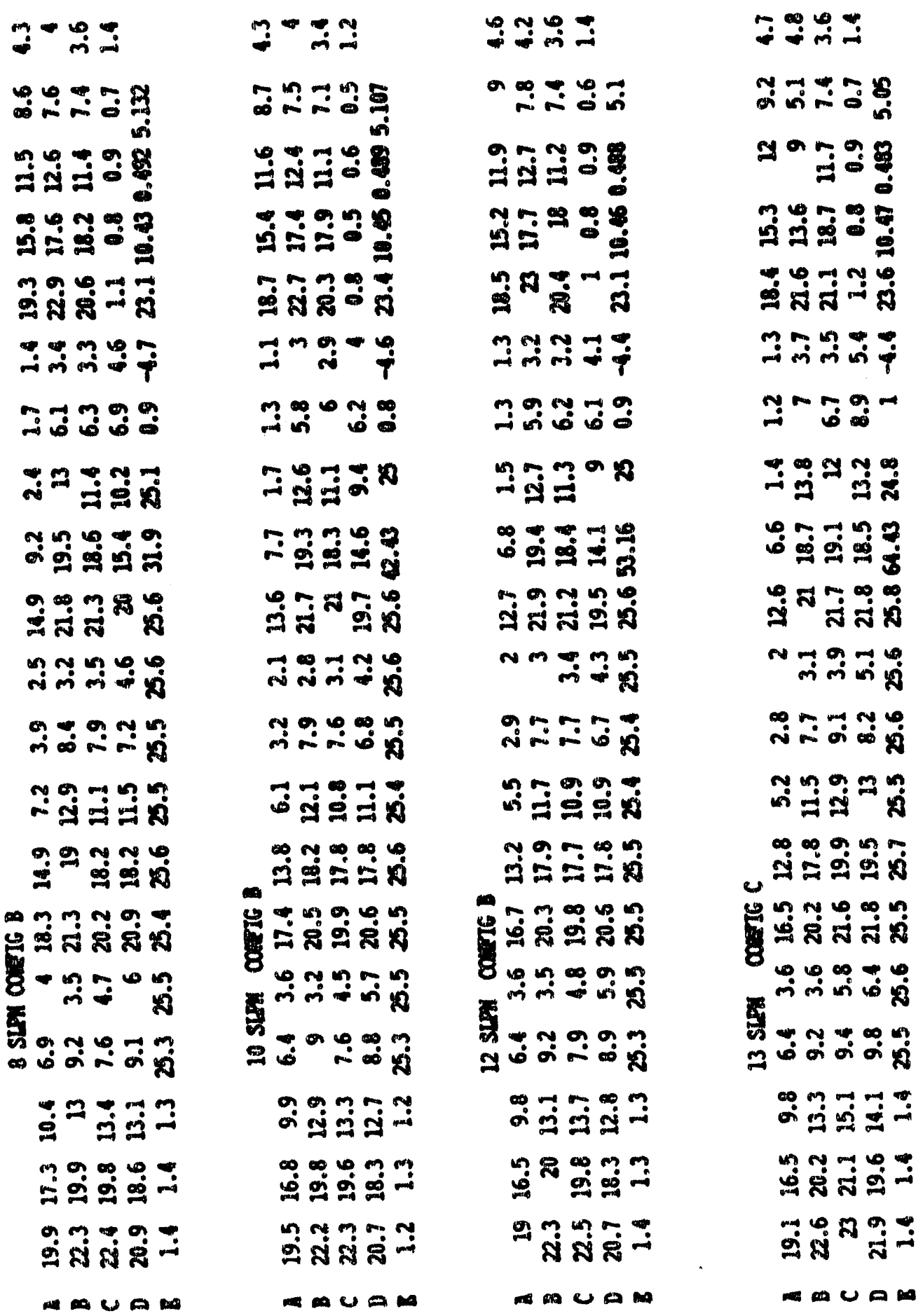




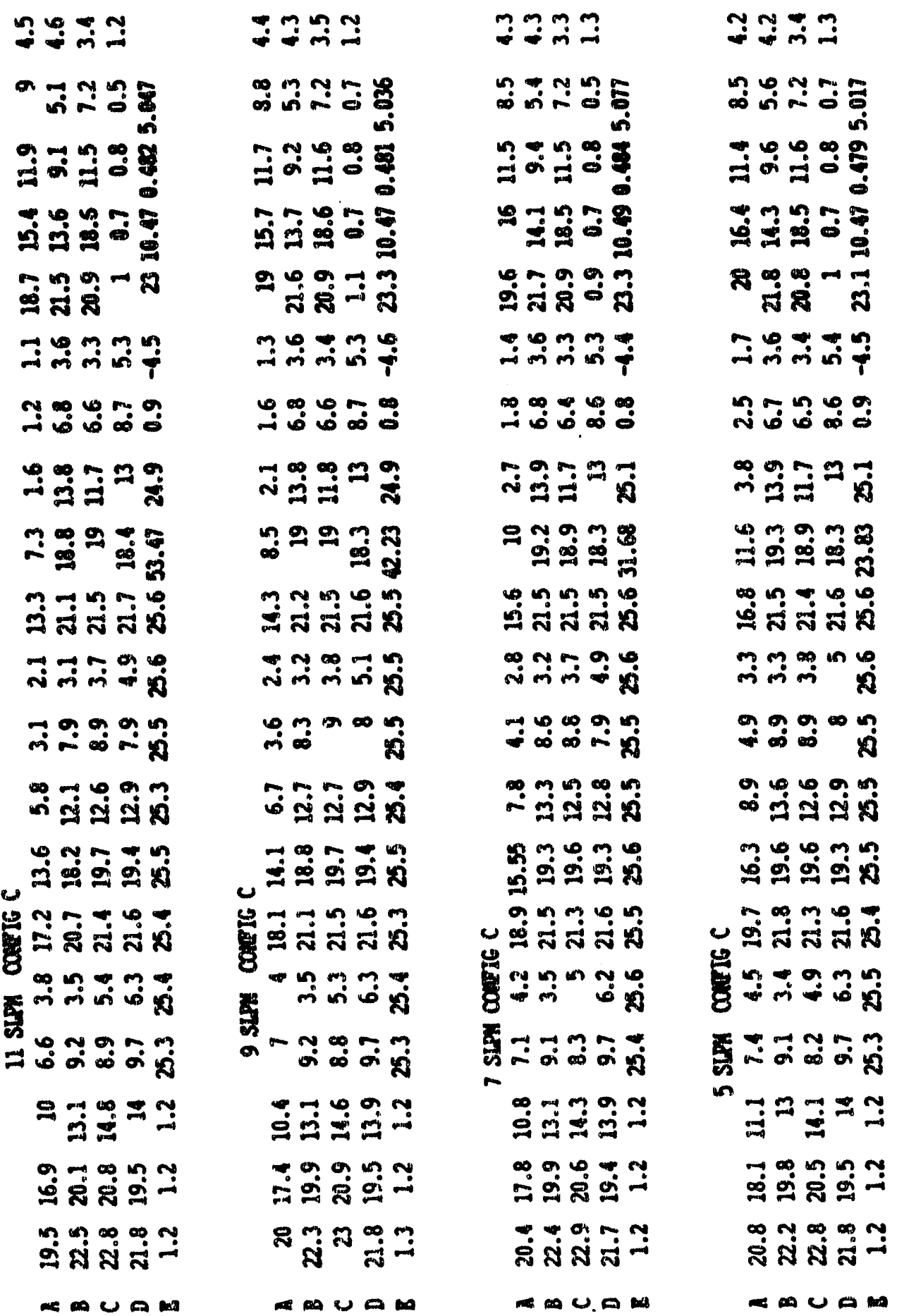




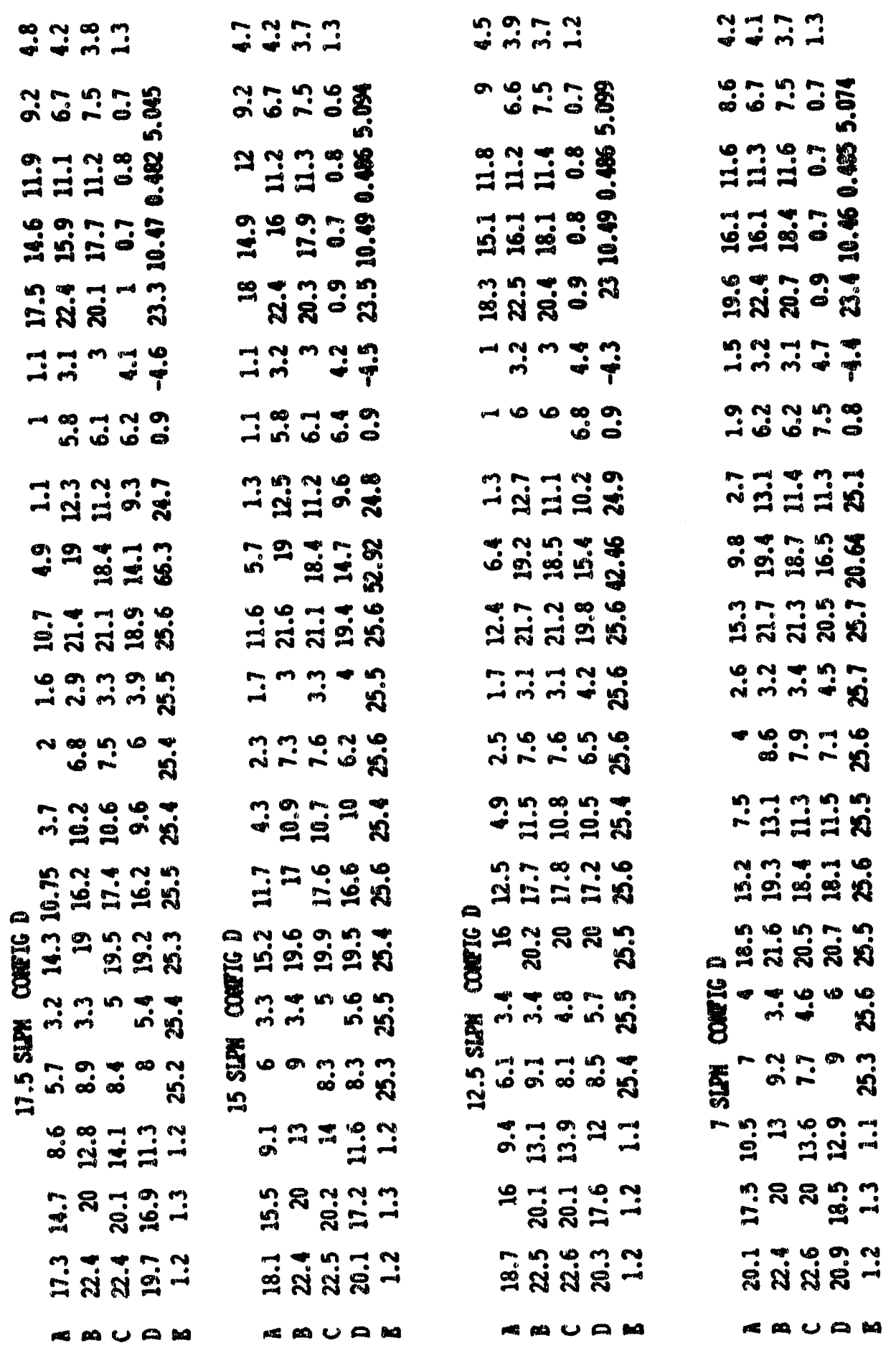




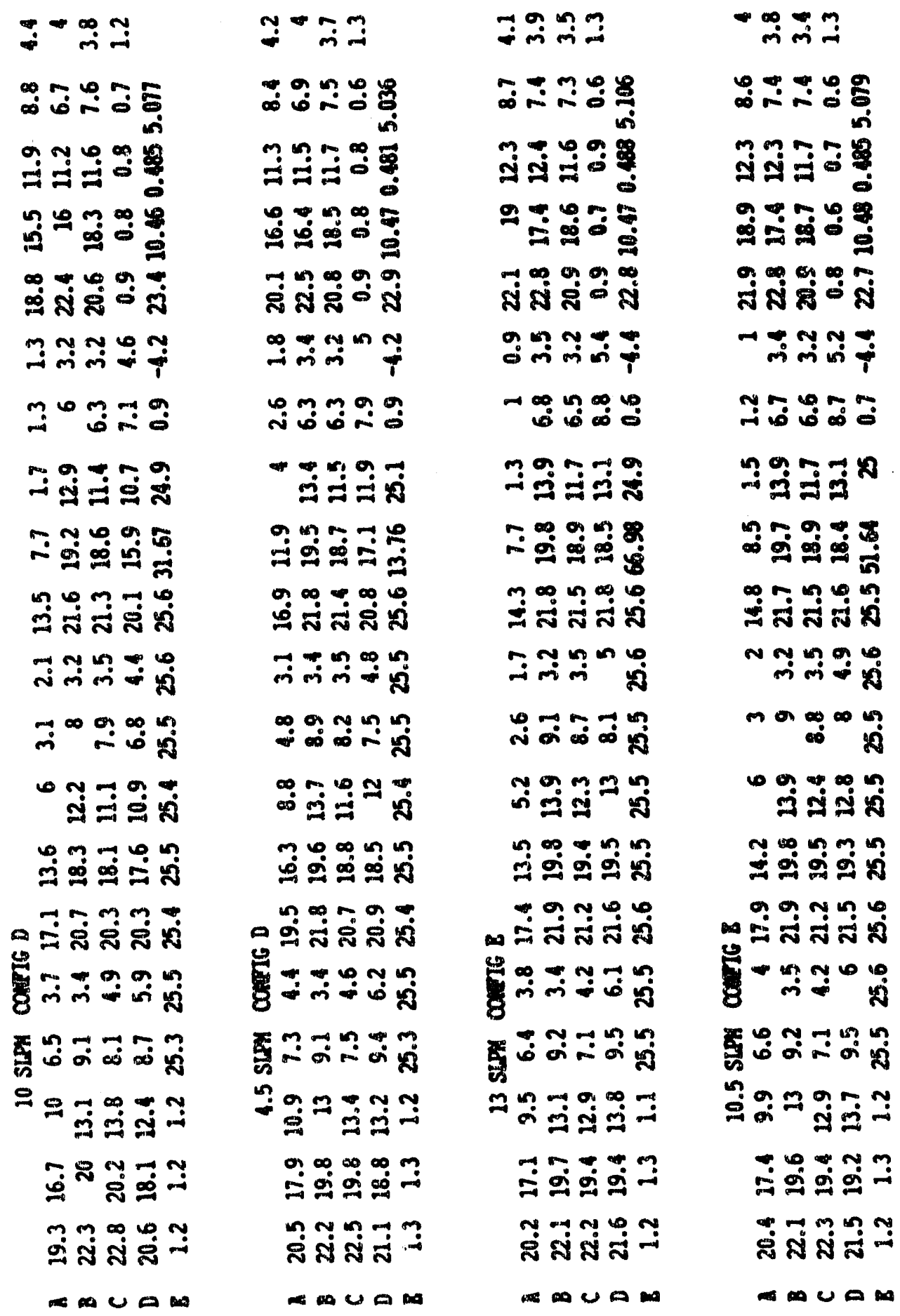




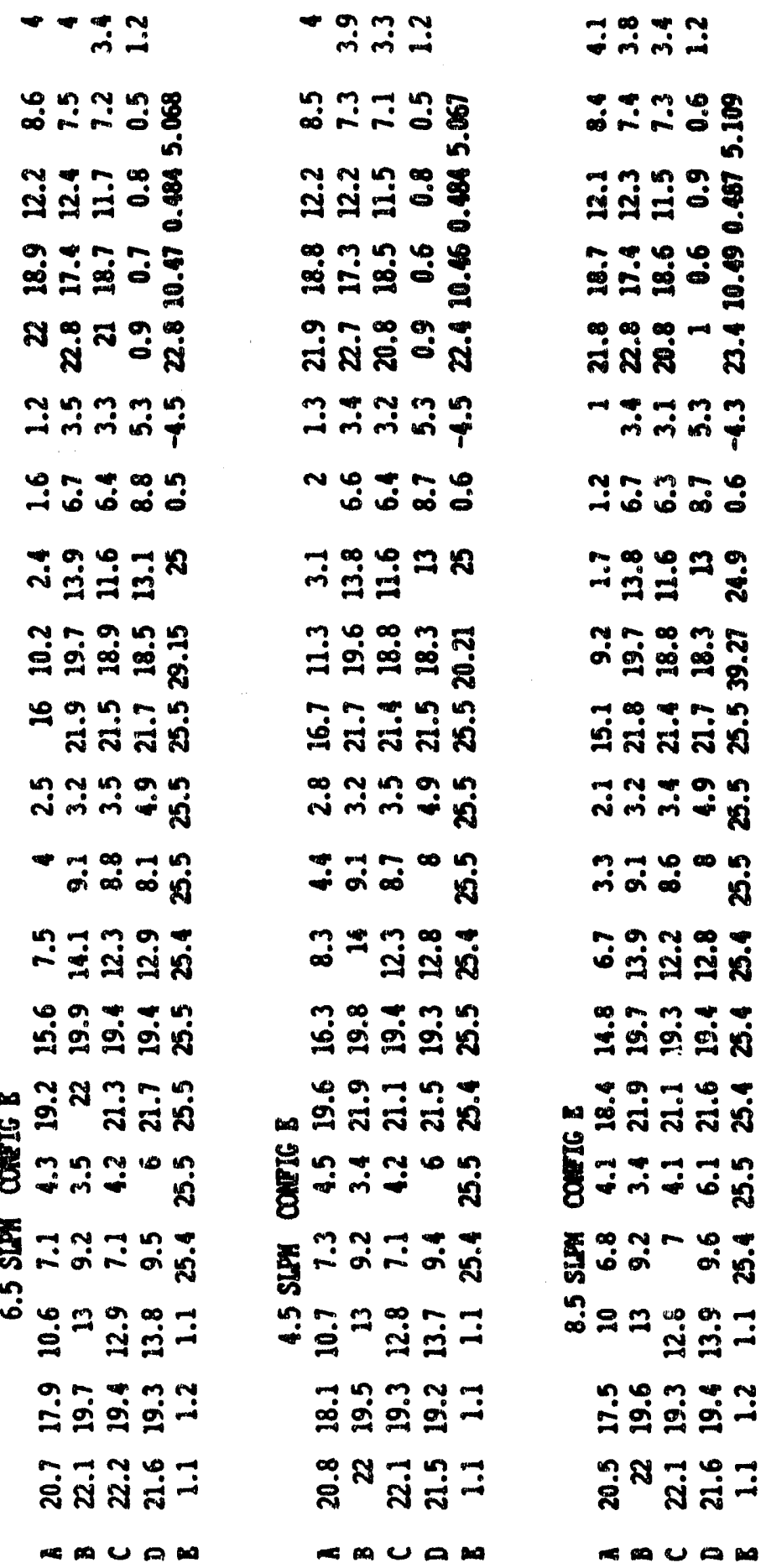




\section{VITA}

Souvik Bhattacharyya was born and brought up in Calcutta, India. His parents are the late Sallendranath Bhattacharyya and Mrs. Pratima Bhattacharyya. He attended Hare School, Calcutta, India from 1970 to 1976 and was awarded Government of India National Merit Scholarships on graduation. He graduated with honors from Jadavpur University, Calcutta, India with a Bachelor of Mechanical Engineering degree in August, 1981. For the next two years he worked as a design engineer with a premier consulting engineering firm in the power and process industry. He obtained a Master of Science in Mechanical Engineering from the University of Cincinnati, Cincinnati, Ohio in Decomber, 1985. The area of specialization was thermal sciences. At Texas A\&M University, in the Mechanical Engineering Department, ne worked with Professor David E. Claridge as part of the Energy Systems Laboratory and obtained a Doctor of Philosophy in Mechanical Engineering in May, 1991.

His permanent mailing address is:

Souvik Bhattacharyya

12, Chaul Patty Road

Calcutta 700010, India. 

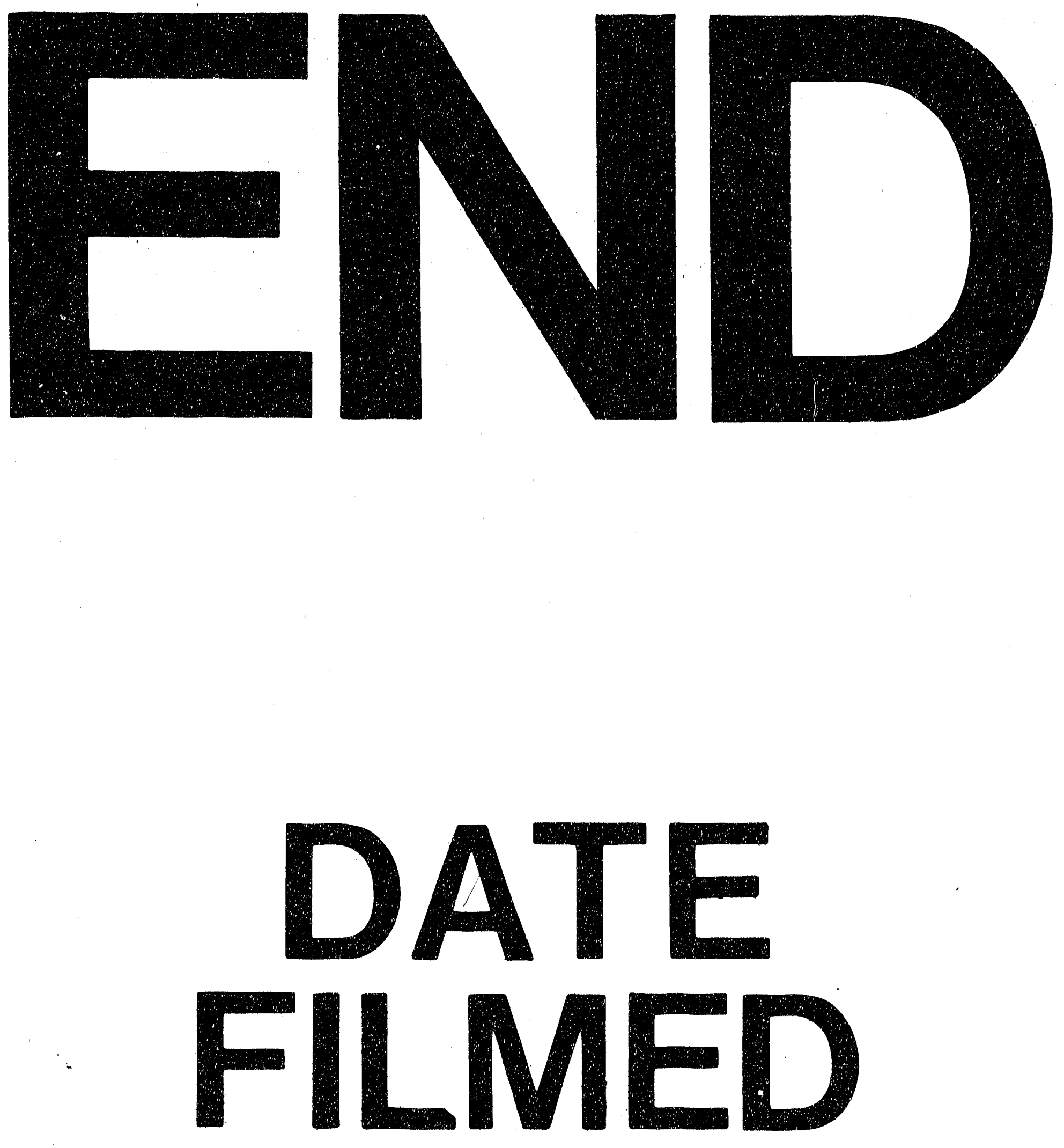

音

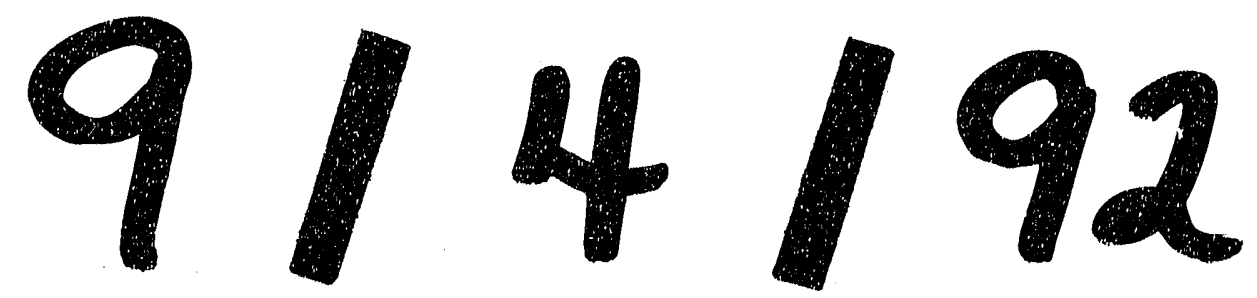


